\title{
Emerging Protein Biomarkers for the Diagnosis or Prediction of Gestational Diabetes-A Scoping Review
}

\author{
Delia Bogdanet ${ }^{1,2, *}$, Catriona Reddin ${ }^{2}(D)$ Dearbhla Murphy ${ }^{2}$, Helen C. Doheny ${ }^{2}$, Jose A. Halperin ${ }^{3}$, \\ Fidelma Dunne ${ }^{1,2}$ and Paula M. O'Shea ${ }^{2}$ (D) \\ 1 College of Medicine Nursing and Health Sciences, National University of Ireland Galway, \\ H91TK33 Galway, Ireland; fidelma.dunne@nuigalway.ie \\ 2 Centre for Diabetes Endocrinology and Metabolism, Galway University Hospital, Newcastle Road, \\ H91YR71 Galway, Ireland; reddin.catriona@gmail.com (C.R.); dearbhlaa.murphy@hse.ie (D.M.); \\ helen.doheny@hse.ie (H.C.D.); paulaM.OShea@hse.ie (P.M.O.) \\ 3 Divisions of Haematology, Brigham \& Women's Hospital, Boston, MA 02115, USA; \\ jhalperin@bwh.harvard.edu \\ * Correspondence: deliabogdanet@gmail.com; Tel.: +35-38-3102-7771
}

Citation: Bogdanet, D.; Reddin, C.; Murphy, D.; Doheny, H.C.; Halperin, J.A.; Dunne, F.; O'Shea, P.M.

Emerging Protein Biomarkers for the Diagnosis or Prediction of Gestational Diabetes-A Scoping Review. J. Clin. Med. 2021, 10, 1533. https:// doi.org/10.3390/jcm10071533

Academic Editor: Katrien Benhalima

Received: 29 January 2021

Accepted: 2 April 2021

Published: 6 April 2021

Publisher's Note: MDPI stays neutral with regard to jurisdictional claims in published maps and institutional affiliations.

Copyright: (c) 2021 by the authors. Licensee MDPI, Basel, Switzerland. This article is an open access article distributed under the terms and conditions of the Creative Commons Attribution (CC BY) license (https:/ / creativecommons.org/licenses/by/ $4.0 /)$.

\begin{abstract}
Introduction: Gestational diabetes (GDM), defined as hyperglycemia with onset or initial recognition during pregnancy, has a rising prevalence paralleling the rise in type 2 diabetes (T2DM) and obesity. GDM is associated with short-term and long-term consequences for both mother and child. Therefore, it is crucial we efficiently identify all cases and initiate early treatment, reducing fetal exposure to hyperglycemia and reducing GDM-related adverse pregnancy outcomes. For this reason, GDM screening is recommended as part of routine pregnancy care. The current screening method, the oral glucose tolerance test (OGTT), is a lengthy, cumbersome and inconvenient test with poor reproducibility. Newer biomarkers that do not necessitate a fasting sample are needed for the prompt diagnosis of GDM. The aim of this scoping review is to highlight and describe emerging protein biomarkers that fulfill these requirements for the diagnosis of GDM. Materials and Methods: This scoping review was conducted according to preferred reporting items for systematic reviews and meta-analyses (PRISMA) guidelines for scoping reviews using Cochrane Central Register of Controlled Trials (CENTRAL), the Cumulative Index to Nursing \& Allied Health Literature (CINAHL), PubMed, Embase and Web of Science with a double screening and extraction process. The search included all articles published in the literature to July 2020. Results: Of the 3519 original database citations identified, 385 were eligible for full-text review. Of these, 332 (86.2\%) were included in the scoping review providing a total of 589 biomarkers studied in relation to GDM diagnosis. Given the high number of biomarkers identified, three post hoc criteria were introduced to reduce the items set for discussion: we chose only protein biomarkers with at least five citations in the articles identified by our search and published in the years 2017-2020. When applied, these criteria identified a total of 15 biomarkers, which went forward for review and discussion. Conclusions: This review details protein biomarkers that have been studied to find a suitable test for GDM diagnosis with the potential to replace the OGTT used in current GDM screening protocols. Ongoing research efforts will continue to identify more accurate and practical biomarkers to take GDM screening and diagnosis into the 21st century.
\end{abstract}

Keywords: gestational diabetes; biomarker; protein biomarker

\section{Introduction}

Gestational diabetes (GDM) is defined as hyperglycemia with onset or initial recognition during pregnancy [1]. GDM is a common complication of pregnancy, with a prevalence of $5.8-12.9 \%$ globally, the prevalence varying by region, and diagnostic criteria [2]. GDM is associated with substantial short and long-term adverse outcomes for both mother 
and child. Short-term complications include preeclampsia and pregnancy-induced hypertension, increased risk of delivery by cesarean section, macrosomia, and neonatal hypoglycemia [3,4]. Long-term complications include increased risk of type 2 diabetes mellitus (T2DM), obesity and cardiovascular complications for both mother and offspring [5,6]. Studies have established that effective treatment of GDM reduces the rate of short-term perinatal complications and improves the quality of life of the mother [7,8]. Given this evidence, it is of utmost importance that we identify those at risk and accurately diagnose GDM [9]. Current diagnostic strategies use the oral glucose tolerance test (OGTT) performed between 24 and 28 weeks of gestation, with universal screening advised in populations with a high prevalence of T2DM [10].

As with any screening program, we must continue to re-evaluate the test suitability, accuracy, and reproducibility. The OGTT was first described in 1957 [11] and has been the gold standard for the diagnosis of GDM for decades [12]. The OGTT is onerous, lengthy and requires a fasting state [13]. A recent review by our research group [14] has detailed the numerous factors contributing to its poor reproducibility [15].

In view of the cumbersome nature and poor reproducibility of the OGTT, it is necessary to look for and identify a more robust, convenient, and accurate biomarker for the diagnosis of GDM. Over recent years, substantial progress has been made in this field of biomarkers. There is an unmet clinical need to identify an easily measurable biomarker, which is superior to the traditional OGTT. In addition, a more convenient biomarker could be used to diagnose GDM in early pregnancy, reducing the period of intra-uterine hyperglycemic exposure. This scoping review aims to synthesize the literature on emerging biomarkers for GDM diagnosis.

\section{Materials and Methods}

\subsection{Scoping Review Question}

What are the emerging biomarkers reported in the literature for the diagnosis of gestational diabetes?

\subsection{Aim}

The aim of this scoping review was to systematically identify the evidence available on emerging biomarkers with the potential to diagnose GDM (beyond glucose, fructosamine and $\mathrm{HbA} 1 \mathrm{c})$.

\subsection{Methods}

This review was conducted based on the framework for scoping reviews recommended by Arksey and O'Malley [16] and the later improvements to this method [17,18]. By contrast to systematic reviews, this approach was found to be more appropriate for a comprehensive search reflecting the vast number of biomarkers with a potential to diagnose GDM at the same time, enabling us to provide an in-depth analysis of selected key biomarkers [19]. Scoping reviews are a method for recording evidence from a particular research area by presenting existing research results and highlighting gaps in the evidence at the same time.

Preferred reporting items for systematic reviews and meta-analyses (PRISMA) guidelines were followed using the PRISMA extension for scoping reviews checklist [20].

No review protocol for this study has been published.

\subsection{Data Sources and Search Strategy}

Using a broad-based search strategy, the following databases were searched for relevant studies from database inception through July 2020: Cochrane Central Register of Controlled Trials (CENTRAL), the Cumulative Index to Nursing and Allied Health Literature (CINAHL), PubMed, Embase and Web of Science. Search terms used included "gestational diabetes", "GDM", "emerging/novel/new", "biomarkers", "tests", and "diag- 
noses" combined as appropriate using the Boolean operators "AND" and "OR" (Supplemental Material).

Results were inputted into the reference manager, Rayyan web application [21], and duplicates were identified and removed. Two reviewers (DB and CR) screened the titles and the abstracts. The reference lists of included studies were also reviewed. Full texts of the remaining articles were independently assessed by two reviewers (DB and CR) for eligibility based on predefined criteria. Disagreements were resolved by consensus. Where a resolution was not reached by discussion, two other reviewers were consulted (FD, POS). The electronic search strategy can be found in (Supplemental Material)

\subsection{Eligibility Criteria}

Studies were eligible for inclusion if study participants were pregnant women, and the study reported on a biomarker for GDM diagnosis. All study designs were eligible for inclusion. We did not apply a language restriction. However, if translation to English was not possible, the study was excluded. There was no time restriction on the date of publication of the studies. Only full-text articles were included in this review. When the full text was unavailable, the corresponding authors were contacted.

\subsection{Data extraction and Synthesis}

Data were extracted independently by two authors (DB and CR) using a standardized predetermined data collection form. For each study, we extracted the title, year of publication, journal, and biomarker (which was identified on review of the methods and results section of each paper).

Extracted data were compared for inconsistencies and merged into a final database. Disagreement was resolved through discussion and, where necessary, consultation with two further reviewers (FD, POS).

The biomarkers identified were grouped alphabetically together with all the papers citing the specific biomarker for easier identification.

It was decided that if the number of potential biomarkers identified was considerable, rendering the analysis and discussion impractical, post hoc criteria would be implemented. This would help focus the discussion on the most recent, most cited protein biomarkers.

\subsection{Post Hoc Inclusion Criteria}

Once all the biomarkers were identified, we selected for analysis and discussion biomarkers that fulfilled 3 criteria:

1. Protein biomarkers;

2. Biomarkers that had at least 5 citations in our search results;

3. Study publication year: 2017-2020.

The resulting biomarkers were grouped into categories and brought forward for discussion.

\section{Results}

A total of 3519 articles were identified after the database search (Figure 1). Following title screening and deletion of duplicates, 843 abstracts were selected. A total of 458 articles were further excluded after abstract screening by two researchers, thereby reducing the articles eligible for full-paper screening to 385 . A total of 53 articles were excluded (articles not in English $n=5$, the test assessed was not used for GDM diagnosis $n=13$, no biomarker was discussed $n=4$, duplicates $n=8$ and conference proceeding/abstract publication only $\mathrm{n}=23$ ). Finally, 332 articles were selected for data extraction. Following data extraction, a total of 589 biomarkers were identified (Supplemental Table S1). 
श्रा PRISMA 2009 Flow Diagram
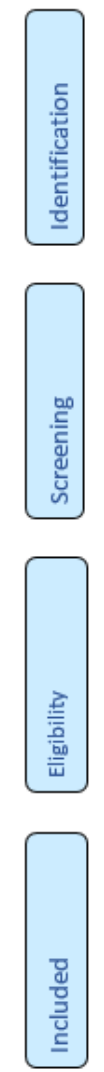

Figure 1. Prisma diagram.

After the application of the post hoc criteria, 15 biomarkers were identified, reviewed, and discussed. These biomarkers were grouped into 3 categories: cytokines, glycoproteins, and other proteins (Table 1). The biomarkers' testing performance at the time of GDM and as a predictive indicator of GDM are shown in Tables 2 and 3, and Supplemental Material Figures S1 and S2.

Table 1. Protein biomarkers $(n=15)$ identified post-application of post hoc criteria.

\begin{tabular}{|c|c|c|}
\hline Biomarker & Function & Molecular Characteristics \\
\hline \multicolumn{3}{|c|}{ Cytokines } \\
\hline * Adiponectin & $\begin{array}{l}\text { Regulation of glucose and lipid metabolism. Role } \\
\text { in cell apoptosis, inflammation and angiogenesis }\end{array}$ & $\begin{array}{l}\text { Molecular mass } 30 \mathrm{kDa} \text {; consists of } 244 \text { aa in multimeric } \\
\text { circulating forms: a } 90-\mathrm{kDa} \text { low molecular weight trimer, a } \\
\text { middle molecular weight hexamer of } 180 \mathrm{kDa} \text { and a high } \\
\text { molecular weight multimer of } \sim 360 \mathrm{kDa}\end{array}$ \\
\hline * Chemerin & $\begin{array}{l}\text { Adipogenesis regulation and adipocyte } \\
\text { metabolism; role in glucose and lipid } \\
\text { metabolism; pro/anti-inflammatory modulator }\end{array}$ & $\begin{array}{l}\text { Molecular mass of } 18 \mathrm{kDa} \text {; chemerin is translated as a } 163 \text { aa } \\
\text { preproprotein that is secreted as a } 143 \mathrm{aa}(18 \mathrm{kDa}) \text { proprotein } \\
\text { following proteolytic cleavage of a signal peptide }\end{array}$ \\
\hline * Fetuin & $\begin{array}{l}\text { Transport of fatty acids in the circulation with a } \\
\text { role in insulin resistance; inhibits vascular } \\
\text { calcification; role in inflammatory responses }\end{array}$ & $\begin{array}{l}\text { Molecular mass of } 64 \mathrm{kDa} \text {; comprises a two-chain form whose } \\
\mathrm{N} \text {-terminal heavy chain ( } 321 \text { amino acid residues) is disulfide } \\
\text { bonded to the C-terminal light chain ( } 27 \mathrm{aa})\end{array}$ \\
\hline * Leptin & Regulation of food intake and energy balance & $\begin{array}{l}\text { Molecular mass of } 16 \mathrm{kDa} \text {; consists of } 146 \text { aa structured in } \\
\text { four antiparallel } \alpha \text {-helices }\end{array}$ \\
\hline
\end{tabular}


Table 1. Cont.

\begin{tabular}{|c|c|c|}
\hline Biomarker & Function & Molecular Characteristics \\
\hline *Omentin & $\begin{array}{l}\text { Role in glucose and lipid metabolism and } \\
\text { adipocyte mediated inflammation }\end{array}$ & $\begin{array}{l}\text { Molecular mass of } 34 \mathrm{kDa} \text {; consists of } 313 \mathrm{aa} \text {; contains a } \\
\text { secretory signal sequence and a fibrinogen-related domain } \\
\text { and appears as a glycolyzed trimer of } 120 \mathrm{kDa} \text { molecular } \\
\text { weight in its negative form }\end{array}$ \\
\hline IL-6 & $\begin{array}{l}\text { Role in immunity as a mediator of the acute } \\
\text { phase response. Acts as both a proinflammatory } \\
\text { cytokine and an anti-inflammatory myokine. } \\
\text { Additional role in adipocyte-mediated } \\
\text { inflammation and glucose metabolism }\end{array}$ & $\begin{array}{l}\text { Molecular mass of } 21 \mathrm{kDa} \text {; single, non-glycosylated } \\
\text { polypeptide chain with a four- } \alpha \text {-helix structure containing } \\
185 \text { aa }\end{array}$ \\
\hline TNF & $\begin{array}{l}\text { Role in the regulation of immune cells, growth } \\
\text { regulation, inflammation, viral replication, } \\
\text { tumorigenesis, and autoimmune diseases }\end{array}$ & Molecular mass of $17.3 \mathrm{kDa}$; homotrimer composed of 233 aa \\
\hline \multicolumn{3}{|c|}{ Glycoproteins } \\
\hline Afamin & $\begin{array}{l}\text { Vitamin E transport. Possible role in glucose and } \\
\text { lipid metabolism }\end{array}$ & $\begin{array}{l}\text { Molecular mass of } 87 \mathrm{kDa} \text { with } 55 \% \text { aa sequence similarity to } \\
\text { albumin; composed of a } 21 \text {-aa leader peptide, followed by } \\
\text { 578aa of the mature protein and consists of } 2 \\
\text { structural domains }\end{array}$ \\
\hline hCG & $\begin{array}{l}\text { Maintains the production of progesterone from } \\
\text { the corpus luteum during pregnancy; role in } \\
\text { glucose and insulin metabolism; role in } \\
\text { adipocyte-mediated inflammation }\end{array}$ & $\begin{array}{l}\text { Molecular mass of } 36.7 \mathrm{kDa},(\sim 14.5 \alpha \mathrm{hCG} \text { and } 22.2 \mathrm{kDa} \\
\beta \mathrm{hCG}) \text {, composed of } 237 \mathrm{aa} \text {; it is heterodimeric, with an } \alpha \\
\text { subunit identical to that of luteinizing, follicle-stimulating and } \\
\text { thyroid-stimulating hormone and an } \beta \text { subunit that is unique } \\
\text { to hCG }\end{array}$ \\
\hline CD59 & $\begin{array}{l}\text { Inhibits the complement membrane attack } \\
\text { complex action }\end{array}$ & Molecular mass of $14.2 \mathrm{kDa}$; consists of 128 aa \\
\hline SHBG & $\begin{array}{l}\text { Binding protein for testosterone and estradiol; } \\
\text { regulates sex steroid effects in target cells by } \\
\text { direct action; role in lipid and } \\
\text { glucose metabolism }\end{array}$ & $\begin{array}{l}\text { Molecular mass of } 43.7 \mathrm{kDa} \text {; homodimer, each monomer } \\
\text { consists of } 402 \text { aa }\end{array}$ \\
\hline \multicolumn{3}{|c|}{ Other Proteins } \\
\hline CRP & $\begin{array}{l}\text { Activation of the complement system, promoting } \\
\text { phagocytosis by macrophages Role in the innate } \\
\text { immune system }\end{array}$ & $\begin{array}{l}\text { Molecular mass of } 120 \mathrm{kDa} \text {, belonging to the family of } \\
\text { pentraxins; consists of five identical subunits that contain each } \\
206 \text { aa }\end{array}$ \\
\hline Nefatin-1 & $\begin{array}{l}\text { Regulation of food intake and glucose } \\
\text { homeostasis }\end{array}$ & Molecular mass of $9.7 \mathrm{kDa}$ containing 82 aa residues \\
\hline PAPP-A & $\begin{array}{l}\text { Cleavage of insulin-like growth factor-binding } \\
\text { proteins promoting somatic growth }\end{array}$ & $\begin{array}{l}\text { Molecular mass of } 400 \mathrm{kDa} \text { composed of two } 200-\mathrm{kDa} \\
\text { disulfide-bound subunits, each subunit consists of } 1547 \text { aa: } \\
\text { belonging to the pappalysin protein family }\end{array}$ \\
\hline RBP4 & $\begin{array}{l}\text { Transporter protein for retinol; role in insulin } \\
\text { resistance and tumor growth }\end{array}$ & $\begin{array}{l}\text { Molecular mass of } 21 \mathrm{kDa} \text { consisting of } 184 \text { aa; the entire } \\
\text { molecule consists of an N-terminal loop, a } \beta \text {-barrel structure, } \\
\text { an alpha helix and a C-terminal loop }\end{array}$ \\
\hline
\end{tabular}

* adipokines; IL-6-interleukin 6; TNF-tumor necrosis factor; hCG-human chorionic gonadotropin; SHBG; sex hormone-binding globulin; CRP—C-reactive protein; PAPP-A—placental associated plasma protein A; RBP4—retinol-binding protein 4; aa—amino acids.

Table 2. Summary of test performance at the time of gestational diabetes (GDM) diagnosis *.

\begin{tabular}{|c|c|c|c|c|c|c|}
\hline Biomarker & First Author (Ref.) & $\begin{array}{l}\text { Analytical } \\
\text { Method }\end{array}$ & $\begin{array}{c}\text { Diagnostic } \\
\text { Sensitivity \% }\end{array}$ & $\begin{array}{c}\text { Diagnostic } \\
\text { Specificity \% }\end{array}$ & AUC & Cutoff Value \\
\hline \multicolumn{7}{|c|}{ Cytokines } \\
\hline Adinonoctin & Bozkurt et al. [22] & RIA & NS & ns & 0.62 & ns \\
\hline Adiponectin & Weerakiet et al. [23] & ELISA & 91.7 & 30.8 & 0.63 & $10 \mu \mathrm{g} / \mathrm{mL}$ \\
\hline Chemerin & Wang et al. [24] & ELISA & 73.3 & 76 & 0.82 & $6.78 \mu \mathrm{g} / \mathrm{L}$ \\
\hline \multirow{3}{*}{ Leptin } & Bozkurt et al. [22] & RIA & ns & ns & 0.61 & ns \\
\hline & \multirow{2}{*}{\multicolumn{6}{|c|}{ Boyadzhieva et al. [25] }} \\
\hline & & & & & & \\
\hline \multirow{3}{*}{$\begin{array}{l}\text { CD59 } \\
\text { SHBG }\end{array}$} & Ghosh et al. [26] & ELISA & 85 & 92 & 0.92 & ns \\
\hline & Ma et al. [27] & ELISA & 54 & 93 & 0.86 & ns \\
\hline & Tawfeek et al. [28] & ELISA & 96 & 95 & 0.91 & $50 \mathrm{nmol} / \mathrm{L}$ \\
\hline
\end{tabular}


Table 2. Cont.

\begin{tabular}{|c|c|c|c|c|c|c|}
\hline Biomarker & First Author (Ref.) & $\begin{array}{l}\text { Analytical } \\
\text { Method }\end{array}$ & $\begin{array}{c}\text { Diagnostic } \\
\text { Sensitivity \% }\end{array}$ & $\begin{array}{c}\text { Diagnostic } \\
\text { Specificity \% }\end{array}$ & AUC & Cutoff Value \\
\hline \multicolumn{7}{|c|}{ Other Proteins } \\
\hline RBP4 & Du et al. [29] & ELISA & 79.4 & 79.1 & 0.87 & $34.84 \mu \mathrm{g} / \mathrm{mL})$ \\
\hline
\end{tabular}

Table 3. Summary of test performance as a predictive indicator of GDM *

\begin{tabular}{|c|c|c|c|c|c|c|}
\hline Biomarker & First Author, Year (Ref.) & $\begin{array}{c}\text { Analytical } \\
\text { Method }\end{array}$ & $\begin{array}{c}\text { Diagnostic } \\
\text { Sensitivity \% }\end{array}$ & $\begin{array}{c}\text { Diagnostic } \\
\text { Specificity \% }\end{array}$ & AUC & Cutoff Value \\
\hline \multicolumn{7}{|c|}{ Cytokines } \\
\hline \multirow{4}{*}{ Adiponectin } & Georgiou et al. [30] & ELISA & $85^{1}$ & $85.7^{1}$ & 0.86 & $3.5 \mu \mathrm{g} / \mathrm{mL}$ \\
\hline & Ferreira et al. [31] & ELISA & ns & ns & $0.85^{2}$ & ns \\
\hline & Madhu et al. [32] & ELISA & 100 & 95.6 & ns & $9.1 \mu \mathrm{g} / \mathrm{mL}$ \\
\hline & Iliodromiti et al. [33] ** & ns & 64.7 & 77.8 & 0.78 & ns \\
\hline \multirow{2}{*}{ Fetuin } & Kansu-Celik et al. [34] & ELISA & 58.6 & 76.2 & 0.33 & $166 \mathrm{ng} / \mathrm{mL}$ \\
\hline & Jin et al. [35] & ELISA & 64.4 & 58.5 & 0.61 & $305.9 \mathrm{pg} / \mathrm{mL}$ \\
\hline Leptin & Bawah et al. [36] & ELISA & 95.7 & 68.6 & 0.81 & $18.9 \mathrm{ng} / \mathrm{mL}$ \\
\hline TNF & Syngelaki et al. [37] & ELISA & ns & ns & 0.82 & ns \\
\hline \multicolumn{7}{|c|}{ Glycoproteins } \\
\hline \multirow{3}{*}{ Afamin } & Tramontana et al. [38] & ELISA & ns & ns & $0.66^{3}$ & ns \\
\hline & Koninger et al. [39] ** & ELISA & 79.3 & 79.4 & 0.78 & $88.6 \mathrm{mg} / \mathrm{L}$ \\
\hline & Ravnsborg et al. [40] ${ }^{* *}$ & nanoLC-MS & ns & ns & 0.67 & ns \\
\hline \multirow{4}{*}{ SHBG } & Caglar et al. [41] & RIA & 46.7 & 84.1 & 0.87 & $97.47 \mathrm{nmol} / \mathrm{L}$ \\
\hline & Maged et al. [42] & ELISA & 85.2 & 37 & 0.69 & $211.5 \mathrm{nmol} / \mathrm{L}$ \\
\hline & Veltman-Verhulst et al. [43] ${ }^{* *}$ & $\mathrm{ECL}$ & 81 & 82.8 & 0.86 & $58.5 \mathrm{nmol} / \mathrm{L}$ \\
\hline & Badon et al. [44] ** & ELISA & ns & ns & $0.71^{2}$ & $44.2 \mathrm{nmol} / \mathrm{L}$ \\
\hline \multicolumn{7}{|c|}{ Other Proteins } \\
\hline \multirow[t]{4}{*}{ CRP } & Kansu-Celik et al. [34] & Nephelometry & 86.2 & 50.8 & 0.70 & ns \\
\hline & Lovati et al. [45] & DELFIA & $81.4^{2}$ & $50.5^{2}$ & $0.70^{2}$ & ns \\
\hline & Ramezani et al. [46] & ELISA & 73.3 & 57.3 & 0.61 & $1896 \mathrm{mU} / \mathrm{L}$ \\
\hline & Ramezani et al. [46] & ELISA & 34.4 & 83.2 & 0.62 & $0.3 \mathrm{mU} / \mathrm{L}$ \\
\hline \multirow[t]{4}{*}{ PAPP-A } & Ren et al. [47] & TRFIA & 72.5 & 82.3 & 0.86 & $16.34 \mathrm{ng} / \mathrm{L}$ \\
\hline & Snyder et al. [48] & DELFIA & $75.7^{2}$ & $55.5^{2}$ & $0.71^{2}$ & ns \\
\hline & Xiao et al. [49] & DELFIA & ns & ns & $0.53 ; 0.68^{2}$ & ns \\
\hline & Syngelaki et al. [50] & DELFIA & ns & ns & $0.84^{2}$ & ns \\
\hline RBP4 & Yuan et al. [51] & EIA & 63.6 & 75 & 0.72 & $30.45 \mu \mathrm{g} / \mathrm{mL}$ \\
\hline
\end{tabular}

* no information on test performance as a predictive indicator of GDM was found for the following biomarkers: chemerin, omentin, IL-6, CD59, hCG, nesfatin-1. AUC - area under the curve; IL-6-interleukin 6; TNF-tumor necrosis factor; hCG-human chorionic gonadotropin; SHBG—-sex hormone-binding protein; CRP—C-reactive protein; PAPP-A—pregnancy-associated plasma protein A; RBP4retinol-binding protein 4; RIA—radioimmunoassay; ELISA—enzyme-linked immunosorbent assay; nanoLC-MS-nano-flow liquid chromatography-tandem mass spectrometry; ECL—electrochemiluminescence; DELFIA—dissociation-enhanced lanthanide fluorescent immunoassay, TRFIA—time-resolved fluorescence immunoassay analyzer; EIA—enzyme immunoassay; ns—not stated; ${ }^{1}$ combined model with insulin levels; ${ }^{2}$ combined model with risk factors; ${ }^{3}$ combined model with BMI; ** prior to pregnancy.

\section{Cytokines}

Cytokines are cell-signaling proteins, peptides or glycoproteins that are secreted by specific cells of the immune system. They regulate and modulate both the innate and adaptive immune response to inflammation and infection.

\subsection{Adipokines}

The adipokines are cytokines secreted by the adipose tissue and comprise a group of over 600 molecules that have paracrine and endocrine functions [52]. Inflammation and dysfunction of the adipose tissue lead to a pattern of adipokines secretion, which reflects a proinflammatory, dysmetabolic and diabetogenic model [52,53]. 


\subsubsection{Adiponectin}

Adiponectin is a protein secreted primarily by the fat tissue but also by the brain, the skeletal muscle, and the placenta [54-56], comprising 244 amino acids. Adiponectin has a role in insulin sensitivity [57,58], reduces liver gluconeogenesis [59] and enhances skeletal muscle fatty acid oxidation [60]. Low adiponectin levels are associated with an increased incidence of T2DM [61,62], and furthermore, low adiponectin levels were found in women with GDM [63,64]. This raised the question of adiponectin can be used to diagnose GDM.

Hedderson et al. [65] looked at the relationship of prepregnancy adiponectin levels and the risk of subsequent development of GDM in a case-control study within a cohort of 4098 women (GDM women $\mathrm{n}=256,100 \mathrm{~g} 3 \mathrm{~h}$ OGTT, American College of Obstetricians and Gynecologists criteria [66] controls $n=497$ ). The team found that low adiponectin levels measured as far as six years prior to pregnancy were associated with an increased risk of developing GDM independent of age, BMI, family history or ethnicity. This finding suggests that adiponectin could have the potential to identify women at high risk of developing GDM, who otherwise would not be classified as high risk. This study, however, does not capture the changes in lifestyle, diet, and exercise between the baseline adiponectin measurement and the GDM diagnosis, and it also does not provide any information on body composition, such as percentage of fat or anthropomorphic measurements. One study has found that the first-trimester of pregnancy adiponectin is significantly lower in GDM cases compared to controls and has the potential to determine the risk of developing GDM [30] with an AUC of 0.86, thus showing promise despite the small sample size of their cohorts $(n=28)$. Similar results come from Williams et al. [67] and Ferreira et al. [31], who found that adiponectin levels taken at 13 weeks of gestation were lower in women, who developed GDM compared to controls. Choosing a cutoff point of $9.1 \mu \mathrm{g} / \mathrm{mL}$ for the first-trimester adiponectin levels, Madhu et al. [32] found the test to have a sensitivity of $100 \%$ and a specificity of $95.6 \%$ in predicting GDM.

In 2018 Bozkurt et al. [22] investigated the relationship between adiponectin levels and the development of GDM. The study included 223 participants, who were assessed for their glycemic status (75 g $2 \mathrm{~h}$ OGTT, IADPSG criteria) and adiponectin level at the first visit (<21 weeks of gestation) and at the second visit (24-28 weeks of gestation). The team found that adiponectin levels were significantly lower in women that developed GDM, and the association between adiponectin levels and GDM was even stronger in study participants that developed early GDM ( $<21$ weeks), with a calculated predictive value for GDM of 0.67 (95\% CI 0.57 to 0.77$)$. Adiponectin taken during the OGTT at 24-28 weeks of gestation could predict GDM with an AUC of 0.65 (95\% CI 0.57-0.74). These findings were independent of the prepregnancy maternal BMI; this is consistent with previous studies $[68,69]$ that found adiponectin levels to be similar between individuals with a normal BMI and obese individuals that are classified as being metabolically healthy (based on lipid levels, glycemic status and blood pressure readings) compared to obese individuals classified as metabolically unhealthy. Therefore, in pregnancy, low adiponectin levels may indicate a prepregnancy predisposition for metabolic complications, such as diabetes, hypertension, or dyslipidemia, rather than a reflection on the individual's adipose tissue mass. Weerakiet et al. [23] measured adiponectin levels in 359 women at the same time as the glucose challenge test between 21st and 27th week of gestation and, while the results were consistent with previous findings in that adiponectin level are lower in women that develop GDM independent of age and BMI, in terms of screening. However, the AUC of adiponectin was less than the glucose challenge test (GCT) AUC $(0.63$ (95\% CI 0.53-0.67) Vs. $0.73(95 \%$ CI $0.71-080)$ and had a sensitivity of $91.7 \%$ and a specificity of $30.8 \%$. These calculations, however, were based on an arbitrarily chosen cutoff value for adiponectin at $10 \mu \mathrm{g} / \mathrm{mL}$.

Xu et al. [70], in their systematic review and meta-analysis, looked at the association between adiponectin and GDM and included 15 studies and 560 GDM patients. They found that adiponectin levels were significantly decreased in women who developed GDM compared to controls, independent of BMI, similar to previous studies. The study, however, 
had its limitations, including large variability in adiponectin cutoff points and a high degree of heterogeneity. Iliodromiti et al. [33] conducted a systematic review and meta-analysis on the accuracy of adiponectin in predicting GDM and included 11 studies and data on 794 GDM women. They found that pooled sensitivity for adiponectin as a GDM diagnostic biomarker was $64.7 \%$ (95\% CI 51\%, 76.4\%), and the pooled specificity was $77.8 \%(95 \% \mathrm{CI}$ $66.4 \%, 86.1 \%$ with an AUC of 0.78 (95\% CI 0.74, 0.81). While the researchers conclude that adiponectin has a moderate predictive value, there are several limitations to their paper, including the study heterogeneity, the limited access to data (2 studies), the variability of adiponectin levels cutoff points for "low" or "high" levels, the diversity of ethnicities in the populations involved and the various study designs and retrospective nature of the data that may have contributed to the results.

Adiponectin is a very promising biomarker for the diagnosis of GDM and has a significant advantage over the OGTT/GCT of not mandating a fasting state for measurements [71]. While some studies determined less than ideal performance parameters for adiponectin, we need to consider that in the first-trimester, fasting glucose has been shown to have a sensitivity of $47 \%$, a specificity of $77 \%$ and AUC of 0.62 [72], improving in the second-trimester [73]; $\mathrm{HbA} 1 \mathrm{c}$ has a sensitivity of $32 \%$ and a specificity of $94 \%$ [74] and fructosamine has a sensitivity of $12.2 \%$ and a specificity of $94.7 \%$ [75]. More so, there are no studies assessing adiponectin level cutoff points for best prognostic/diagnostic capacity, nor are any studies on adiponectin-trimester-specific interval ranges.

Large prospective studies together with health economic input analyzing best diagnostic cutoff points, natural level variation in GDM and normal glucose tolerance (NGT) cohorts, the impact of confounders, such as ethnicity, percentage of body fat, etc. are required to accurately determine the true value of adiponectin in diagnosing GDM.

\subsubsection{Chemerin}

Discovered more than 20 years ago [76], chemerin (163 amino acids) is an inflammatory adipokine with a role in adipogenesis, adipocyte metabolism [77] and insulin resistance [78] secreted from the adipose tissue, liver, intestine [79] and placenta [80]. Chemerin plays a role in adipocyte metabolism, inflammation, insulin resistance and metabolic processes $[77,78,81]$, and chemerin levels have been associated with adverse pregnancy outcomes [82-84].

Yang et al. [85] measured chemerin levels in the first-trimester of pregnancy (8-12 weeks' gestation) in 212 women and in 39 women (GDM n $=19$, IADPSG criteria) after the $75 \mathrm{~g} 2 \mathrm{~h}$ OGTT. Chemerin levels were significantly lower in the GDM group compared to NGT in the first-trimester but significantly higher in the third-trimester. In both GDM and NGT groups, chemerin significantly rose between the first and third-trimester, paralleling the rise in HOMA-IR.

In 2020 Wang et al. [24] found that the AUC of chemerin (cutoff value $6.78 \mu \mathrm{g} / \mathrm{L}$ ) in the diagnosis of GDM (24-28 weeks of gestation) was 0.82 (95\% CI $0.74-0.89)$ with a sensitivity of $73.3 \%$ and specificity of $76 \%$.

Pfau et al. [86] measured chemerin levels in 40 GDM women and, while the levels were higher in GDM subjects, there was no significant difference when compared to controls; there was, however, an independent association between chemerin and markers of insulin resistance. Guelfi et al. [87] measured adipokine levels, including chemerin in 123 pregnant women at 14 and 28 weeks of gestation and found no change in chemerin concentration between the two time points and no difference in chemerin levels between women who developed GDM compared to those who did not (unlike adiponectin and leptin that showed significant changes). The cohort in this study included only women with a history of GDM with a different metabolic profile compared to the general population, so the results cannot be extrapolated. Van Poppel et al. [88] found no difference in chemerin levels between GDM ( $\mathrm{n}=15$, IADPSG criteria) and NGT subjects. However, chemerin levels were significantly higher in obese women compared to non-obese women. In their systematic review and meta-analysis (10 studies), Sun et al. [89] did not find any difference 
in chemerin levels between GDM and NGT women but did find a positive correlation between chemerin and BMI. These results contradict the findings of Zhou et al. [90], who conducted a systematic review and meta-analysis (11 studies) looking specifically at chemerin levels and GDM and found that chemerin levels are significantly raised in the GDM population compared to NGT women. While both systematic reviews and metaanalyses had significant heterogeneity, the discrepancy in results may arise either from the different studies comprising the analysis or either from the type of subanalysis and confounders included.

The main reason for the discordant results is the fact that chemerin is influenced by numerous factors, such as inflammation, insulin resistance, metabolic syndrome, obesity, diabetes, nutrition, activity level and pregnancy [80,82,91-95]. It seems that chemerin may play a better role as a risk-stratifying tool rather than a GDM diagnostic biomarker, identifying women at risk of GDM, but future research might prove otherwise.

\subsubsection{Fetuin}

Fetuins are a group of adipokines mainly secreted by the liver. Fetuin-A is secreted from the liver and adipose tissue with elevated levels in obesity [96,97], metabolic syndrome [98], fatty liver disease [99], and T2DM [100,101]. Fetuin-B, secreted by hepatocytes, tongue and placenta [102], is increased in hepatic steatosis and is linked to gluconeogenesis through insulin suppression $[103,104]$. Based on the association with insulin resistance and glucose metabolism, it was hypothesized that fetuins could serve as markers for GDM diagnosis.

Kansu-Celik et al. [34] measured first-trimester fetuin-A as a biomarker for GDM diagnosis in 88 pregnant women (GDM n = 29, GCT/OGTT, Carpenter and Coustan criteria) and found significantly lower levels in GDM women compared with controls. Fetuin-A below $166 \mathrm{ng} / \mathrm{mL}$ could predict GDM with a sensitivity of $58.6 \%$, specificity of $76.2 \%$ and AUC of 0.337 (95\% CI 0.21-0.46).

Kalabay et al. [105] measured fetuin-A in 134 pregnant women (GDM n $=30,75 \mathrm{~g} 2 \mathrm{~h}$ OGTT, 1999 WHO criteria) and 30 non-pregnant women in each-trimester of pregnancy (including at the time of the OGTT) and found significantly higher levels of fetuin-A in GDM women at all time points compared to the NGT and non-pregnant women; fetuin-A was also positively associated with markers of insulin resistance, TNF- $\alpha$ and leptin levels. Iydir et al. [106] also found higher fetuin-A levels (sample collected at the time of the OGTT) in GDM women ( $\mathrm{n}=26$, Carpenter and Coustan criteria [107]) compared to NGT and decreased post-partum. The authors found a positive correlation between fetuin-A and $\mathrm{HbA} 1 \mathrm{c}$ levels. Jin et al. [35] measured fetuin-A in 270 women (GDM $\mathrm{n}=135$, IADPSG criteria) in the first and second-trimester of pregnancy and found significantly higher levels of fetuin-A in GDM women compared to controls at both time points, and it was positively correlated with the changes in the markers of insulin resistance. In this study, a fetuin-A cutoff value of $305.9 \mathrm{pg} / \mathrm{mL}$ in the first-trimester would predict GDM with a sensitivity of $64.4 \%$, specificity of $58.5 \%$ and AUC of 0.61 (95\% CI 0.54 to 0.68 ).

Farhan et al. [108] measured fetuin-A in 20 women $(G D M n=10)$ at the time of the $75 \mathrm{~g} 2 \mathrm{~h}$ OGTT (28 weeks of gestation) and 3 months post-partum; they found no difference in fetuin-A levels between GDM and NGT study participants at any time point.

The discrepancy between these study results arises from the different study designs, different population characteristics and sample size, and the different time-point sampling making the results inconsistent and difficult to compare.

It is unclear what the exact role of fetuin-A is in the pathophysiology of GDM. Some hypotheses suggest that its main action is through insulin resistance through the inhibition of the insulin receptor, while others suggest that fetuin-A induces adipose tissue inflammation, which leads to lipid-induced insulin resistance. There is even less information on fetuin-B, as its mode of action, signaling, and even receptor have not been adequately described. However, the minimal studies available show promising results. Prospective 
studies with a longitudinal sampling of both fetuins while assessing correlations with markers of insulin resistance are required.

\subsubsection{Leptin}

Leptin (167 amino acids), the first adipokine to be discovered in 1994, [109] is predominantly secreted by adipose cells [110], but also by the stomach [111], placenta [112] and the brain [113]. Leptin has a role in energy homeostasis by inhibiting hunger and mediating food intake $[114,115]$ through its action on the hypothalamus, dopamine system and brain stem [116]. More so, in both animal and human models, leptin administration improved hyperinsulinemia, hyperglycemia, insulin resistance and hyperlipidemia [117-119].

While leptin levels rise in pregnancy compared to the non-pregnant state, peaking between 20 and 30 weeks of gestation most likely secondary to fat accumulation [71,120], even higher leptin levels have been associated with GDM.

Bawah et al. [36] found that first-trimester leptin levels (11-13 weeks of gestation) in 140 women (GDM n = 70, 75 g 2 h OGTT, American Diabetes Association (ADA) criteria [121]) could predict the development of GDM with a sensitivity of $95.7 \%$, specificity of $68.6 \%$ and AUC of 0.81 .

Kautzky-Willer et al. [122] measured leptin levels at 28 weeks of gestation in GDM women ( $\mathrm{n}=55,1999$ WHO criteria [1]), women with NGT ( $\mathrm{n}=25)$ and women with T1DM $(\mathrm{n}=10)$. These samples were collected in a fasting state and 30 minutes after the glucose load during the OGTT. They found that leptin levels were higher in women with GDM compared to NGT and T1DM and similar between NGT women and T1DM women, all matched for BMI. There were no differences between leptin levels between fasting and post-glucose-load values, indicating that this test could be done in a non-fasting state. Boyadzhieva et al. [25] measured fasting leptin levels during the OGTT in 286 women (GDM $n=127$, IADPSG criteria) and found significantly higher levels in the GDM group compared to the controls. They also assessed if leptin could be used as a screening test and, setting the cutoff value at $28.7 \mathrm{ng} / \mathrm{mL}$; the test could exclude GDM with a sensitivity of $81.2 \%$, a specificity of $64.2 \%$ and AUC of 0.827 . Bozkurt et al. [22] found higher levels of leptin in women with GDM compared to controls, but the predictive value for GDM was 0.66 (95\% CI 0.57 to 0.74 ). Leptin taken during the OGTT at 24-28 weeks of gestation could identify GDM with an AUC of 0.61 (95\% CI 0.53-0.69).

Contradictory results come from the work of McLachlan et al. [123], who found higher leptin levels in the control group compared to GDM. However, this was of borderline significance $p=0.05$. More so, the number of women in this study was small (19 women in each arm) but well-matched, and the measurements for leptin levels were taken during an intravenous glucose tolerance test (IVGTT) in the third-trimester of pregnancy. While the OGTT is preferred over the IVGTT in detecting glucose intolerance [124], we also know from previous studies $[71,120]$ that leptin levels peak up to 30 weeks of gestation and start decreasing thereafter.

In a systematic review and meta-analysis, $\mathrm{Xu}$ et al. [70] found that high levels of leptin in early pregnancy may be predictive for developing GDM independent of BMI. In their systematic review (which included 9 prospective studies), Bao et al. [125] found that leptin levels taken in the first or second-trimester of pregnancy were $7.25 \mathrm{ng} / \mathrm{mL}$ higher $(95 \% \mathrm{CI}$ 3.27-11.22) in women who were subsequently diagnosed with GDM compared to women with NGT.

The data on leptin is slightly contradictory, and that may be due to the leptin correlation with adipose tissue. Despite that, most studies show great promise. While there is some evidence that stress, sleep deprivation or exercise influence leptin levels [126-128], similar to the OGTT [14], the test can be done in a non-fasting state, which is a clear advantage over the OGTT. Similar to adiponectin, prospective studies are required to determine-trimesterspecific reference ranges for the non-diabetic pregnant population,-trimester-specific cutoff points for the GDM population, the impact of confounders (including adiposity markers) on leptin levels and association with pregnancy outcomes. 


\subsubsection{Omentin}

Omentin (313 amino acids) is an adipose-tissue-specific factor selectively expressed in visceral tissue relative to subcutaneous adipose tissue. Omentin has a role in fat distribution, energy expenditure and insulin action modulation [129,130]. In 2007, de Souza Batista et al. [131] found that omentin levels correlated negatively with BMI/obesity, leptin level, and markers of insulin resistance and correlated positively with HDL and adiponectin levels in healthy subjects.

Barker et al. [132] studied the effects of pregnancy on omentin levels, also assessing the impact of BMI and GDM on omentin levels. Blood samples were collected in the first and second-trimester from 83 pregnant women $(\mathrm{GDM} \mathrm{n}=39,75 \mathrm{~g} 2 \mathrm{~h}$ OGTT, Australasian Diabetes in Pregnancy Society (ADIPS) [133]). The study found significantly decreased omentin levels in non-obese GDM women compared to controls with no difference in levels between obese GDM and NGT study participants. Omentin was negatively associated with fasting glucose, and maternal BMI and no association was found between omentin and adiponectin or leptin levels. While the subgroup numbers were small and the outcomes most likely underpowered, this research was one of the first to explore the role of omentin in pregnancy and GDM, raising further questions, such as what is the balance between omentin secretion and clearance at each stage of the pregnancy; does the ratio between adipose tissue omentin secretion and placental tissue omentin secretion change during pregnancy?

Abell et al. [134] measured omentin levels in the first-trimester of pregnancy in 103 women ( 25 of whom later developed GDM) and found lower omentin-1 levels in women with GDM compared to controls and a negative association with $1 \mathrm{~h}$ and $2 \mathrm{~h}$ glucose levels of the OGTT. They also found that omentin-1 levels less than $38.36 \mathrm{ng} / \mathrm{mL}$ were associated with a 4 -fold increased risk of GDM and that for $1 \mathrm{ng} / \mathrm{mL}$ increase in omentin levels, the risk of GDM was OR 0.97 (95\% CI 0.94-0.99). Limitations of the study include that all the participants in this study were at high risk for GDM with all pregnant women being overweight or obese, and the women were initially screened with a GCT followed by the OGTT if deemed necessary with arguably milder GDM cases being missed (thus this is only attributable to the very highest risk group and not suitable for population screening). Regardless, this study also highlights that-trimester 1 omentin may have the potential to predict GDM.

Contradictory data comes from Franz et al. [135], who measured omentin levels in 192 pregnant women (GDM n = 96, German and Austrian Society for Diabetes criteria based on the hyperglycemia and adverse pregnancy outcomes (HAPO) study [136]) at the time of the OGTT, at 32 weeks and from the umbilical cord at the time of the delivery. While omentin levels were lower in the GDM group compared to the NGT group at all timepoints, this was only statistically significant at the delivery timepoint. Omentin levels were also lower in women with a higher BMI and a lower HDL cholesterol.

In a systematic review and meta-analysis, which included 20 studies (GDM $n=1493)$, Sun et al. [89] found that omentin levels were significantly lower in women with GDM than in healthy controls. The authors also suggested that age and BMI may be important parameters influencing omentin levels in GDM patients. While there was significant heterogeneity in this review and a limited number of studies identified, the authors conclude that omentin has the potential to be a novel biomarker for early GDM diagnosis.

Omentin shows some promise as a GDM diagnostic biomarker, however further studies are required to clarify the actual role in GDM pathophysiology-if it is linked to visceral adiposity, vascular/endothelial dysfunction in either visceral adipose tissue or placenta or insulin mediation. Prospective studies are required to detect specific reference ranges and cut-offs and assess the impact of adiposity and inflammation on omentin levels and consecutively on omentin capacity to diagnose GDM. More so, omentin levels are influenced by fasting state $[137,138]$, which makes it a less attractive biomarker compared to other biomarkers discussed. 


\subsubsection{Interleukin 6 (IL-6)}

IL-6 is an inflammatory cytokine [139] secreted by monocytes/macrophages, but also endothelial cells, myocytes, adipocytes, pancreatic cells and placenta $[139,140]$ with primary roles in immune response regulation, inflammation and hematopoiesis [141], but also roles in obesity, insulin resistance and T2DM [142-144]. Some of the mechanisms proposed for its role in metabolism are the percentage of body fat [145], the degree of visceral fat [146], IL-6 direct effect on hepatocytes [142,147], the immune response induced dyslipidemia, IL6 lipolytic effect [148] or even a central effect of IL-6 on food intake [149,150]. A systematic review and meta-analysis by Liu et al. (Liu 2016) explored the association between IL-6 and T2DM. It comprised 16 studies involving 24,929 subjects and found that IL-6 was a strong predictor of developing T2DM. In pregnancy, the role of IL-6 in GDM prediction has given conflicting results.

Sudharshana Murthy et al. [151] explored the role of IL-6 in GDM. IL-6 levels were taken at the time of the OGTT in 60 pregnant women (GDM n = 30, OGTT) and found significantly raised IL-6 levels at the time of diagnosis. Siddiqui et al. [152], using a very similar study design, measured IL-6 levels in 103 pregnant women (GDM $\mathrm{n}=53$, OGTT, ADA criteria) at the time of the OGTT and found significantly increased IL-6 levels in the GDM cohort compared to the NGT and a strong association between IL-6 levels and prepregnancy BMI and fasting and post-prandial glucose levels. The participants in both studies were Asian with a median normal/normal-high BMI. A prospective study by Braga et al. [153] involving 176 South American pregnant women (GDM n = 78, $100 \mathrm{~g}$ OGTT, Carpenter and Coustan criteria) found no difference in IL-6 levels (taken at the time of the OGTT) between GDM and NGT women. Similar results were found by Simjak et al. [154] in 24 European pregnant women (GDM n $=12$, OGTT, IADPSG criteria) with normal BMI, who examined IL-6 levels in the second and third-trimester and post-partum and found no difference between GDM and NGT women.

Driven by the discordance in results, a recent systematic review by Amirian et al. [155] has explored the relationship between Il- 6 and GDM in studies published between 2009 and 2020 and included 24 articles. The study highlighted the diversity of ethnicities involved, the different measurement methods, but also the numerous criteria used to diagnose GDM (14 different diagnostic criteria) in the studies selected, making significant research synthesis difficult. The common denominator for all studies, however, was the small sample size with the largest cohort in a study by Abdel Gader et al. [156], who found no difference in IL-6 levels between GDM and NGT women. Out of 24 studies, 16 found a positive association between IL-6 levels and GDM, the authors concluding that IL-6 can be used as a GDM biomarker. However, such a statement requires more scientific evidence. The heterogeneity of the studies to date involved in assessing the relationship between IL-6 and GDM is too high to be able to make any meaningful comparison.

Conceptually, IL-6 could be linked to GDM pathogenesis either through a higher degree of inflammation in GDM pregnancies [157], driven by increased subcutaneous or visceral adipose tissue [158] or increased IL-6 secretion by the placenta in GDM pregnancies [159]. While IL-6 might prove to be a good GDM biomarker in the future, there are too many unanswered questions at present for such a claim. Larger studies with increased homogeneity in GDM diagnostic methods and criteria are required with serial IL-6 measurements in each-trimester of pregnancy for identification of-trimester-specific ranges, measurements of subcutaneous and visceral adipose tissue, which might be the driver for its increase, and associations with adverse pregnancy outcomes.

\subsubsection{Tumor Necrosis Factor (TNF)}

TNF is an inflammatory cytokine family primarily secreted by monocytes/macrophages [160] with two main components TNF- $\alpha$ (also secreted from the placenta [161]) and TNF- $\beta$. The initial role for TNF was thought to be the death of tumor cells [162], but it was soon discovered that TNF plays an important role in inflammatory diseases [163], neurodegenerative disease [164], and depression [165]. Given its pro-inflammatory effects, TNF 
has been identified as a marker of metabolic syndrome [166,167], obesity [168] and insulin resistance [169,170]. Evidence suggests that TNF stimulates the secretion of IL-6 [171,172], inhibits the secretion of adiponectin [173], induces apoptosis in adipose cells [174,175] and inhibits the insulin receptor, thus promoting insulin resistance $[170,176]$. A recent study by Alzamil et al. [177] examined the correlation between TNF- $\alpha$ and insulin resistance, T2DM and obesity in 128 Asian subjects (T2DM $n=65$ ). These authors found significantly higher TNF- $\alpha$ in T2DM subjects compared to controls, in obese subjects (T2DM or non-T2DM) compared to non-obese subjects, and TNF- $\alpha$ levels were positively correlated with $\mathrm{HbA1c}$ levels and HOMA-IR highlighting the role TNF- $\alpha$ plays in the pathogenesis of insulin resistance and T2DM and the link with both obesity and glucose intolerance.

Guillemette et al. [178] studied TNF- $\alpha$ levels in both the first-trimester of pregnancy and at the time of GDM diagnosis and its relationship to GDM in 756 pregnant women (GDM $n=61$, GCT /OGTT, IADPSG criteria). They found a positive association between TNF- $\alpha$ levels and BMI, adiponectin, and insulin levels in the first-trimester and HOMA-IR, $\mathrm{BMI}$, triglycerides, and fasting insulin levels in the third-trimester. The authors also showed that TNF- $\alpha$ levels are strongly positively linked to insulin resistance and that it behaves differently during the OGTT in insulin-sensitive and insulin-resistant women.

Kirwan et al. [179] described longitudinal changes in TNF- $\alpha$ levels and the association with maternal insulin resistance in 15 women (GDM n $=5$, euglycemic-hyperinsulinemic clamp, Carpenter and Coustan criteria). They found that TNF- $\alpha$ in normal pregnancy had lower levels in early pregnancy, increasing in late pregnancy paralleling insulin sensitivity changes, with higher levels in GDM women compared to lean NGT women. They also found that TNF- $\alpha$ was positively correlated with insulin sensitivity independent of BMI or glycemic status. Proposed mechanisms for this were either increased TNF- $\alpha$ secretion by the placenta in GDM women and direct inhibition of the insulin receptor. This hypothesis is also supported by Desoye et al. [159]. Syngelaky et al. [37] studied the link between first-trimester TNF- $\alpha$ and the development of GDM in 1000 women (GDM $n=200$, random glucose/OGTT, WHO criteria) and found higher TNF- $\alpha$ levels in women with GDM compared to controls. The authors calculated that TNF- $\alpha$ could predict GDM development with an AUC of 0.82 , but adding TNF- $\alpha$ levels to a multi-variable prediction model did not improve any of the estimated variables. While this was a large study, the GDM diagnostic method may have omitted milder cases of GDM that could have been included in the NGT group. A recent study by Wang et al. [24] explored TNF- $\alpha$ levels at GDM diagnosis in 110 Chinese pregnant women (GDM $n=60$, OGTT, ADA 2017 criteria) and found significantly higher TNF- $\alpha$ levels in GDM women compared to controls.

No correlation between TNF- $\alpha$ levels (samples were taken in both first-trimester and at GDM diagnosis) and GDM development was found by Georgiou et al. [30] in 250 women (GDM n = 14, OGTT, ADIPS criteria).

A systematic review and meta-analysis by $\mathrm{Xu}$ et al. [70] on the association between GDM and TNF- $\alpha$ levels comprised 10 studies, and despite the increased heterogeneity of the studies and missing confounders from the analysis, the authors found overall significant high levels of TNF- $\alpha$ in GDM pregnancies compared to controls independent of BMI.

The discrepancy in study results most likely lies in the different sample sizes, ethnicities, diagnostic methods and criteria and concentration limits employed. In addition, fasting, exercise and stress influence TNF- $\alpha$ levels [180-184], and this needs to be taken into account when considering new diagnostic tests. While there is no doubt that TNF- $\alpha$ plays a role in the pathogenesis of GDM and insulin resistance, the actual predictability value of this biomarker is yet to be established.

\subsection{Glycoproteins}

4.2.1. Afamin

Afamin is a glycoprotein present in plasma, cerebrospinal fluid, ovarian and seminal fluid [185,186], primarily expressed in the liver, but also expressed in the brain and kidneys and its main role to bind and transport vitamin E $[185,187]$ to peripheral tissues and organs. 
Studies examining afamin levels in polycystic ovary syndrome (PCOS) cohorts, despite a relatively small sample size, have found an association between afamin and insulin resistance and metabolic syndrome [188,189]. In a large multicenter study $(n=20,136)$, Kollerits et al. [190] found that afamin was a strong predictor for the development of T2DM and strongly correlated with insulin levels, HOMA-IR and insulin resistance, suggesting that afamin has the potential to be a biomarker for early prediction for future development of T2DM.

In pregnancy, afamin levels raise progressively with each-trimester of pregnancy, decreasing back to baseline post-partum with even higher levels in pregnancies complicated by preeclampsia or hypertension [191]. Based on the previous findings, which linked afamin with the development of insulin resistance and diabetes, it has been hypothesized that afamin may serve as a predictor for GDM. In two studies, Tramontana et al. [38,192] explored the relationship between first-trimester afamin and pregnancy complications in 4948 pregnant women and found significantly higher levels of afamin in women who subsequently developed GDM ( $n=207$, IADPSG criteria) compared to NGT women. Afamin (cutoff value $>65 \mathrm{mg} / \mathrm{L}$ ) was shown to be an independent predictor for developing GDM with a risk ratio of 2.07 (95\% CI 1.33-3.22) and an AUC of 0.66. Koninger et al. [39] looked at prepregnancy afamin levels in predicting GDM in a PCOS population $(n=63, \mathrm{GDM} n=29)$ and found higher afamin levels and HOMA-IR in women who developed GDM compared to controls with a strong positive correlation between afamin and HOMA-IR. The team showed that an afamin level of $88.6 \mathrm{mg} / \mathrm{L}$ identified GDM patients with a sensitivity of $79.3 \%$, specificity of $79.4 \%$ and an AUC of 0.78 (95\% CI 0.65-0.90). Ravnsborg et al. [40] studied potential GDM biomarkers in 270 first-trimester samples with shotgun proteomics (GDM $n=135$ ), diagnosed according to the Danish guidelines [193] and found higher afamin levels in GDM women compared with controls and that afamin could predict GDM diagnosis with an AUC of 0.67 (95\% CI 0.53-0.81).

Koninger et al. [194] studied the predictive power of afamin in diagnosing GDM in both the first-trimester ( $\mathrm{n}=110$, of which 59 developed GDM) and the second-trimester of pregnancy ( $n=105$, of which 29 developed GDM). GDM was diagnosed according to the German Diabetes Association (DDG) and the German Association for Gynecology and Obstetrics (DGGG) [195]. They found that both first and second-trimester afamin levels were higher in GDM women compared to NGT. Because this study comprised two different cohorts for first and second-trimester samples, the samples were not taken longitudinally. Therefore, the team was not able to determine-trimester-specific cutoff values for afamin levels. Another limitation of the study is the heterogeneity of the GDM diagnosis method and criteria used as not all women were screened with $75 \mathrm{~g} 2 \mathrm{~h}$ OGTT, and milder cases of GDM might have been missed.

Afamin is a very novel biomarker for GDM. It is not fully clear what is the exact mechanism through which afamin is linked to insulin resistance, metabolic syndrome, and glucose intolerance. In previous studies [186,196], there has been observed no variation in afamin levels between fasting and non-fasting state, no circadian variation, no variation with the menstrual cycle or gender variation, suggesting that afamin is a stable biomarker for longitudinal measurements. There is not enough evidence to clearly state the true potential of afamin in predicting GDM, but the results to date are promising.

\subsubsection{CD59}

CD59 is an 18-20 kDa glycoprotein, which is also known as membrane attack complex (MAC) inhibitory protein (MAC-IP) [197,198]. Its main role is to restrict MAC formation in the cell membrane, thus preventing cell lysis and cell death. While CD59 is a protein bound to the cell membrane, soluble forms are present in the blood, urine, and saliva [199-201].

The link between diabetes complications and increased MAC deposits has been well documented [202-207]. The first paper linking the increased MAC deposits in diabetes with CD59 inactivation was by Acosta et al. [208]. They showed that in vitro CD59 exposure to glucose reduced its protection role leading to cell lysis. Building on this work, 
Qin et al. [207] measured CD59 levels in the red blood cells (RBC) of subjects with and without T2DM and found that there are significantly lower levels of CD59 in diabetic RBC compared to subjects without T2DM.

In 2013, Ghosh et al. [209] hypothesized that glycated CD59 (gCD59) levels might mirror glucose control in human subjects and developed a sandwich ELISA assay to identify plasma gCD59, which they tested initially in 24 participants with and without T2DM (T2DM n $=14 \mathrm{HbA} 1 \mathrm{c}>48 \mathrm{mmol} / \mathrm{mol}$ ) and then validated it in 190 subjects (T2DM $\mathrm{n}=100$ ). gCD59 levels were significantly higher in the 14 individuals with T2DM from the initial testing set compared to controls and were strongly associated with $\mathrm{HbA1c}$ levels. gCD59 was able to identify T2DM with a sensitivity of $93 \%$, specificity of $100 \%$ and AUC of 0.98. In the follow-up testing set, gCD59 levels were indeed higher in the T2DM group and positively associated with $\mathrm{HbA1c}$ levels, with the test generating an AUC of 0.88 . Continuing this work, Ghosh et al. [210] explored the link between gCD59 and glycemic variables, such as HbA1c (in 400 subjects (T2DM n = 226) and glucose levels during the OGTT $(n=109)$. The results supported previous findings, with gCD59 levels higher in diabetic vs. participants without diabetes and independently associated with $\mathrm{HbA} 1 \mathrm{c}$ and with the $2 \mathrm{~h}$ glucose level on the OGTT. More so, the team also showed an acute response of gCD59 levels to insulin therapy in 21 poorly controlled subjects, with changes in levels in 2 weeks of treatment, while $\mathrm{HbA1c}$ and fructosamine took 6-8 weeks to respond. This rapid turnover of values would have particular importance in pregnancy and GDM where time is limited and in utero exposure to hyperglycemia not without consequences.

Ma et al. [27] studied gCD59's capacity to predict GDM earlier in pregnancy (sample collected and OGTT performed $<20$ week's gestation) and the association with adverse pregnancy outcomes using 770 frozen samples collected as part of the vitamin D and lifestyle intervention (DALI) study (Simmons D 2017). All the participants in the DALI study had a BMI $\geq 29 \mathrm{~kg} / \mathrm{m}^{2}$ and underwent 3 OGTT s (<20 weeks GDM n = 207, 24-28 weeks GDM $\mathrm{n}=77$ and 35 weeks of gestation) and were diagnosed according to the IADPSG criteria. gCD59 levels were higher in GDM women diagnosed $<20$ weeks of gestation independent of age, BMI or ethnicity and predicted the OGTT results $<20$ weeks with an adjusted AUC of 0.86 (95\% CI, 0.83-0.90). Restricting the analysis to the OGTT performed between 14 and 20 weeks of gestation, the AUC was calculated at 0.90 (95\% CI 0.86-0.93). Early gCD59 predicted GDM at 24-28 weeks with an AUC of 0.68 (95\% CI 0.64-0.73). The team also found that higher gCD59 levels were associated with the risk of delivering an LGA baby. Some limitations of the study include the retrospective nature of the study, the inclusion of only high-risk women with a BMI $\geq$ of $29 \mathrm{~kg} / \mathrm{m}^{2}$ and low ethnic diversity.

In 2017, Ghosh et al. [26] explored the association between gCD59 and the results of the GCT, the results of the OGTT and the prevalence of large for gestational age (LGA) babies in 1000 pregnant women at 26 weeks of gestation (500 women passed the GCT and were controls and 500 women failed the GCT and underwent a 3 h OGTT). gCD59 was 8.5 times higher in women who failed the GCT compared to those who passed it and 10 times higher in women who were diagnosed with GDM $(n=127)$ on the $3 \mathrm{~h}$ OGTT (Carpenter and Coustan criteria). gCD59 predicted GCT failure with a sensitivity of $90 \%$, specificity of $88 \%$ and adjusted AUC of 0.92 (95\% CI 0.88-0.93) and predicted the development of GDM compared to controls with a sensitivity of $85 \%$, specificity of $92 \%$ and adjusted AUC of 0.92 (95\% CI 0.77-0.91), independent of age, BMI, ethnicity of history of diabetes. More so, the team also identified significantly higher gCD59 levels in women who gave birth to an LGA baby. There are some limitations to this study, including its observational nature, the use of GCT (which may not be done in the morning), the 3 h-OGTT and the Carpenter and Coustan criteria for GDM diagnosis arguably missing milder cases of GDM.

gCD59 is a very promising biomarker that has shown much potential in the diagnosis and early diagnosis of GDM and the prediction of LGA-born infants. The rapid turnover of values and the lack of need for fasting certainly is a significant advantage for a pregnancy biomarker. However, there are still unanswered questions, such as: what are the-trimester-specific cutoff values? Are there any discrepancies in cutoff values among 
different ethnicities? Could early pregnancy gCD59 predict the 24-28 OGTT results in a BMI diverse population? Larger prospective studies are required to answer these questions, and one such study is currently underway [211].

\subsubsection{Human Chorionic Gonadotropin (hCG)}

HCG is a glycoprotein hormone, mainly secreted by the placenta, whose main role is in embryo implantation and control of embryogenesis [212]. Recently, however, Ma et al. [213] have shown that hCG influences insulin sensitivity and induces adipocyte-mediated inflammation and consequently may contribute to GDM pathogenesis. The beta isoform of hCG $(\beta-h C G)$ is part of the first-trimester screening for fetal aneuploidy.

Sirikunalai et al. [214] retrospectively studied the link between $\beta$-hCG levels and adverse pregnancy outcomes, including GDM in 13,620 pregnant Thai women and found that high first-trimester $\beta$-hCG levels were associated with a decreased risk of developing GDM. This finding was not sustained in the second-trimester. While this study had a large sample size, a high number of women had incomplete data, and due to the retrospective nature of the study, adequate adjustments and multivariate analysis could not be done due to the lack of absent confounders. Ong et al. [215] measured $\beta$-hCG levels between 10 and 14 weeks of gestation in 5584 pregnant women. Women were diagnosed with GDM with a $2 \mathrm{~h}$ OGTT and diagnosed according to the $1980 \mathrm{WHO}$ criteria [216]. The team found significantly lower $\beta$-hCG levels in women that developed GDM $(n=49)$ compared to NGT, suggesting that first-trimester $\beta$-hCG could predict second-trimester GDM diagnosis. A limitation of this study and an explanation for the small number of GDM cases detected is the GDM diagnosis criteria used, which would only identify severe cases of GDM, with milder cases not being included in the study. The use of IADPSG criteria in this cohort would have led to a more representative sample of the general population and ease the generalizability of results. Xiong et al. [217] retrospectively analyzed $\beta$-hCG levels in 1596 cases, 11 days after single blastocyst transfers (assisted reproduction) with 370 live births and found significantly higher rates of GDM (GDM total $n=61)$ in women with low levels of $\beta$-hCG compared to women with high levels of $\beta$-hCG. Beyond the retrospective nature of the study, no information is provided on the GDM diagnosis and criteria used; the number of GDM women in the low-level $\beta$-hCG subgroup is quite small $(n=5)$ and insufficient for a robust comparison. Controversially, Yue et al. [218] measured $\beta$-hCG levels between 14 and 20 weeks of gestation in 8333 pregnant Asian women, 1336, of which developed GDM (ADA criteria) and found high $\beta$-hCG levels are an independent risk factor for the development of GDM. A possible explanation for this discrepancy may be the more advanced week of gestation when the sample was collected with reactive $\beta$-hCG levels secreted by a hypoxic placenta as a response to hyperglycemia; also, the overall BMI of the cohort was very low compared to previous studies.

In a retrospective study, Tul et al. [219] measured first-trimester $\beta$-hCG levels in 1136 Caucasian women (GDM $n=27)$ and found lower yet not statistically significant levels in women who developed GDM. In this cohort, GDM was diagnosed with the $3 \mathrm{~h}$ OGTT and given the number diagnosed, and it would equate to a GDM prevalence of $2.37 \%$, which is extremely low compared with the overall European GDM prevalence. It is unclear from the paper whether this low prevalence is due to missing data. However, these results are supported by Savvidou et al. [220], who retrospectively assessed $\beta$-hCG levels at $11-13$ weeks of gestation in 42,102 pregnant women. GDM $(n=779)$ was diagnosed with a 2-step approach, the women undergoing an OGTT only if the random plasma glucose at 24-28 weeks of gestation was higher than $6.7 \mathrm{mmol} / \mathrm{L}$. The team found no difference in $\beta$-hCG levels between women who developed GDM and NGT. No correlation in firsttrimester $\beta$-hCG levels and GDM development was also found in Beneventi et al. [221] (GDM n = 228, GCT / $100 \mathrm{~g} 3$ h OGTT, Carpenter and Coustan criteria) or Sweeting et al. [222] (GDM n=248, OGTT, Australian Diabetes in Pregnancy Society criteria [133]).

There is quite a high degree of heterogeneity in design, populations and GDM diagnosis methods leading to inconsistent results. None of the studies looked at the longitudinal 
trend of $\beta$-hCG levels in the first and second-trimester and GDM diagnosis, which would have clarified the cause of variable levels-low levels in the first-trimester secondary to compromised placentation or reduced placental mass; high levels in the second-trimester of pregnancy secondary to hyperglycemia-induced placental hypoperfusion. It seems, however, that studies, which involved a higher-risk population for the development of GDM (assisted reproduction, GDM diagnosis criteria that identifies more severe cases of GDM, etc.) were more likely to find an association between $\beta$-hCG levels and GDM. Perhaps single $\beta$-hCG levels could be used to identify a possible at-risk GDM population that should be adequately followed up and screened. However, current evidence does not support this, and future more consistent studies are required.

\subsubsection{Sex-Hormone Binding Protein (SHBG)}

SHBG is a glycoprotein produced by the liver, brain, uterus, testes and placenta [223], and its main role is to bind and transport biologically active androgens and estrogens [224]. SHBG is linked to adipose tissue with lower levels in obese subjects [225], which increases when weight loss is achieved [226,227]. SHBG also has been linked to insulin resistance [228,229], metabolic syndrome [230-232] and the development of non-alcoholic fatty liver disease (NAFLD) independent of BMI and T2DM [233-235]. Potential mechanisms suggested for this are either a direct effect of insulin on SHBG production [236,237] or fat accumulation in the liver and/or increased hepatic triglycerides levels leading to decreased SHBG gene expression [238-240]. The role of SHBG in GDM diagnosis has been explored in numerous studies at different time points during pregnancy, including prepregnancy, with overall promising results.

Veltman-Verhulst et al. [43], in a prospective study, measured SHBG in 50 women with PCOS prior to pregnancy (median 35 weeks) following fertility treatment. GDM diagnosis was made based on a 3 h OGTT at 24-28 weeks of gestation (GDM n=21). SHBG levels were significantly lower in the GDM group compared to NGT and, with a cutoff level of $58.5 \mathrm{nmol} / \mathrm{L}$, SHBG could predict GDM with a sensitivity of $81 . \%$, specificity of $82.8 \%$ and AUC of 0.86 (95\% CI 0.75-0.97). Hedderson et al. [241] studied the link between prepregnancy (median 6.2 years) levels of SHBG and the subsequent development of GDM in a case-control study (GDM n = 267, 3 h OGTT, Carpenter and Coustan criteria) and found a significantly lower level of SHBG in women, who developed GDM independent of GDM risk-factors. This study showed that SHBG levels measured years (min. 6 years) prior to pregnancy could predict the development of GDM even in very low-risk women, and this is of high clinical importance. Study limitations include the lack of longitudinal anthropomorphic data, additional SHBG measurements during pregnancy and the lack of markers of visceral adiposity. Badon et al. [44] measured SHBG in a case-control study within a cohort of 4098 pregnant women (GDM $n=267$ ) at a median 7 years prior to pregnancy and similar to previous studies found significantly lower SHBG levels in women who subsequently developed GDM compared to controls with a predictive value of 0.71 .

In a longitudinal study, Li et al. [242] measured SHBG levels in 321 women (GDM $\mathrm{n}=107$ ) in all 3-trimesters of pregnancy. SHBG levels increased progressively with thetrimester of pregnancy in both GDM and NGT groups, with significantly lower levels in GDM compared to controls in the first-trimester. This significance disappeared in late pregnancy, suggesting that perhaps the best time to measure SHBG is early in pregnancy as lifestyle changes or treatment for GDM in late pregnancy may influence SHBG levels. They also found SHBG levels to be negatively associated with markers of insulin resistance. This study confirmed the results of a previous study by Smirnakis et al. [243], who measured SHBG levels in 145 women (GDM n = 37, GCT, ACOG criteria [244]) at 11 and 17 weeks of gestation and found lower levels in women, who subsequently developed GDM compared to controls, with the stronger association at 11 weeks of gestation. Caglar et al. [41] found that an SHBG cutoff level of $97.47 \mathrm{nmol} / \mathrm{L}$ (at 13-16 weeks of gestation) could predict GDM with a sensitivity of $46.7 \%$, specificity $84.1 \%$ and AUC 0.67 (95\% CI $0.55-0.79)$, while 
Maged et al. [42] using a first-trimester SHBG cutoff value of $211.5 \mathrm{nmol} / \mathrm{L}$ calculated a sensitivity of $85.2 \%$, specificity $37 \%$ and AUC of 0.69 .

Tawfeek et al. [28], in a case control study, measured SHBG levels at the time of the OGTT at 24-28 weeks of gestation (GDM n = 45, $75 \mathrm{~g} 2 \mathrm{~h}$ OGTT, IADPSG criteria) and found significant lower SHBG levels in the GDM group compared to NGT. At a cutoff value of $50 \mathrm{nmol} / \mathrm{L}$, SHBG could identify GDM with a sensitivity of $96 \%$, specificity of $95 \%$ and AUC of 0.91 (95\% CI 0.82-1.) A similar study in the same population by Siddiqui et al. [245] (GDM $\mathrm{n}=53$, OGTT, ADA criteria) also found lower levels of SHBG in GDM women compared to controls, but only in nulliparous women with a positive correlation with gestational age. Limitations of both studies include the small sample size with a relatively high BMI and ethnically confined to Asian participants, which tend to have a higher prevalence of metabolic syndrome [246].

McElduff et al. [247], however, found no difference in SHBG levels between GDM and NGT groups in their cross-sectional study, which included 220 pregnant women (GDM $\mathrm{n}=642$, GCT /OGTT, Carpenter and Coustan criteria). Despite a robust study methodology similar to previous studies, the main reason for these discordant results lies in the difference in population characteristics and diagnostic method.

SHBG is a straightforward, low-cost test that does not require fasting [248] and has no diurnal variation [249]. This test has shown some promise as a predictor of GDM when used prior to or in the first-trimester of pregnancy, and this might be because the difference in insulin resistance markers reduces as the pregnancy progresses. Catalano et al. [250] found higher levels of insulin resistance in the first-trimester of pregnancy in women with NGT in the first-trimester, who eventually developed GDM compared to women with NGT all throughout. In most studies, the link between SHBG and GDM was independent of subcutaneous adiposity, suggesting, perhaps, that liver adiposity would be a better marker for SHBG production [251]. However, further studies are required to measure SHBG levels, markers of insulin resistance, glycemic control and hepatic steatosis for a better understanding of the role of SHBG in GDM. Beyond that, however, we cannot ignore the positive results in studies assessing prepregnancy and first-trimester predictability of GDM development, which would allow for early interventions on the modifiable factors involved in GDM development. Standardization of prepregnancy and-trimester-specific cut-offs, GDM diagnosis cutoff value, exploration of the variability of levels in different populations and standardizations of assays would make SHBG a very promising marker for the early diagnosis of GDM.

\subsection{Other Proteins}

\subsubsection{C-Reactive Protein (CRP)}

CRP is an acute-phase protein secreted and released by numerous cells in the context of inflammation [252,253]. Obesity, which is a proinflammatory state, is a known risk factor of GDM. CRP is a nonspecific marker, which may be elevated in settings, such as infection or obesity, in the absence of GDM [254-256]. High levels of CRP have been described in the association with insulin resistance and metabolic syndrome [257-260]. Numerous studies have found an association between obesity and high CRP levels independent of insulin resistance [261-263]. Therefore, it is biologically plausible that inflammatory markers, such as C-reactive protein (CRP), could be a promising biomarker of GDM.

Alamolhoda et al. [264] prospectively studied the relationship between first-trimester CRP levels and the risk of developing GDM in 120 pregnant women (GDM $n=11$, OGTT) and found a significant difference between GDM women and controls independent of BMI. The sample size, however, was small, and the cutoff value for fasting glucose at diagnosis was $7 \mathrm{mmol} / \mathrm{L}$ (126 mg/dL), which selected only the more severe cases, fasting glucose of $7 \mathrm{mmol} / \mathrm{L}$ being the cutoff diagnostic value for T2DM. In a case-control study involving 372 women (GDM n = 124, OGTT, WHO criteria), Savvidou et al. [265] also found higher first-trimester CRP levels in women who subsequently developed GDM compared to controls. While the sample size was larger, similar to the previous study, the fasting glucose 
cutoff was $7 \mathrm{mmol} / \mathrm{L}$ (126 mg/dL). Kansu-Celik et al. [34] investigated first-trimester high-sensitivity CRP (hsCRP) as a biomarker for GDM diagnosis in 88 pregnant women (GDM n = 29, GCT/OGTT, Carpenter and Coustan criteria) and found that hsCRP was significantly higher in women, who subsequently developed GDM independent of BMI with a sensitivity of $86.2 \%$, specificity of $50.8 \%$ and AUC of 0.70 (95\% CI $0.59-0.81)$ at a cutoff value for hsCRP of $4.65 \mathrm{ng} / \mathrm{mL}$. Wolf et al. [266] measured first-trimester CRP levels in 131 women (GDM n = 43, GCT/OGTT, ADA criteria) and found that women diagnosed with GDM had higher CRP levels in the first-trimester of pregnancy with a strong positive correlation between CRP levels and $1 \mathrm{~h}$ post glucose load levels and systolic blood pressure. The team also found that the addition of BMI in a multivariate model attenuated the correlation between CRP and GDM diagnosis suggesting the influence of adipose tissue on CRP levels. Some of the limitations of this study include the small sample size, the single time point measurement of CRP and the lack of additional adiposity markers beyond BMI (such as waist circumference, visceral fat).

Alyas et al. [267] measured high-sensitivity CRP (hsCRP) levels at 14-18 weeks of gestation and 24-28 weeks of gestation in 158 women (GDM n =58, OGTT, IADPSG criteria) and found significantly higher CRP levels at both time points in women diagnosed with GDM compared to controls. No analysis on BMI category was done in this study.

Conflicting results are found in a cross-sectional study by Korkmazer et al. [268], who measured hsCRP at GDM screening time point in 116 women, who underwent a GCT followed by an OGTT and were classified in GDM ( $\mathrm{n}=39$, failed GCT and OGTT, Carpenter and Coustan criteria) and glucose intolerant ( $\mathrm{n}=37$, abnormal GCT, normal OGTT) and controls. The team found no differences in hsCRP levels between the three groups. The sample size was small, which may explain these findings, and no analysis was done between the GDM and glucose intolerance groups together and the controls. Corcoran et al. [269] evaluated hsCRP in 225 pregnant women with one or more risk factors for GDM in the first-trimester (46, of which developed GDM, OGTT, IADPSG criteria) and found no difference in hsCRP levels between the GDM and the control group findings also supported by Adam et al. [270]. Retnakaran et al. [255] measured CRP levels at the time of the OGTT in 180 women (GDM n =39, impaired glucose tolerance $\mathrm{n}=48$, GCT/OGTT, National Diabetes Data Group (NDDG) criteria [271]) and found no association between CRP levels and glycemic pregnancy status, but did describe a strong association between CRP levels and prepregnancy BMI and fasting glucose.

A systematic review by Amirian et al. [272] investigated the association between CRP and GDM diagnosis and included 31 articles. Even though no meta-analysis was done in this study due to the lack of clinical data, the authors found a positive association between high CRP levels and GDM development in 20 studies (CRP $\mathrm{n}=8$ articles, hsCRP $\mathrm{n}=12$ articles), while 11 studies (CRP $\mathrm{n}=6$ articles, hsCRP $\mathrm{n}=5$ articles) did not identify any correlation. The main reasons for these discrepancies are the variations in diagnostic methods and criteria, the difference in sample size and population characteristics, different methods to quantify CRP levels or the lack of adjustment for BMI and other confounders.

While CRP/hsCRP shows some potential, the literature shows inconsistent and contradictory data, with most studies having small sample size cohorts. This arises from the wide arrays of methodology and study population features. A big disadvantage of using CRP as a diagnostic biomarker is its nonspecificity as a high result will possibly lead to a wide range of investigations, some unnecessary, increasing costs and the pregnant woman's stress levels. Further research is required to clarify the correlation between adiposity (subcutaneous or visceral) and CRP levels and the reflection of this association in glycemic status. CRP may play a more meaningful role as a risk assessment tool for GDM screening rather than GDM diagnosis.

\subsubsection{Nesfatin-1}

Nesfatin-1, initially described in 2006, is a neuropeptide produced primarily by the hypothalamus and brain stem, and its main role is in food and water intake regulation, 
control of appetite with anorexigenic properties [273]. Research on animal models [274,275] found that intravenous nesfatin-1 regulated fatty acid metabolism, reduced insulin levels, improved insulin sensitivity and reduced blood glucose levels in mice. Li et al. [276] measured nesfatin-1 levels in healthy adults and adults with T1DM and T2DM and found significantly lower nesfatin-1 levels in individuals with T2DM compared to controls (not valid for T1DM) independent of BMI and no significant change in levels during the OGTT. A systematic review and meta-analysis by Zhai et al. [277] studied the association between T2DM and nesfatin- 1 and comprised 7 studies and 627 participants (T2DM n $=328$ ), with 6 out of 7 studies being carried out in China. The authors found significantly higher nesfatin-1 levels in newly diagnosed T2DM compared to controls; however, overall, when all participants were included, there was no significant association between T2DM and nesfatin-1. All the studies included had small size numbers of participants, and there was no subanalysis on the duration of diabetes, BMI subcategory, insulin resistance markers or glycemic control (HbA1c) on or off treatment.

Given the anorexigenic, the antihyperglycemic effect of nesfatin-1 and moderate evidence of the association with T2DM, studies have also assessed a possible implication of nesfatin-1 in GDM. A prospective study by Kucukler et al. [278] measured nesfatin-1 levels at 24-28 weeks of gestation in 79 pregnant women (GDM n = 38, GCT/OGTT, ADA criteria) and found significantly lower nesfatin-1 levels in the GDM group compared to NGT at diagnosis. Nesfatin-1 was negatively associated with BMI, fasting glucose, and HOMAIR. Measurements at 24-28 weeks of gestation were also taken by Ademoglu et al. [279] in 70 pregnant women (GDM n = 30, GCT/OGTT, Carpenter and Coustan criteria) and similar to previous studies found lower nesfatin-1 levels in women with GDM compared to NGT women independent of age, BMI, fasting glucose and HOMA-IR at diagnosis. No correlation was found between nesfatin-1 and fasting glucose, BMI, or markers of insulin resistance. In a larger study, Mierzynski et al. [280] measured nesfatin-1 levels at 24-28 weeks of gestation in 237 women (GDM n = 153, OGTT, WHO criteria) and found lower nesfatin-1 levels in GDM subjects compared to controls. There was a positive association between nesfatin-1 levels and BMI, glucose levels and gestational age.

Nesfatin-1 is a recent biomarker with only a few small size studies exploring its role in GDM pathogenesis. It is a possibility that nesfatin-1 could act as an antidiabetic agent by enhancing insulin action/ secretion, reducing glucose levels, and reducing food intake, and a decrease in nesfatin-1 levels in pregnant women may lead to insulin resistance and GDM. Another theory is that insulin resistance and hyperinsulinemia may inhibit the secretion of nesfatin-1. There are no studies assessing nesfatin-1 levels dynamically in a normal pregnancy or any studies measuring first-trimester levels in women who will develop GDM. Nesfatin-1 has been shown to be an important component of the glucose dysregulation pathway in both GDM and T2DM, but the exact mechanisms and the exact cutoff values required for accurate interpretation require substantial future studies.

\subsubsection{Pregnancy-Associated Plasma Protein A (PAPP-A)}

PAPP-A is a zinc-binding matrix metalloproteinase secreted by the trophoblast and can be measured as early as 28 days of pregnancy [281]. PAPP-a has been used as a screening test in the first-trimester of pregnancy for aneuploidy and for identifying certain adverse pregnancy outcomes [282,283]. Through its properties, PAPP-A increases insulin-like growth factor 1 (IGF-1) bioavailability through its cleavage from the IGF binding protein-4, suggesting a possible link between PAPP-A and insulin sensitivity. Pellitero et al. [284] found lower PAPP-A levels in diabetic patients compared to controls with a negative association between PAPP-A levels and HbA1c. In addition, it has been documented that TNF- $\alpha$ (an inflammatory cytokine with a role in insulin resistance) strongly stimulates PAPP-A secretion [285]. Therefore, it has been hypothesized that low PAPP-A levels are linked to insulin resistance in pregnancy through low levels of IGF-1 that led to hyperinsulinemia.

Lovati et al. [45], in a case-control study, explored the association of first-trimester levels of PAPP-A and GDM development in 673 Caucasian pregnant women (GDM n = 307, 
$100 \mathrm{~g} 3 \mathrm{~h}$ OGTT / $75 \mathrm{~g} 2 \mathrm{~g}$ OGTT) and found significantly lower levels in women, who were diagnosed with GDM and even lower levels in women that required insulin therapy. PAPPA (in addition to clinical risk factors) could predict GDM development with a sensitivity of $81.4 \%$, specificity of $50.5 \%$ and an AUC of 0.70 (95\% CI 0.66-0.73). Similar results are found by Ramezani et al. [46], who prospectively measured first-trimester PAPP-A in 286 Middle Eastern women (GDM n = 45, OGTT, IADPSG criteria) and found significantly lower PAPP-A levels in women who developed GDM. PAPP-A could identify the future development of GDM with a sensitivity of $73.3 \%$, specificity of $57.3 \%$ and AUC of 0.61 . This study, however, did not record certain variables, and adequate adjustments in the analysis have not been made. A similar design study [47] in a comparative size Asian cohort (GDM n $=45$, OGTT, IADPSG criteria) found that PAPP-A could predict GDM with a sensitivity of $72.5 \%$, specificity of $82.3 \%$ and AUC of 0.86 .

In a large retrospective study, Snyder et al. [48] studied clinical and biomarker models for early GDM diagnosis in 66,687 (GDM n $=4874$ ) in ethnically and racially diverse pregnant women. Samples were collected in both the first and second-trimesters of pregnancy. The team found significantly lower levels of PAPP-A in women who subsequently developed GDM compared to controls with no difference between groups in second-trimester samples. The addition of PAPP-A to the clinical risk prediction model only slightly improved the prediction accuracy of the model. These findings are supported by other studies [49,50], who did not find a significant change to AUC by the addition of PAPP-A to the clinical prediction model. While this was a large study, it only included nulliparous women, there was no information on the GDM diagnostic method or criteria used, and there was no BMI category sub-analysis. These findings suggest that PAPP-A could be useful as the first-trimester of pregnancy predictor for GDM development with limited utility as in GDM diagnosis in the second-trimester of pregnancy.

A systematic review and meta-analysis by Donovan et al. [286] included 13 studies and 83,921 subjects (GDM $n=3786$ ). While the study identified a high degree of heterogeneity mostly due to the analysis method, the GDM diagnostic criteria and the ethnicity of subjects involved, the overall analysis and sub-analysis identified significantly lower first-trimester PAPP-A levels in women who developed GDM compared with controls with even lower levels in GDM women diagnosed prior to 24 weeks of gestation. This correlation was not as strong in women of Asian origin. The correlation between PAPP-A levels and the degree of glucose intolerance in GDM was also highlighted by Wells et al. [287], who found lower levels of PAPP-A in women with early GDM diagnosis compared to late diagnosis and the lowest levels of PAPP-A in women diagnosed with T2DM.

Research to date has not clarified if low levels of PAPP-A promote or are rather the result of impaired glucose metabolism and insulin resistance. The reduced observed levels of PAPP-A in GDM pregnancies may reflect a defect in placentation or placental insufficiency encountered in GDM pathology. The studies, however, have consistent results with overall lower PAPP-A first-trimester levels in GDM pregnancies. Moreover, these findings are also supported by studies exploring exosomes profiles as a biomarker for GDM diagnosis [288]. Despite the variable reported predictive value across the literature, which is mostly due to patients' characteristics, sample size and GDM diagnostic criteria variability, PAPP-A is routinely assessed in first-trimester abnormalities screening, and it may identify women at high risk for early development of GDM. Further prospective studies are required to elucidate the clinical utility of this biomarker on its own or incorporated in risk identification models.

\subsubsection{Retinol-Binding Protein 4 (RBP4)}

RBP4 is secreted mainly by the liver and adipose tissue. Its main role is to transport retinol (vitamin A) from the liver to the peripheral tissues [289]. RBP4 also has a role in inflammation and adipose tissue dysfunction [290], in increasing hepatic glucose output, in reducing insulin signaling in the muscle and in increasing insulin resistance [291]. 
Jin et al. [292] measured RBP4 levels in the first and second-trimester of pregnancy in 270 women (GDM n $=135$, IADPSG criteria) and found that GDM women had higher first-trimester levels of RBP4 compared to NGT women, that higher levels of RBP4 were associated with a higher risk of developing GDM and that RBP4 levels in both-trimesters were positively independently associated with markers of insulin resistance. Yuan et al. [51] measured a panel of biomarkers with the potential to diagnose GDM in 359 pregnant women (GDM n $=86$, IADPSG criteria) at 16-18 weeks of gestation. RBP4 was significantly higher in women that developed GDM compared to NGT. The study also found that RPB4 (cutoff value $>30.45 \mu \mathrm{g} / \mathrm{mL}$ ) could predict the development of GDM with a sensitivity of $63.6 \%$, specificity of $75 \%$ and AUC 0.72 (95\% CI 0.64-0.79) and that RPB4/adiponectin ratio (cutoff $>0.37$ ) could predict GDM with a sensitivity of $81.8 \%$, specificity of $75.6 \%$ and AUC of 0.80 (95\% CI 0.73-0.87). A retrospective study by Du et al. [29] found that secondtrimester RBP4 levels were significantly higher in the GDM group ( $\mathrm{n}=194$, OGTT, IADPSG criteria) compared to NGT women with a strong association between RBP4 levels, insulin levels and HOMA-IR. The authors found that RBP4 (cutoff levels $34.84 \mu \mathrm{g} / \mathrm{mL}$ ) can predict GDM with a sensitivity of $79.4 \%$, specificity of $79.1 \%$ and AUC of 0.87 (85\% CI $0.83-0.92$ ).

Discordant results are found in a study by Khovidhunkit et al. [293], who measured RBP4 in 532 women (GDM n = 171, GCT/OGTT, Carpenter and Coustan criteria) between 24 and 28 weeks of gestation and found no difference in RBP4 levels between GDM and NGT women and no correlation with insulin levels and HOMA-IR. They did find a positive independent association with fasting triglycerides and weight gain in pregnancy. All the women in this study were of Thai ethnicity with a low/normal BMI, which may account for the discordant result with previous studies along with different diagnosis methods (OGTT/GCT) and different sampling gestational weeks.

Two meta-analyses [294,295] studied the link between RBP4 and GDM. Huang et al. [294] included 14 studies (GDM $n=884$ ) and found that RBP4 levels were significantly higher in women with GDM compared to NGT women, independent of age or BMI. On subgroup analysis, however, this significant difference was only maintained for Asian populations with no difference in levels in non-Asian populations. This study had a low probability of bias but a high degree of heterogeneity; the link between RBP4 levels and GDM varied with GDM diagnostic criteria (WHO criteria-higher levels of RBP4 in GDM patients compared to controls; ADA criteria-no difference in levels between groups) and varied with different assays used for RBP4 determination. These findings are supported by a meta-analysis by Jia et al. [296], who found higher levels of RBP4 in patients of Asian ethnicity compared to controls, but not in patients of European ethnicity compared to controls. A meta-analysis by Hu et al. [295] pooled results from 14 studies (case-control) $(\mathrm{GDM} \mathrm{n}=647)$ and found that RBP4 levels taken between 24 and 28 weeks of gestation were associated with the risk of developing GDM. Similar to the previous meta-analysis, there was no difference between groups in studies that used the ADA criteria for GDM diagnosis, suggesting that higher glucose levels on the OGTT are associated with higher RBP4 levels.

There are contradictory findings in the literature, with some studies finding a positive link between RBP4 and GDM [293,297-300] (Asian population), while other studies could not determine an association [301-304] (non-Asian population), and there is scarce evidence on the first-trimester of pregnancy RBP4 and the risk of GDM. If ethnicity plays such an important role in RBP4 levels, this requires further evaluation in much larger studies with multi-ethnic participation.

It is unclear if the free or bound RBP4 (or total) serves as a better predictor for GDM. Some studies [302,305] suggest that, in fact, the RBP4/transthyretin (RBP s binding protein) ratio may be a better marker for insulin resistance and GDM compared to RBP4 alone.

A possible cause for discordant results is the different assays used in the measurement of RBP4. Graham et al. [306] measured RBP4 levels in subjects with insulin resistance and glucose intolerance and insulin-sensitive subjects with NGT using three commercial assays and a quantitative Western blotting assay and found substantial inconsistency among the 
results with enzyme immunoassays underestimating RBP4 levels concluding that Western blotting is the most reliable method for measuring RBP4.

\section{Discussion}

This scoping review highlighted the large number of biomarkers described in the literature investigated for their potential to identify GDM and described 15 protein biomarkers selected based on the higher number of citations in very recent publications in our literature search.

\subsection{The Current Screening Methods for GDM Pose Several Issues}

5.1.1. Universal vs. Selective Screening

Numerous studies [307-310] have shown that universal screening offers a significant advantage over selective screening by identifying all GDM cases, enabling timely lifestyle interventions and treatment, leading to a reduction in GDM associated adverse events. Proponents of selective screening invoke reduced complications associated with milder cases of GDM that would be diagnosed through universal screening as the argument in addition to the increased healthcare costs of screening. It is well known that GDM poses a long-term threat to the health of the mother and child through chronic metabolic diseases in a young population that will considerably increase the lifetime overall healthcare costs. Identifying GDM and intervening to prevent long-term issues has been shown to be costeffective. A systematic review by Mo et al. [311] included 10 economic evaluations on different GDM screening strategies and found that universal screening is more likely to be cost-effective compared to selective screening. This finding is supported by other studies [312,313].

Beyond the costs, the focus should be on the accurate identification of causes and the prevention of adverse outcomes. In a Malaysian population, Idris et al. [307] found that when universal screening was employed, the OGTT yielded a sensitivity of $83.5 \%$ and specificity of $82.6 \%$. When the selective screening was employed, the sensitivity and specificity of the OGTT were lower, $76.1 \%$ and $60.9 \%$, respectively, leading to $23.8 \%$ of women with GDM being missed. In a European cohort, Miaihle et al. [314] showed that selective screening would have missed one-sixth of GDM cases. Similar results were found by Cosson et al. [315] in a retrospective study, which included 18,775 pregnancies. The authors found that applying selective screening criteria would lead to $34.7 \%$ of GDM cases being missed.

It was suggested that low-risk women with GDM would have a good prognosis, and not being diagnosed with GDM would not lead to adverse pregnancy outcomes. The literature has conflicting data, with some studies finding no benefit on adverse pregnancy outcomes when universal screening was applied [314,316], while others have shown significant benefits [317-319].

As selective screening would miss a significant number of women with GDM, and as universal screening has been shown to be cost-effective compared to selective screening, most international bodies now recommend universal screening. One of the barriers to the implementation of universal screening is the logistics of performing OGTT in the entire pregnant population. Accurate biomarkers as an alternative to the OGTT would allow universal screening to become a reality.

\subsubsection{Time of Screening}

Standard GDM screening occurs between 24 and 28 weeks of gestation. This arguably leaves a very narrow window for intervention. Some studies suggest that women that develop GDM early in pregnancy ( $<12$ weeks of gestation) have outcomes comparable to women with prepregnancy diabetes despite treatment [320,321], while others found that early diagnosis and treatment may lead to a reduction in LGA [322]. Research has focused on the differences in pregnancy outcomes between women with GDM diagnosed in the first and late second-trimester, but we also need to consider the possible long-term 
impact of the fetal intrauterine exposure to hyperglycemia between onset and diagnosis and, while this may not be obvious at birth, the hyperglycemia-triggered fetal metabolic programming can lead to metabolic syndrome, insulin resistance and obesity in young adults [323]. One of the concerns with early screening is that while some women with more severe forms of GDM will be diagnosed early in pregnancy, others will only develop glucose abnormalities later in pregnancy and will require another test at 24-28. A single non-fasting biomarker would allow repetitive testing through pregnancy to facilitate rapid identification of hyperglycemia.

\subsubsection{Diagnostic Criteria}

As illustrated, it is difficult to make a meaningful comparison between studies when different criteria are employed to diagnose GDM. Studies that use a two-step approach with higher glucose cutoff thresholds will select a population with more severe forms of GDM, and the results cannot be extrapolated to the general population. Using a common new diagnostic biomarker will lead to harmonization of GDM diagnosis and all data synthesis to be performed

\subsubsection{OGTT}

Women are currently diagnosed with GDM using an OGTT. This test is unreliable with poor reproducibility and high vulnerability to external and internal factors [14]. More so, the OGTT does not identify the continuous correlation between hyperglycemia in the mother and pregnancy complications and possibly omits milder forms of glucose abnormalities that may identify pregnancy risks. Studies to date evaluating novel biomarkers as diagnostic tests/tools in GDM use the OGTT as the gold standard for comparison. However, how valid are the results if the comparator test is flawed? It may be more accurate to assess the predictive power of the biomarker to identify adverse pregnancy outcomes. Hyperglycemia is not the only contributor to adverse pregnancy outcomes, and other metabolic factors, such as adiposity, dyslipidemia, inflammation, should be considered when considering a test (or panel of tests) with the highest potential to identify pregnant women at risk. Changing the focus from the glucose value to the outcomes we need to prevent-and the factors contributing to them - will bring the research community closer to identifying the next screening test. This would start with a consensus on what are the outcomes we are aiming to prevent (macrosomia, LGA, hypertensive disorders of pregnancy, polyhydramnios, etc.), a reflection on the pathophysiology of the outcome and a reassessment of novel biomarkers not in their capacity to identify an out-of-range glucose value but in their capacity to capture the cumulus of mechanisms that lead to adverse pregnancy outcomes.

The COVID-19 pandemic has highlighted the difficulties in performing the OGTT in such a challenging environment, leading to OGTT screening being terminated and a high number of women being undiagnosed. This further emphasizes the urgent need for a single non-fasting sample biomarker test that could be performed in a family practice setting (GP) rather than a hospital setting.

Identifying a biomarker for the accurate diagnosis of GDM would have numerous practical benefits. A single blood test would reduce the appointment length, would enable a greater number of women to be screened (aiming for universal screening) and would enable the test to be performed in a non-hospital setting. A test that does not require fasting would not only considerably reduce the discomfort a pregnant woman experiences but would also enable appointments for sample collection throughout the day, thus increasing the number of women being screened. A test that does not require glucose loading, reducing adverse experiences, such as nausea, vomiting, pre-syncopal episodes, would considerably increase compliance with testing. Studies assessing the robustness of novel biomarkers to pre-analytical and analytical variables, time-to-result analysis and cost-effectiveness analysis will be required in the future. 
Biomarker research has grown exponentially in recent years out of a need for more accurate, more direct measurement of disease and has proven to be a powerful tool in the understanding of physiology and pathophysiology. However, while biomarkers have many advantages, much like other tests, several things need to be considered and assessed when conducting biomarker research: (1) interindividual variability; (2) intraindividual variability; (3) sample collection/transportation/storage; (4) biomarker validity; (5) predictive power; (6) confounding variables; (7) normal ranges and (8) cost [324].

The main limitation of this study lies in the nature of its design. Scoping reviews do not formally evaluate the quality of evidence, and the evidence is collected from studies of different designs and methodology. Therefore, the data collected cannot be presented in a systematic way; but instead, it gives an overall view of the existent literature. The scope of this review was to offer the reader an insight into the vast number of molecules studied in relation to GDM diagnosis and the potential diagnostic value of the selected novel protein biomarkers. This approach, however, led to a certain degree of selection bias. Another limitation of the study is the time lapse between the systematic review search and the publication of the manuscript leading to very recent research not being included in our study.

\subsection{Perspectives}

Given the limitation mentioned above, several protein biomarkers did not fulfill our inclusion criteria and were not included in the discussion. Therefore, we want to give a short overview of promising protein biomarkers evaluated for GDM prognosis/diagnosis in articles published between January 2020 and March 2021 that should be considered in the future.

Secreted frizzled-related protein 4 (sFRP4) has been shown to play a role in glucose metabolism, reflecting islet inflammation and impaired insulin secretion [325]. Schuitemaker et al. [326] found significantly higher first-trimester levels of sFRP4 in women, who subsequently developed GDM ( $\mathrm{n}=50$, diagnostic criteria fasting glucose $\geq 7.0 \mathrm{mmol} / \mathrm{L}$, $2 \mathrm{~h}$ glucose $\geq 7.8 \mathrm{mmol} / \mathrm{L}$ ) compared to controls and a predictive capacity expressed as AUC of $0.60(95 \%$ CI $0.50-0.70)$. The correlation between sFRP4 and GDM is supported by other studies $[327,328]$

Amini et al. [329] studied alfa-fetoprotein (AFP) as a predictor for GDM in the early second-trimester (14-17 weeks of gestation) in 523 pregnant women. The authors found that AFP alone could predict GDM diagnosis with a sensitivity of $70 \%$, specificity of $93 \%$ and AUC of 0.58 (95\% CI 0.51-0.62) and AFP combined with unconjugated estriol and $\beta$-hCG levels can predict GDM with a sensitivity of $95 \%$, specificity of $86 \%$ and AUC of 0.91 (95\% CI 0.87-0.98).

Wnt1-inducible signaling pathway protein-1 (WISP1) was studied by Liu et al. [330] in 313 pregnant women (GDM $\mathrm{n}=61,2 \mathrm{~h} 75 \mathrm{~g}$ OGTT, IADPSG criteria). The samples were taken at the time of the OGTT. The authors found that WISP1 levels were significantly higher in GDM patients with prepregnancy overweight or obesity compared to normoglycemic and normal-weight subjects, suggesting a possible role of this protein in the mechanisms involved in obesity-induced insulin resistance in GDM. This hypothesis was also suggested by Sahin Esroy et al. [331].

Irisin levels were measured by AL-Ghazali et al. [332] in 90 pregnant women (GDM $\mathrm{n}=60,2 \mathrm{~h} 75 \mathrm{~g}$ OGTT, IADPSG criteria) at the time of the OGTT and found significantly lower levels of irisin in women with GDM compared to controls. Diagnostic capacity (i.e., AUC) was not calculated. These findings are supported by other studies [333,334]

Asprosin levels [335] were found to be significantly higher in women with GDM compared with controls at the time of OGTT, but also as early as 18-20 weeks of gestation, suggesting a potential role as an early biomarker. Similarly, spexin and subfatin levels [336] and fibrinogen-like protein 1 (FGL-1) [337] were found to be higher in women with GDM compared with controls (samples taken at the time of the OGTT). 
Finally, coiled-coil domain-containing 80 (CCDC80) levels [338] and complement C1q tumor necrosis factor-related protein 1 (CTRP1) levels [339] taken at the time of the OGTT ( $2 \mathrm{~h} 75 \mathrm{~g}$ OGTT, IADPSG criteria) were significantly lower in women with GDM compared with controls. Additionally, CCDC 80 could identify GDM cases with an AUC of 0.61 (95\% CI 0.53-0.68), which increased to 0.74 when additional variables were included in the model (maternal age, gestational age, BMI, blood pressure).

\section{Conclusions}

This review has identified and described 15 promising biomarkers that could potentially replace the OGTT and be used to both predict and diagnose GDM. Steps required to move the biomarker agenda forward should include large multicenter, multi-ethnic prospective studies using uniform screening and diagnostic criteria for GDM, with longitudinal sampling in all three trimesters and with well-recorded patient characteristics. One such study would answer many questions and help identify the best candidate marker. Recently, the Lames Lindt Alliance (Priority Setting Partnerships) has identified the top 10 research priorities for GDM, one of which is identifying the best test to diagnose GDM [340]. The scientific community agrees that the OGTT is a dated, cumbersome, imperfect test and needs to be replaced, and this review highlights some very promising contenders.

Supplementary Materials: The following are available online at https:/ /www.mdpi.com/article/10 .3390/jcm10071533/s1, Supplemental Material: PubMed Search Strategy; Supplemental Table S1: Biomarkers identified through the scoping review in alphabetical order; Figure S1: Reported AUC at the time of GDM diagnosis; Figure S2: Reported AUC for prediction of GDM.

Author Contributions: D.B., P.M.O. and F.D. were responsible for the conception and design of the study. D.B., C.R., D.M. screened, collected, extracted, and analyzed the data. D.B. drafted the manuscript. All authors (D.B., C.R., D.M., H.C.D., J.A.H., P.M.O., F.D.) made substantial contributions to the interpretation of data, critically revised the manuscript for important intellectual content and approved the final version to be published. D.B. is responsible for the integrity of the work as a whole. All authors have read and agreed to the published version of the manuscript.

Funding: This research received no external funding.

Conflicts of Interest: The authors declare no conflict of interest.

\section{References}

1. Alberti, K.G.; Zimmet, P.Z. Definition, diagnosis and classification of diabetes mellitus and its complications. Part 1: Diagnosis and classification of diabetes mellitus provisional report of a WHO consultation. Diabet. Med. 1998, 15, 539-553. [CrossRef]

2. Zhu, Y.; Zhang, C. Prevalence of Gestational Diabetes and Risk of Progression to Type 2 Diabetes: A Global Perspective. Curr. Diabetes Rep. 2016, 16, 1-11. [CrossRef]

3. Goedegebure, E.A.R.; Koning, S.H.; Hoogenberg, K.; Korteweg, F.J.; Lutgers, H.L.; Diekman, M.J.M.; Stekkinger, E.; Berg, P.P.V.D.; Zwart, J.J. Pregnancy outcomes in women with gestational diabetes mellitus diagnosed according to the WHO-2013 and WHO-1999 diagnostic criteria: A multicentre retrospective cohort study. BMC Pregnancy Childbirth 2018, 18, 152. [CrossRef]

4. Koivunen, S.; Viljakainen, M.; Männistö, T.; Gissler, M.; Pouta, A.; Kaaja, R.; Eriksson, J.; Laivuori, H.; Kajantie, E.; Vääräsmäki, M. Pregnancy outcomes according to the definition of gestational diabetes. PLoS ONE 2020, 15, e0229496. [CrossRef]

5. Metzger, B.E. Long-term Outcomes in Mothers Diagnosed With Gestational Diabetes Mellitus and Their Offspring. Clin. Obstet. Gynecol. 2007, 50, 972-979. [CrossRef]

6. O'Sullivan, E.P.; Avalos, G.; O’Reilly, M.; Dennedy, M.C.; Gaffney, G.; Dunne, F.P. Atlantic DIP: The prevalence and consequences of gestational diabetes in Ireland. Ir. Med. J. 2012, 105, 13-15. [PubMed]

7. Crowther, C.A.; Hiller, J.E.; Moss, J.R.; McPhee, A.J.; Jeffries, W.S.; Robinson, J.S. Effect of treatment of gestational diabetes mellitus on pregnancy outcomes. N. Engl. J. Med. 2005, 352, 2477-2486. [CrossRef] [PubMed]

8. Landon, M.B.; Spong, C.Y.; Thom, E.; Carpenter, M.W.; Ramin, S.M.; Casey, B.; Wapner, R.J.; Varner, M.W.; Rouse, D.J.; Thorp, J.M.; et al. A Multicenter, Randomized Trial of Treatment for Mild Gestational Diabetes. N. Engl. J. Med. 2009, 361, 1339-1348. [CrossRef] [PubMed]

9. Koivusalo, S.B.; Rönö, K.; Klemetti, M.M.; Roine, R.P.; Lindström, J.; Erkkola, M.; Kaaja, R.J.; Pöyhönen-Alho, M.; Tiitinen, A.; Huvinen, E.; et al. Gestational Diabetes Mellitus Can Be Prevented by Lifestyle Intervention: The Finnish Gestational Diabetes Prevention Study (RADIEL): A Randomized Controlled Trial. Diabetes Care 2016, 39, 24-30. [CrossRef] 
10. International Association of Diabetes and Pregnancy Study Groups Consensus Panel. International Association of Diabetes and Pregnancy Study Groups Recommendations on the Diagnosis and Classification of Hyperglycemia in Pregnancy. Diabetes Care 2010, 33, 676-682. [CrossRef]

11. Wilkerson, H.L.C.; Remein, Q.R. Studies of Abnormal Carbohydrate Metabolism in Pregnancy: The Significance of Impaired Glucose Tolerance. Diabetes 1957, 6, 324-329. [CrossRef] [PubMed]

12. Metzger, B.E.; Gabbe, S.G.; Persson, B.; Lowe, L.P.; Dyer, A.R.; Oats, J.J.; Buchanan, T.A. International Association of Diabetes and Pregnancy Study Groups Recommendations on the Diagnosis and Classification of Hyperglycemia in Pregnancy: Response to Weinert. Diabetes Care 2010, 33, e98. [CrossRef]

13. Lachmann, E.H.; Fox, R.A.; Dennison, R.A.; Usher-Smith, J.A.; Meek, C.L.; Aiken, C.E. Barriers to completing oral glucose tolerance testing in women at risk of gestational diabetes. Diabet. Med. 2020, 37, 1482-1489. [CrossRef]

14. Bogdanet, D.; O'Shea, P.; Lyons, C.; Shafat, A.; Dunne, F. The Oral Glucose Tolerance Test-Is It Time for a Change?-A Literature Review with an Emphasis on Pregnancy. J. Clin. Med. 2020, 9, 3451. [CrossRef] [PubMed]

15. Catalano, P.M.; Avallone, D.A.; Drago, N.M.; Amini, S.B. Reproducibility of the oral glucose tolerance test in pregnant women Am. J. Obstet. Gynecol. 1993, 169, 874-881. [CrossRef]

16. Arksey, H.; O'Malley, L. Scoping studies: Towards a methodological framework. Int. J. Soc. Res. Methodol. 2005, 8, 19-32. [CrossRef]

17. Levac, D.; Colquhoun, H.; O’Brien, K.K. Scoping studies: Advancing the methodology. Implement Sci. 2010, 5, 69. [CrossRef] [PubMed]

18. Peters, M.D.; Godfrey, C.M.; Khalil, H.; McInerney, P.; Parker, D.; Soares, C.B. Guidance for conducting systematic scoping reviews. Int. J. Evid. Based Health 2015, 13, 141-146. [CrossRef]

19. Munn, Z.; Peters, M.D.J.; Stern, C.; Tufanaru, C.; McArthur, A.; Aromataris, E. Systematic review or scoping review? Guidance for authors when choosing between a systematic or scoping review approach. BMC Med. Res. Methodol. 2018, 18, 1-7. [CrossRef]

20. Tricco, A.C.; Lillie, E.; Zarin, W.; O’Brien, K.K.; Colquhoun, H.; Levac, D.; Moher, D.; Peters, M.D.; Horsley, T.; Weeks, L.; et al. PRISMA Extension for Scoping Reviews (PRISMA-ScR): Checklist and Explanation. Ann. Intern. Med. 2018, 169, $467-473$. [CrossRef] [PubMed]

21. Ouzzani, M.; Hammady, H.; Fedorowicz, Z.; Elmagarmid, A. Rayyan-A web and mobile app for systematic reviews. Syst. Rev. 2016, 5, 1-10. [CrossRef] [PubMed]

22. Bozkurt, L.; Göbl, C.S.; Baumgartner-Parzer, S.; Luger, A.; Pacini, G.; Kautzky-Willer, A. Adiponectin and Leptin at Early Pregnancy: Association to Actual Glucose Disposal and Risk for GDM-A Prospective Cohort Study. Int. J. Endocrinol. 2018, 2018, 1-8. [CrossRef] [PubMed]

23. Weerakiet, S.; Lertnarkorn, K.; Panburana, P.; Pitakitronakorn, S.; Vesathada, K.; Wansumrith, S. Can adiponectin predict gestational diabetes? Gynecol. Endocrinol. 2006, 22, 362-368. [CrossRef] [PubMed]

24. Wang, X.; Liu, J.; Wang, D.; Zhu, H.; Kang, L.; Jiang, J. Expression and correlation of Chemerin and FABP4 in peripheral blood of gestational diabetes mellitus patients. Exp. Ther. Med. 2019, 19, 710-716. [CrossRef] [PubMed]

25. Boyadzhieva, M.; Atanasova, I.; Zacharieva, S.; Kedikova, S. Adipocytokines during pregnancy and postpartum in women with gestational diabetes and healthy controls. J. Endocrinol. Investig. 2013, 36, 944-949.

26. Ghosh, P.; Luque-Fernandez, M.A.; Vaidya, A.; Ma, N.; Sahoo, R.; Chorev, M.; Zera, C.; McElrath, T.F.; Williams, M.A.; Seely, E.W.; et al. Plasma Glycated CD59, a Novel Biomarker for Detection of Pregnancy-Induced Glucose Intolerance. Diabetes Care 2017, 40, 981-984. [CrossRef]

27. Ma, D.; Luque-Fernandez, M.A.; Bogdanet, D.; Desoye, G.; Dunne, F.; Halperin, J.A. Plasma Glycated CD59 Predicts Early Gestational Diabetes and Large for Gestational Age Newborns. J. Clin. Endocrinol. Metab. 2020, 105, e1033-e1040. [CrossRef]

28. Tawfeek, M.A.; Alfadhli, E.M.; Alayoubi, A.M.; El-Beshbishy, H.A.; Habib, F.A. Sex hormone binding globulin as a valuable biochemical marker in predicting gestational diabetes mellitus. BMC Women's Health 2017, 17, 1-5. [CrossRef]

29. Du, X.; Dong, Y.; Xiao, L.; Liu, G.-H.; Qin, W.; Yu, H. Association between retinol-binding protein 4 concentrations and gestational diabetes mellitus (A1GDM and A2GDM) in different pregnancy and postpartum periods. Ann. Transl. Med. 2019, 7, 479. [CrossRef]

30. Georgiou, H.M.; Lappas, M.; Georgiou, G.M.; Marita, A.; Bryant, V.J.; Hiscock, R.; Permezel, M.; Khalil, Z.; Rice, G.E. Screening for biomarkers predictive of gestational diabetes mellitus. Acta Diabetol. 2008, 45, 157-165. [CrossRef]

31. Ferreira, A.F.A.; Rezende, J.C.; Vaikousi, E.; Akolekar, R.; Nicolaides, K.H. Maternal Serum Visfatin at 11-13 Weeks of Gestation in Gestational Diabetes Mellitus. Clin. Chem. 2011, 57, 609-613. [CrossRef]

32. Madhu, S.V.; Bhardwaj, S.; Jhamb, R.; Srivastava, H.; Sharma, S.; Raizada, N. Prediction of Gestational Diabetes from First Tri-mester Serum Adiponectin Levels in Indian Women. Indian J Endocrinol Metab. 2019, 23, 536-539. [CrossRef] [PubMed]

33. Iliodromiti, S.; Sassarini, J.; Kelsey, T.W.; Lindsay, R.S.; Sattar, N.; Nelson, S.M. Accuracy of circulating adiponectin for predicting gestational diabetes: A systematic review and meta-analysis. Diabetologia 2016, 59, 692-699. [CrossRef]

34. Kansu-Celik, H.; Ozgu-Erdinc, A.S.; Kisa, B.; Findik, R.B.; Yilmaz, C.; Tasci, Y. Prediction of gestational diabetes mellitus in the first trimester: Comparison of maternal fetuin-A, N-terminal proatrial natriuretic peptide, high-sensitivity C-reactive protein, and fasting glucose levels. Arch. Endocrinol. Metab. 2019, 63, 121-127. [CrossRef] [PubMed] 
35. Jin, C.; Lin, L.; Han, N.; Zhao, Z.; Liu, Z.; Luo, S.; Xu, X.; Liu, J.; Wang, H. Effects of dynamic change in fetuin-A levels from the first to the second trimester on insulin resistance and gestational diabetes mellitus: A nested case-control study. BMJ Open Diabetes Res. Care 2020, 8, e000802. [CrossRef] [PubMed]

36. Bawah, A.T.; Seini, M.M.; Abaka-Yawason, A.; Alidu, H.; Nanga, S. Leptin, resistin and visfatin as useful predictors of gestational diabetes mellitus. Lipids Health Dis. 2019, 18, 1-8. [CrossRef]

37. Syngelaki, A.; Visser, G.H.; Krithinakis, K.; Wright, A.; Nicolaides, K.H. First trimester screening for gestational diabetes mellitus by maternal factors and markers of inflammation. Metabolism 2016, 65, 131-137. [CrossRef]

38. Tramontana, A.; Pablik, E.; Stangl, G.; Hartmann, B.; Dieplinger, H.; Hafner, E. Combination of first trimester serum afamin levels and three-dimensional placental bed vascularization as a possible screening method to detect women at-risk for adverse pregnancy complications like pre-eclampsia and gestational diabetes mellitus in low-risk pregnancies. Placenta 2018, 62, 9-15. [CrossRef]

39. Köninger, A.; Iannaccone, A.; Hajder, E.; Frank, M.; Schmidt, B.; Schleussner, E.; Kimmig, R.; Gellhaus, A.; Dieplinger, H. Afamin predicts gestational diabetes in polycystic ovary syndrome patients preconceptionally. Endocr. Connect. 2019, 8, 616-624. [CrossRef]

40. Ravnsborg, T.; Svaneklink, S.; Andersen, L.L.T.; Larsen, M.R.; Jensen, D.M.; Overgaard, M. First-trimester proteomic profiling identifies novel predictors of gestational diabetes mellitus. PLoS ONE 2019, 14, e0214457. [CrossRef]

41. Caglar, G.S.; Ozdemir, E.D.; Cengiz, S.D.; Demirtaş, S. Sex-hormone-binding globulin early in pregnancy for the prediction of severe gestational diabetes mellitus and related complications. J. Obstet. Gynaecol. Res. 2012, 38, 1286-1293. [CrossRef]

42. Maged, A.M.; Moety, G.A.F.; Mostafa, W.A.; Hamed, D.A. Comparative study between different biomarkers for early prediction of gestational diabetes mellitus. J. Matern. Neonatal Med. 2014, 27, 1108-1112. [CrossRef] [PubMed]

43. Veltman-Verhulst, S.M.; Van Haeften, T.W.; Eijkemans, M.J.C.; De Valk, H.W.; Fauser, B.C.J.M.; Goverde, A.J. Sex hormone-binding globulin concentrations before conception as a predictor for gestational diabetes in women with polycystic ovary syndrome. Hum. Reprod. 2010, 25, 3123-3128. [CrossRef]

44. Badon, S.E.; Zhu, Y.; Sridhar, S.B.; Xu, F.; Lee, C.; Ehrlich, S.F.; Quesenberry, C.P.; Hedderson, M.M. A Pre-Pregnancy Biomarker Risk Score Improves Prediction of Future Gestational Diabetes. J. Endocr. Soc. 2018, 2, 1158-1169. [CrossRef] [PubMed]

45. Lovati, E.; Beneventi, F.; Simonetta, M.; Laneri, M.; Quarleri, L.; Scudeller, L.; Albonico, G.; Locatelli, E.; Cavagnoli, C.; Tinelli, C.; et al. Gestational diabetes mellitus: Including serum pregnancy-associated plasma protein-A testing in the clinical management of primiparous women? A case-control study. Diabetes Res. Clin. Pr. 2013, 100, 340-347. [CrossRef] [PubMed]

46. Ramezani, S.; Doulabi, M.A.; Saqhafi, H.; Alipoor, M. Prediction of Gestational Diabetes by Measuring the Levels of Pregnancy Associated Plasma Protein-A (PAPP-A) During Gestation Weeks 11-14. J. Reprod. Infertil. 2020, 21, $130-137$.

47. Ren, Z.; Zhe, D.; Li, Z.; Sun, X.-P.; Yang, K.; Lin, L. Study on the correlation and predictive value of serum pregnancy-associated plasma protein A, triglyceride and serum 25-hydroxyvitamin D levels with gestational diabetes mellitus. World J. Clin. Cases 2020, 8, 864-873. [CrossRef]

48. Snyder, B.M.; Baer, R.J.; Oltman, S.P.; Robinson, J.G.; Breheny, P.J.; Saftlas, A.F.; Bao, W.; Greiner, A.L.; Carter, K.D.; Rand, L.; et al. Early pregnancy prediction of gestational diabetes mellitus risk using prenatal screening biomarkers in nulliparous women. Diabetes Res. Clin. Pr. 2020, 163, 108139. [CrossRef]

49. Xiao, D.; Chenhong, W.; Yanbin, X.; Lu, Z. Gestational diabetes mellitus and first trimester pregnancy-associated plasma protein A: A case-control study in a Chinese population. J. Diabetes Investig. 2018, 9, 204-210. [CrossRef]

50. Syngelaki, A.; Kotecha, R.; Pastides, A.; Wright, A.; Nicolaides, K.H. First-trimester biochemical markers of placentation in screening for gestational diabetes mellitus. Metabolism 2015, 64, 1485-1489. [CrossRef]

51. Yuan, X.; Shi, H.; Wang, H.; Yu, B.; Jiang, J. Ficolin-3/adiponectin ratio for the prediction of gestational diabetes mellitus in pregnant women. J. Diabetes Investig. 2017, 9, 403-410. [CrossRef] [PubMed]

52. Blüher, M. Adipose Tissue Dysfunction in Obesity. Exp. Clin. Endocrinol. Diabetes 2009, 117, 241-250. [CrossRef]

53. Blüher, M. Adipokines-Removing road blocks to obesity and diabetes therapy. Mol. Metab. 2014, 3, 230-240. [CrossRef] [PubMed]

54. Maeda, K.; Okubo, K.; Shimomura, I.; Funahashi, T.; Matsuzawa, Y.; Matsubara, K. cDNA Cloning and Expression of a Novel Adipose Specific Collagen-like Factor, apM1 (AdiposeMost Abundant Gene Transcript 1). Biochem. Biophys. Res. Commun. 1996, 221, 286-289. [CrossRef] [PubMed]

55. Martinez-Huenchullan, S.F.; Tam, C.S.; Ban, L.A.; Ehrenfeld-Slater, P.; McLennan, S.V.; Twigg, S.M. Skeletal muscle adiponectin induction in obesity and exercise. Metabolism 2020, 102, 154008. [CrossRef]

56. Chen, J.; Tan, B.; Karteris, E.; Zervou, S.; Digby, J.; Hillhouse, E.W.; Vatish, M.; Randeva, H.S. Secretion of adiponectin by human placenta: Differential modulation of adiponectin and its receptors by cytokines. Diabetologia 2006, 49, 1292-1302. [CrossRef] [PubMed]

57. Yamauchi, T.; Kamon, J.; Waki, H.; Terauchi, Y.; Kubota, N.; Hara, K.; Mori, Y.; Ide, T.; Murakami, K.; Tsuboyama-Kasaoka, N.; et al. The fat-derived hormone adiponectin reverses insulin resistance associated with both lipoatrophy and obesity. Nat. Med. 2001, 7, 941-946. [CrossRef]

58. Berg, A.H.; Combs, T.P.; Du, X.; Brownlee, M.; Scherer, P.E. The adipocyte-secreted protein Acrp30 enhances hepatic insulin action. Nat. Med. 2001, 7, 947-953. [CrossRef] 
59. Combs, T.P.; Berg, A.H.; Obici, S.; Scherer, P.E.; Rossetti, L. Endogenous glucose production is inhibited by the adipose-derived protein Acrp30. J. Clin. Invest. 2001, 108, 1875-1881. [CrossRef]

60. Fruebis, J.; Tsao, T.S.; Javorschi, S.; Ebbets-Reed, D.; Erickson, M.R.; Yen, F.T.; Bihain, B.E.; Lodish, H.F. Proteolytic cleavage product of $30-\mathrm{kDa}$ adipocyte complement-related protein increases fatty acid oxidation in muscle and causes weight loss in mice. Proc. Natl. Acad. Sci. USA 2001, 98, 2005-2010. [CrossRef]

61. Duncan, B.B.; Schmidt, M.I.; Pankow, J.S.; Bang, H.; Couper, D.; Ballantyne, C.M.; Hoogeveen, R.C.; Heiss, G. Adiponectin and the Development of Type 2 Diabetes: The Atherosclerosis Risk in Communities Study. Diabetes 2004, 53, 2473-2478. [CrossRef]

62. Wang, Y.; Meng, R.-W.; Kunutsor, S.K.; Chowdhury, R.; Yuan, J.-M.; Koh, W.-P.; Pan, A. Plasma adiponectin levels and type 2 diabetes risk: A nested case-control study in a Chinese population and an updated meta-analysis. Sci. Rep. 2018, 8, 406. [CrossRef] [PubMed]

63. Mohammadi, T.; Paknahad, Z. Adiponectin Concentration in Gestational Diabetic Women: A Case-Control Study. Clin. Nutr. Res. 2017, 6, 267-276. [CrossRef] [PubMed]

64. Ranheim, T.; Haugen, F.; Staff, A.C.; Braekke, K.; Harsem, N.K.; Drevon, C.A. Adiponectin is reduced in gestational diabetes mellitus in normal weight women. Acta Obstet. Gynecol. Scand. 2004, 83, 341-347. [CrossRef]

65. Hedderson, M.M.; Darbinian, J.; Havel, P.J.; Quesenberry, C.P.; Sridhar, S.; Ehrlich, S.; Ferrara, A. Low Prepregnancy Adiponectin Concentrations Are Associated With a Marked Increase in Risk for Development of Gestational Diabetes Mellitus. Diabetes Care 2013, 36, 3930-3937. [CrossRef] [PubMed]

66. Committee opinion no. 504: Screening and diagnosis of gestational diabetes mellitus. Obstet Gynecol. 2011, 118, 751-753. [CrossRef]

67. Williams, M.A.; Qiu, C.; Muy-Rivera, M.; Vadachkoria, S.; Song, T.; Luthy, D.A. Plasma Adiponectin Concentrations in Early Pregnancy and Subsequent Risk of Gestational Diabetes Mellitus. J. Clin. Endocrinol. Metab. 2004, 89, 2306-2311. [CrossRef]

68. Aguilar-Salinas, C.A.; García, E.G.; Robles, L.; Riaño, D.; Ruiz-Gomez, D.G.; García-Ulloa, A.C.; Melgarejo, M.A.; Zamora, M.; Guillen-Pineda, L.E.; Mehta, R.; et al. High Adiponectin Concentrations Are Associated with the Metabolically Healthy Obese Phenotype. J. Clin. Endocrinol. Metab. 2008, 93, 4075-4079. [CrossRef]

69. Ahl, S.; Guenther, M.; Zhao, S.; James, R.; Marks, J.; Szabo, A.; Kidambi, S. Adiponectin Levels Differentiate Metabolically Healthy vs. Unhealthy among Obese and Nonobese White Individuals. J. Clin. Endocrinol. Metab. 2015, 100, 4172-4180. [CrossRef] [PubMed]

70. Xu, J.; Zhao, Y.H.; Chen, Y.P.; Yuan, X.L.; Wang, J.; Zhu, H.; Lu, C.M. Maternal Circulating Concentrations of Tumor Necrosis Factor-Alpha, Leptin, and Adiponectin in Gestational Diabetes Mellitus: A Systematic Review and Meta-Analysis. Sci. World J. 2014, 2014, 1-12. [CrossRef]

71. Sattar, N.; Wannamethee, S.G.; Forouhi, N.G. Novel biochemical risk factors for type 2 diabetes: Pathogenic insights or prediction possibilities? Diabetologia 2008, 51, 926-940. [CrossRef]

72. Yeral, M.I.; Ozgu-Erdinc, A.S.; Uygur, D.; Seckin, K.D.; Karsli, M.F.; Danisman, A.N. Prediction of gestational diabetes mellitus in the first trimester, comparison of fasting plasma glucose, two-step and one-step methods: A prospective randomized controlled trial. Endocrine 2013, 46, 512-518. [CrossRef] [PubMed]

73. Trujillo, J.; Vigo, A.; Reichelt, A.; Duncan, B.; Schmidt, M. Fasting plasma glucose to avoid a full OGTT in the diagnosis of gestational diabetes. Diabetes Res. Clin. Pr. 2014, 105, 322-326. [CrossRef]

74. Thewjitcharoen, Y.; Elizabeth, A.J.; Butadej, S.; Nakasatien, S.; Chotwanvirat, P.; Wanothayaroj, E.; Krittiyawong, S.; Himathongkam, T.; Himathongkam, T. Performance of HbA1c versus oral glucose tolerance test (OGTT) as a screening tool to diagnose dysglycemic status in high-risk Thai patients. BMC Endocr. Disord. 2019, 19, 1-8. [CrossRef] [PubMed]

75. Aziz, N.L.; Abdelwahab, S.; Moussa, M.; Georgy, M. Maternal fructosamine and glycosylated haemoglobin in the prediction of gestational glucose intolerance. Clin. Exp. Obstet. Gynecol. 1992, 19, 235-241. [PubMed]

76. Nagpal, S.; Patel, S.; Jacobe, H.; Disepio, D.; Ghosn, C.; Malhotra, M.; Teng, M.; Duvic, M.; Chandraratna, R.A. Tazarotene-induced Gene 2 (TIG2), a Novel Retinoid-Responsive Gene in Skin. J. Investig. Dermatol. 1997, 109, 91-95. [CrossRef] [PubMed]

77. Goralski, K.B.; McCarthy, T.C.; Hanniman, E.A.; Zabel, B.A.; Butcher, E.C.; Parlee, S.D.; Muruganandan, S.; Sinal, C.J. Chemerin, a Novel Adipokine That Regulates Adipogenesis and Adipocyte Metabolism. J. Biol. Chem. 2007, 282, 28175-28188. [CrossRef]

78. Sell, H.; Laurencikiene, J.; Taube, A.; Eckardt, K.; Cramer, A.; Horrighs, A.; Arner, P.; Eckel, J. Chemerin Is a Novel AdipocyteDerived Factor Inducing Insulin Resistance in Primary Human Skeletal Muscle Cells. Diabetes 2009, 58, 2731-2740. [CrossRef]

79. Huang, J.; Zhang, J.; Lei, T.; Chen, X.; Zhang, Y.; Zhou, L.; Yu, A.; Chen, Z.; Zhou, R.; Yang, Z. Cloning of porcine chemerin, ChemR23 and GPR1 and their involvement in regulation of lipogenesis. BMB Rep. 2010, 43, 491-498. [CrossRef] [PubMed]

80. Garces, M.; Sanchez, E.; Acosta, B.; Angel, E.; Ruíz, A.; Rubio-Romero, J.; Diéguez, C.; Nogueiras, R.; Caminos, J. Expression and regulation of chemerin during rat pregnancy. Placenta 2012, 33, 373-378. [CrossRef]

81. Bozaoglu, K.; Bolton, K.; McMillan, J.; Zimmet, P.; Jowett, J.; Collier, G.; Walder, K.; Segal, D. Chemerin Is a Novel Adipokine Associated with Obesity and Metabolic Syndrome. Endocrinology 2007, 148, 4687-4694. [CrossRef] [PubMed]

82. Stepan, H.; Philipp, A.; Roth, I.; Kralisch, S.; Jank, A.; Schaarschmidt, W.; Lössner, U.; Kratzsch, J.; Blüher, M.; Stumvoll, M.; et al. Serum levels of the adipokine chemerin are increased in preeclampsia during and 6months after pregnancy. Regul. Pept. 2011, 168, 69-72. [CrossRef] [PubMed]

83. Duan, D.-M.; Niu, J.-M.; Lei, Q.; Lin, X.-H.; Chen, X. Serum levels of the adipokine chemerin in preeclampsia. J. Périnat. Med. 2011, 40, 121-127. [CrossRef] 
84. Xu, Q.-L.; Zhu, M.; Jin, Y.; Wang, N.; Xu, H.-X.; Quan, L.-M.; Wang, S.-S.; Li, S.-S. The predictive value of the first-trimester maternal serum chemerin level for pre-eclampsia. Peptides 2014, 62, 150-154. [CrossRef]

85. Yang, X.; Quan, X.; Lan, Y.; Ye, J.; Wei, Q.; Yin, X.; Fan, F.; Xing, H. Serum chemerin level during the first trimester of pregnancy and the risk of gestational diabetes mellitus. Gynecol. Endocrinol. 2017, 33, 770-773. [CrossRef]

86. Pfau, D.; Stepan, H.; Kratzsch, J.; Verlohren, M.; Verlohren, H.-J.; Drynda, K.; Lössner, U.; Blüher, M.; Stumvoll, M.; Fasshauer, M. Circulating Levels of the Adipokine Chemerin in Gestational Diabetes Mellitus. Horm. Res. Paediatr. 2010, 74, 56-61. [CrossRef]

87. Guelfi, K.J.; Ong, M.J.; Li, S.; Wallman, K.E.; Doherty, D.A.; Fournier, P.A.; Newnham, J.P.; Keelan, J.A. Maternal circulating adipokine profile and insulin resistance in women at high risk of developing gestational diabetes mellitus. Metabolism 2017, 75, 54-60. [CrossRef]

88. Van Poppel, M.N.; Zeck, W.; Ulrich, D.; Schest, E.C.; Hirschmugl, B.; Lang, U.; Wadsack, C.; Desoye, G. Cord blood chemerin: Differential effects of gestational diabetes mellitus and maternal obesity. Clin. Endocrinol. 2014, 80, 65-72. [CrossRef] [PubMed]

89. Sun, J.; Ren, J.; Zuo, C.; Deng, D.; Pan, F.; Chen, R.; Zhu, J.; Chen, C.; Ye, S. Circulating apelin, chemerin and omentin levels in patients with gestational diabetes mellitus: A systematic review and meta-analysis. Lipids Health Dis. 2020, 19, 1-15. [CrossRef]

90. Zhou, Z.; Chen, H.; Ju, H.; Sun, M. Circulating chemerin levels and gestational diabetes mellitus: A systematic review and meta-analysis. Lipids Health Dis. 2018, 17, 169. [CrossRef]

91. El-Mesallamy, H.O.; El-Derany, M.O.; Hamdy, N.M. Serum omentin-1 and chemerin levels are interrelated in patients with Type 2 diabetes mellitus with or without ischaemic heart disease. Diabet. Med. 2011, 28, 1194-1200. [CrossRef] [PubMed]

92. Sell, H.; Divoux, A.; Poitou, C.; Basdevant, A.; Bouillot, J.-L.; Bedossa, P.; Tordjman, J.; Eckel, J.; Clément, K. Chemerin Correlates with Markers for Fatty Liver in Morbidly Obese Patients and Strongly Decreases after Weight Loss Induced by Bariatric Surgery. J. Clin. Endocrinol. Metab. 2010, 95, 2892-2896. [CrossRef] [PubMed]

93. Kukla, M.; Żwirska-Korczala, K.; Hartleb, M.; Waluga, M.; Chwist, A.; Kajor, M.; Ciupińska-Kajor, M.; Berdowska, A.; Wozniak-Grygiel, E.; Buldak, R. Serum chemerin and vaspin in non-alcoholic fatty liver disease. Scand. J. Gastroenterol. 2010, 45, 235-242. [CrossRef] [PubMed]

94. Chakaroun, R.; Raschpichler, M.; Klöting, N.; Oberbach, A.; Flehmig, G.; Kern, M.; Schön, M.R.; Shang, E.; Lohmann, T.; Dreßler, M.; et al. Effects of weight loss and exercise on chemerin serum concentrations and adipose tissue expression in human obesity. Metabolism 2012, 61, 706-714. [CrossRef]

95. Weigert, J.; Neumeier, M.; Wanninger, J.; Filarsky, M.; Bauer, S.; Wiest, R.; Farkas, S.; Scherer, M.N.; Schäffler, A.; Aslanidis, C.; et al. Systemic chemerin is related to inflammation rather than obesity in type 2 diabetes. Clin. Endocrinol. 2010, 72, 342-348. [CrossRef]

96. Brix, J.M.; Stingl, H.; Höllerl, F.; Schernthaner, G.H.; Kopp, H.-P.; Schernthaner, G. Elevated Fetuin-A Concentrations in Morbid Obesity Decrease after Dramatic Weight Loss. J. Clin. Endocrinol. Metab. 2010, 95, 4877-4881. [CrossRef] [PubMed]

97. Trepanowski, J.F.; Mey, J.; Varady, K.A. Fetuin-A: A novel link between obesity and related complications. Int. J. Obes. 2015, 39, 734-741. [CrossRef] [PubMed]

98. Ix, J.H.; Shlipak, M.G.; Brandenburg, V.M.; Ali, S.; Ketteler, M.; Whooley, M.A. Association between human fetuin-A and the metabolic syndrome: Data from the Heart and Soul Study. Circulation 2006, 113, 1760-1767. [CrossRef]

99. Ou, H.-Y.; Yang, Y.-C.; Wu, H.-T.; Wu, J.-S.; Lu, F.-H.; Chang, C.-J. Increased Fetuin-A Concentrations in Impaired Glucose Tolerance with or without Nonalcoholic Fatty Liver Disease, But Not Impaired Fasting Glucose. J. Clin. Endocrinol. Metab. 2012, 97, 4717-4723. [CrossRef] [PubMed]

100. Jensen, M.K.; Bartz, T.M.; Mukamal, K.J.; Djoussé, L.; Kizer, J.R.; Tracy, R.P.; Zieman, S.J.; Rimm, E.B.; Siscovick, D.S.; Shlipak, M.; et al. Fetuin-A, Type 2 Diabetes, and Risk of Cardiovascular Disease in Older Adults: The Cardiovascular Health Study. Diabetes Care 2012, 36, 1222-1228. [CrossRef]

101. Ou, H.-Y.; Yang, Y.; Wu, H.-T.; Wu, J.-S.; Lu, F.-H.; Chang, C. Serum fetuin-A concentrations are elevated in subjects with impaired glucose tolerance and newly diagnosed type 2 diabetes. Clin. Endocrinol. 2011, 75, 450-455. [CrossRef]

102. Denecke, B.; Gräber, S.; Schäfer, C.; Heiss, A.; Wöltje, M.; Jahnen-Dechent, W. Tissue distribution and activity testing suggest a similar but not identical function of fetuin-B and fetuin-A. Biochem. J. 2003, 376, 135-145. [CrossRef] [PubMed]

103. Meex, R.C.; Hoy, A.J.; Morris, A.; Brown, R.D.; Lo, J.C.; Burke, M.; Goode, R.J.; Kingwell, B.A.; Kraakman, M.J.; Febbraio, M.A.; et al. Fetuin B Is a Secreted Hepatocyte Factor Linking Steatosis to Impaired Glucose Metabolism. Cell Metab. 2015, 22, 1078-1089. [CrossRef]

104. Peter, A.; Kovarova, M.; Staiger, H.; Machann, J.; Schick, F.; Königsrainer, A.; Königsrainer, I.; Schleicher, E.; Fritsche, A.; Häring, H.-U.; et al. The hepatokines fetuin-A and fetuin-B are upregulated in the state of hepatic steatosis and may differently impact on glucose homeostasis in humans. Am. J. Physiol. Metab. 2018, 314, E266-E273. [CrossRef] [PubMed]

105. Kalabay, L.; Cseh, K.; Pajor, A.; Baranyi, E.; Csákány, G.M.; Melczer, Z.; Speer, G.; Kovács, M.; Siller, G.; Karádi, I.; et al. Correlation of maternal serum fetuin/alpha2-HS-glycoprotein concentration with maternal insulin resistance and anthropometric parameters of neonates in normal pregnancy and gestational diabetes. Eur. J. Endocrinol. 2002, 147, 243-248. [CrossRef] [PubMed]

106. Iyidir, O.T.; Degertekin, C.K.; Yilmaz, B.A.; Altinova, A.E.; Toruner, F.B.; Bozkurt, N.; Ayvaz, G.; Akturk, M. Serum levels of fetuin A are increased in women with gestational diabetes mellitus. Arch. Gynecol. Obstet. 2014, 291, 933-937. [CrossRef] [PubMed]

107. Coustan, D.R.; Carpenter, M.W. The diagnosis of gestational diabetes. Diabetes Care 1998, 21 (Suppl. 2), B5-B8.

108. Farhan, S.; Handisurya, A.; Todoric, J.; Tura, A.; Pacini, G.; Wagner, O.; Klein, K.; Jarai, R.; Huber, K.; Kautzky-Willer, A. Fetuin-A Characteristics during and after Pregnancy: Result from a Case Control Pilot Study. Int. J. Endocrinol. 2012, 2012, 1-5. [CrossRef] 
109. Zhang, Y.; Proenca, R.; Maffei, M.; Barone, M.; Leopold, L.; Friedman, J.M. Positional cloning of the mouse obese gene and its human homologue. Nature 1994, 372, 425-432. [CrossRef]

110. Considine, R.V.; Sinha, M.K.; Heiman, M.L.; Kriauciunas, A.; Stephens, T.W.; Nyce, M.R.; Ohannesian, J.P.; Marco, C.C.; McKee, L.J.; Bauer, T.L.; et al. Serum Immunoreactive-Leptin Concentrations in Normal-Weight and Obese Humans. N. Engl. J. Med. 1996, 334, 292-295. [CrossRef]

111. Bado, A.; Levasseur, S.; Attoub, S.; Kermorgant, S.; Laigneau, J.-P.; Bortoluzzi, M.-N.; Moizo, L.; Lehy, T.; Guerre-Millo, M.; Le Marchand-Brustel, Y.; et al. The stomach is a source of leptin. Nature 1998, 394, 790-793. [CrossRef]

112. Masuzaki, H.; Ogawa, Y.; Sagawa, N.; Hosoda, K.; Matsumoto, T.; Mise, H.; Nishimura, H.; Yoshimasa, Y.; Tanaka, I.; Mori, T.; et al. Nonadipose tissue production of leptin: Leptin as a novel placenta-derived hormone in humans. Nat. Med. 1997, 3, 1029-1033. [CrossRef] [PubMed]

113. Wilkinson, M.; Morash, B.; Ur, E. The brain is a source of leptin. Front. Horm. Res. 1999, 26, 106-126. [CrossRef]

114. Considine, R.V. Human Leptin: An Adipocyte Hormone with Weight-Regulatory and Endocrine Functions. Semin. Vasc. Med. 2005, 5, 15-24. [CrossRef] [PubMed]

115. Brennan, A.M.; Mantzoros, C.S. Drug Insight: The role of leptin in human physiology and pathophysiology—Emerging clinical applications. Nat. Clin. Pr. Endocrinol. Metab. 2006, 2, 318-327. [CrossRef]

116. Robertson, S.A.; Leinninger, G.M.; Myers, M.G. Molecular and neural mediators of leptin action. Physiol. Behav. 2008, 94, 637-642. [CrossRef] [PubMed]

117. Harris, R.B.; Zhou, J.; Redmann, S.M.; Smagin, G.N.; Smith, S.R.; Rodgers, E.; Zachwieja, J.J. A leptin dose-response study in obese (ob/ob) and lean (+/?) mice. Endocrinology 1998, 139, 8-19. [CrossRef] [PubMed]

118. Gavrilova, O.; Marcus-Samuels, B.; Graham, D.; Kim, J.K.; Shulman, G.I.; Castle, A.L.; Vinson, C.; Eckhaus, M.; Reitman, M.L. Surgical implantation of adipose tissue reverses diabetes in lipoatrophic mice. J. Clin. Investig. 2000, 105, 271-278. [CrossRef]

119. Farooqi, I.S.; Matarese, G.; Lord, G.M.; Keogh, J.M.; Lawrence, E.; Agwu, C.; Sanna, V.; Jebb, S.A.; Perna, F.; Fontana, S.; et al. Beneficial effects of leptin on obesity, T cell hyporesponsiveness, and neuroendocrine/metabolic dysfunction of human congenital leptin deficiency. J. Clin. Invest. 2002, 110, 1093-1103. [CrossRef]

120. Lewandowski, K.; Horn, R.; O'Callaghan, C.J.; Dunlop, D.; Medley, G.F.; O’Hare, P.; Brabant, G. Free leptin, bound leptin, and soluble leptin receptor in normal and diabetic pregnancies. J. Clin. Endocrinol. Metab. 1999, 84, 300-306. [CrossRef]

121. Association, A.D. Diagnosis and classification of diabetes mellitus. Diabetes Care 2010, 33 (Suppl. 1), S62-S69. [CrossRef]

122. Kautzky-Willer, A.; Pacini, G.; Tura, A.; Bieglmayer, C.; Schneider, B.; Ludvik, B.; Prager, R.; Waldhäusl, W. Increased plasma leptin in gestational diabetes. Diabetologia 2001, 44, 164-172. [CrossRef] [PubMed]

123. McLachlan, K.A.; O'Neal, D.; Jenkins, A.; Alford, F.P. Do adiponectin, TNF $\alpha$, leptin and CRP relate to insulin resistance in pregnancy? Studies in women with and without gestational diabetes, during and after pregnancy. Diabetes Metab. Res. Rev. 2006, 22, 131-138. [CrossRef] [PubMed]

124. Olefsky, J.M.; Farquhar, J.W.; Reaven, G.M. Do the Oral and Intravenous Glucose Tolerance Tests Provide Similar Diagnostic Information in Patients with Chemical Diabetes Mellitus? Diabetes 1973, 22, 202-209. [CrossRef]

125. Bao, W.; Baecker, A.; Song, Y.; Kiely, M.; Liu, S.; Zhang, C. Adipokine levels during the first or early second trimester of pregnancy and subsequent risk of gestational diabetes mellitus: A systematic review. Metabolism 2015, 64, 756-764. [CrossRef] [PubMed]

126. Otsuka, R.; Yatsuya, H.; Tamakoshi, K.; Matsushita, K.; Wada, K.; Toyoshima, H. Perceived Psychological Stress and Serum Leptin Concentrations in Japanese Men. Obesity 2006, 14, 1832-1838. [CrossRef]

127. Knutson, K.L.; Spiegel, K.; Penev, P.; Van Cauter, E. The metabolic consequences of sleep deprivation. Sleep Med. Rev. 2007, 11, 163-178. [CrossRef]

128. De Salles, B.F.; Simão, R.; Fleck, S.J.; Dias, I.; Kraemer-Aguiar, L.G.; Bouskela, E. Effects of resistance training on cytokines. Int. J. Sports Med. 2010, 31, 441-450. [CrossRef] [PubMed]

129. Yang, R.-Z.; Lee, M.-J.; Hu, H.; Pray, J.; Wu, H.-B.; Hansen, B.C.; Shuldiner, A.R.; Fried, S.K.; McLenithan, J.C.; Gong, D.-W. Identification of omentin as a novel depot-specific adipokine in human adipose tissue: Possible role in modulating insulin action. Am. J. Physiol. Metab. 2006, 290, E1253-E1261. [CrossRef]

130. Schäffler, A.; Neumeier, M.; Herfarth, H.; Fürst, A.; Schölmerich, J.; Büchler, C. Genomic structure of human omentin, a new adipocytokine expressed in omental adipose tissue. Biochim. Biophys. Acta 2005, 1732, 96-102. [CrossRef]

131. De Souza Batista, C.M.; Yang, R.Z.; Lee, M.J.; Glynn, N.M.; Yu, D.Z.; Pray, J.; Ndubuizu, K.; Patil, S.; Schwartz, A.; Kligman, M. Omentin plasma levels and gene expression are decreased in obesity. Diabetes 2007, 56, 1655-1661. [CrossRef]

132. Barker, G.; Lim, R.; Georgiou, H.M.; Lappas, M. Omentin-1 Is Decreased in Maternal Plasma, Placenta and Adipose Tissue of Women with Pre-Existing Obesity. PLoS ONE 2012, 7, e42943. [CrossRef] [PubMed]

133. Hoffman, L.; Nolan, C.; Wilson, J.D.; Oats, J.J.; Simmons, D. Gestational diabetes mellitus-management guidelines. The Australasian Diabetes in Pregnancy Society. Med. J. Aust. 1998, 169, 93-97. [CrossRef] [PubMed]

134. Abell, S.K.; Shorakae, S.; Harrison, C.L.; Hiam, D.; Moreno-Asso, A.; Stepto, N.K.; De Courten, B.; Teede, H.J. The association between dysregulated adipocytokines in early pregnancy and development of gestational diabetes. Diabetes Metab. Res. Rev. 2017, 33, e2926. [CrossRef]

135. Franz, M.; Polterauer, M.; Springer, S.; Kuessel, L.; Haslinger, P.; Worda, C.; Worda, K. Maternal and neonatal omentin-1 levels in gestational diabetes. Arch. Gynecol. Obstet. 2018, 297, 885-889. [CrossRef] [PubMed] 
136. Metzger, B.; Lowe, L.; Dyer, A.; Trimble, E.; Chaovarindr, U.; Coustan, D.; Hadden, D.; McCance, D.; Hod, M.; McIntyre, H.; et al. Hyperglycemia and Adverse Pregnancy Outcomes. Obstet. Anesth. Dig. 2009, 29, 39-40. [CrossRef]

137. Ebrahimi, S.; Gargari, B.P.; Izadi, A.; Imani, B.; Asjodi, F. The effects of Ramadan fasting on serum concentrations of vaspin and omentin-1 in patients with nonalcoholic fatty liver disease. Eur. J. Integr. Med. 2018, 19, 110-114. [CrossRef]

138. Kiyak Caglayan, E.; Engin-Ustun, Y.; Sari, N.; Gocmen, A.Y.; Polat, M.F. The effects of prolonged fasting on the levels of adiponectin, leptin, apelin, and omentin in pregnant women. J. Obs. Gynaecol. 2016, 36, 555-558. [CrossRef]

139. Kamimura, D.; Ishihara, K.; Hirano, T. IL-6 signal transduction and its physiological roles: The signal orchestration model. Rev. Physiol. Biochem. Pharmacol. 2003, 149, 1-38. [CrossRef]

140. Van Snick, J. Interleukin-6: An overview. Annu. Rev. Immunol. 1990, 8, 253-278. [CrossRef]

141. Jordan, S.C.; Choi, J.; Kim, I.; Wu, G.; Toyoda, M.; Shin, B.; Vo, A. Interleukin-6, A Cytokine Critical to Mediation of Inflammation, Autoimmunity and Allograft Rejection: Therapeutic Implications of IL-6 Receptor Blockade. Transplantation 2017, $101,32-44$. [CrossRef] [PubMed]

142. Senn, J.J.; Klover, P.J.; Nowak, I.A.; Mooney, R.A. Interleukin-6 Induces Cellular Insulin Resistance in Hepatocytes. Diabetes 2002, 51, 3391-3399. [CrossRef]

143. Kim, J.H.; Bachmann, R.A.; Chen, J. Interleukin-6 and insulin resistance. Vitam. Horm. 2009, 80, $613-633$.

144. Hoene, M.; Weigert, C. The role of interleukin-6 in insulin resistance, body fat distribution and energy balance. Obes. Rev. 2007, 9 , 20-29. [CrossRef]

145. Carey, A.L.; Bruce, C.R.; Sacchetti, M.; Anderson, M.J.; Olsen, D.B.; Saltin, B.; Hawley, J.A.; Febbraio, M.A. Interleukin-6 and tumor necrosis factor-? Are not increased in patients with Type 2 diabetes: Evidence that plasma interleukin- 6 is related to fat mass and not insulin responsiveness. Diabetologia 2004, 47, 1029-1037. [CrossRef] [PubMed]

146. Dekker, M.J.; Lee, S.; Hudson, R.; Kilpatrick, K.; Graham, T.E.; Ross, R.; Robinson, L.E. An exercise intervention without weight loss decreases circulating interleukin-6 in lean and obese men with and without type 2 diabetes mellitus. Metabolism 2007, 56, 332-338. [CrossRef]

147. Suzuki, T.; Imai, J.; Yamada, T.; Ishigaki, Y.; Kaneko, K.; Uno, K.; Hasegawa, Y.; Ishihara, H.; Oka, Y.; Katagiri, H. Interleukin-6 enhances glucose-stimulated insulin secretion from pancreatic beta-cells: Potential involvement of the PLC-IP3-dependent pathway. Diabetes 2011, 60, 537-547. [CrossRef] [PubMed]

148. Trujillo, M.E.; Sullivan, S.; Harten, I.; Schneider, S.H.; Greenberg, A.S.; Fried, S.K. Interleukin-6 regulates human adipose tissue lipid metabolism and leptin production in vitro. J. Clin. Endocrinol. Metab. 2004, 89, 5577-5582. [CrossRef]

149. Wallenius, K.; Wallenius, V.; Sunter, D.; Dickson, S.L.; Jansson, J.-O. Intracerebroventricular interleukin-6 treatment decreases body fat in rats. Biochem. Biophys. Res. Commun. 2002, 293, 560-565. [CrossRef]

150. Stenlöf, K.; Wernstedt, I.; Fjällman, T.; Wallenius, V.; Wallenius, K.; Jansson, J.-O. Interleukin-6 Levels in the Central Nervous System Are Negatively Correlated with Fat Mass in Overweight/Obese Subjects. J. Clin. Endocrinol. Metab. 2003, 88, 4379-4383. [CrossRef]

151. Sudharshana Murthy, K.A.; Bhandiwada, A.; Chandan, S.L.; Gowda, S.L.; Sindhusree, G. Evaluation of Oxidative Stress and Proinflammatory Cytokines in Gestational Diabetes Mellitus and Their Correlation with Pregnancy Outcome. Indian J. Endocrinol. Metab. 2018, 22, 79-84. [CrossRef] [PubMed]

152. Siddiqui, S.; Waghdhare, S.; Goel, C.; Panda, M.; Soneja, H.; Sundar, J.; Banerjee, M.; Jha, S.; Dubey, S. Augmentation of IL-6 production contributes to development of gestational diabetes mellitus: An Indian study. Diabetes Metab. Syndr. Clin. Res. Rev. 2019, 13, 895-899. [CrossRef]

153. Braga, F.O.; Negrato, C.A.; Matta, M.D.F.B.D.; Carneiro, J.R.I.; Gomes, M.B. Relationship between inflammatory markers, glycated hemoglobin and placental weight on fetal outcomes in women with gestational diabetes. Arch. Endocrinol. Metab. 2019, 63, 22-29. [CrossRef]

154. Šimják, P.; Cinkajzlová, A.; Anderlová, K.; Kloučková, J.; Kratochvílová, H.; Lacinová, Z.; Kaválková, P.; KREJČÁ, H.; Mráz, M.; PAŔÁZEK, A.; et al. Changes in plasma concentrations and mRNA expression of hepatokines fetuin A, fetuin B and FGF21 in physiological pregnancy and gestational diabetes mellitus. Physiol. Res. 2018, 67 (Suppl. 3), S531-S542. [CrossRef]

155. Amirian, A.; Mahani, M.B.; Abdi, F. Role of interleukin-6 (IL-6) in predicting gestational diabetes mellitus. Obstet. Gynecol. Sci. 2020, 63, 407-416. [CrossRef]

156. Abdel Gader, A.G.; Khashoggi, T.Y.; Habib, F.; Awadallah, S.B. Haemostatic and cytokine changes in gestational diabetes mellitus. Gynecol. Endocrinol. 2011, 27, 356-360. [CrossRef] [PubMed]

157. Wolf, M.; Sauk, J.; Shah, A.; Smirnakis, K.V.; Jimenez-Kimble, R.; Ecker, J.L.; Thadhani, R. Inflammation and Glucose Intolerance: A prospective study of gestational diabetes mellitus. Diabetes Care 2003, 27, 21-27. [CrossRef]

158. Wedell-Neergaard, A.-S.; Lehrskov, L.L.; Christensen, R.H.; Legaard, G.E.; Dorph, E.; Larsen, M.K.; Launbo, N.; Fagerlind, S.R.; Seide, S.K.; Nymand, S.; et al. Exercise-Induced Changes in Visceral Adipose Tissue Mass are Regulated by IL-6 Signaling: A Randomized Controlled Trial. SSRN Electron. J. 2018, 29, 844-855. [CrossRef]

159. Desoye, G.; Mouzon, S.H.-D. The Human Placenta in Gestational Diabetes Mellitus: The insulin and cytokine network. Diabetes Care 2007, 30, S120-S126. [CrossRef]

160. Grivennikov, S.I.; Tumanov, A.V.; Liepinsh, D.J.; Kruglov, A.A.; Marakusha, B.I.; Shakhov, A.N.; Murakami, T.; Drutskaya, L.N.; Förster, I.; Clausen, B.E. Distinct and Nonredundant In Vivo Functions of TNF Produced by T Cells and Macrophages/NeutrophilsProtective and Deleterious Effects. Immunity 2005, 22, 93-104. [CrossRef] 
161. Chen, H.L.; Yang, Y.P.; Hu, X.L.; Yelavarthi, K.K.; Fishback, J.L.; Hunt, J.S. Tumor necrosis factor alpha mRNA and protein are present in human placental and uterine cells at early and late stages of gestation. Am. J. Pathol. 1991, 139, 327-335.

162. Carswell, E.A.; Old, L.J.; Kassel, R.L.; Green, S.; Fiore, N.; Williamson, B. An endotoxin-induced serum factor that causes necrosis of tumors. Proc. Natl. Acad. Sci. USA 1975, 72, 3666-3670. [CrossRef] [PubMed]

163. Williams, R.O.; Paleolog, E.; Feldmann, M. Cytokine inhibitors in rheumatoid arthritis and other autoimmune diseases. Curr. Opin. Pharmacol. 2007, 7, 412-417. [CrossRef] [PubMed]

164. Tweedie, D.; Sambamurti, K.; Greig, N.H. TNF- $\alpha$ Inhibition as a Treatment Strategy for Neurodegenerative Disorders: New Drug Candidates and Targets. Curr. Alzheimer Res. 2007, 4, 378-385. [CrossRef] [PubMed]

165. Bortolato, B.; Carvalho, A.F.; Soczynska, J.K.; Perini, G.I.; McIntyre, R.S. The Involvement of TNF- $\alpha$ in Cognitive Dysfunction Associated with Major Depressive Disorder: An Opportunity for Domain Specific Treatments. Curr. Neuropharmacol. 2015, 13, 558-576. [CrossRef]

166. Mohammadi, M.; Gozashti, M.H.; Aghadavood, M.; Mehdizadeh, M.R.; Hayatbakhsh, M.M. Clinical Significance of Serum IL-6 and TNF- $\alpha$ Levels in Patients with Metabolic Syndrome. Rep. Biochem. Mol. Biol. 2017, 6, 74-79.

167. Emanuela, F.; Grazia, M.; Marco, D.R.; Paola, L.M.; Giorgio, F.; Marco, B. Inflammation as a Link between Obesity and Metabolic Syndrome. J. Nutr. Metab. 2012, 2012, 1-7. [CrossRef]

168. Bastard, J.-P.; Maachi, M.; Lagathu, C.; Kim, M.J.; Caron, M.; Vidal, H.; Capeau, J.; Feve, B. Recent advances in the relationship between obesity, inflammation, and insulin resistance. Eur. Cytokine Netw. 2006, 17, 4-12. [PubMed]

169. Lorenzo, M.; Fernández-Veledo, S.; Vila-Bedmar, R.; Garcia-Guerra, L.; De Alvaro, C.; Nieto-Vazquez, I. Insulin resistance induced by tumor necrosis factor- $\alpha$ in myocytes and brown adipocytes. J. Anim. Sci. 2008, 86, E94-E104. [CrossRef]

170. Nieto-Vazquez, I.; Fernández-Veledo, S.; Krämer, D.K.; Vila-Bedmar, R.; Garcia-Guerra, L.; Lorenzo, M. Insulin resistance associated to obesity: The link TNF-alpha. Arch. Physiol. Biochem. 2008, 114, 183-194. [CrossRef] [PubMed]

171. Wang, B.; Trayhurn, P. Acute and prolonged effects of TNF- $\alpha$ on the expression and secretion of inflammation-related adipokines by human adipocytes differentiated in culture. Pflügers Arch. 2006, 452, 418-427. [CrossRef] [PubMed]

172. Patel, A.B.; Tsilioni, I.; Weng, Z.; Theoharides, T.C. TNF stimulates IL-6, CXCL8 and VEGF secretion from human keratinocytes via activation of mTOR, inhibited by tetramethoxyluteolin. Exp. Dermatol. 2017, 27, 135-143. [CrossRef] [PubMed]

173. Chang, E.; Choi, J.M.; Kim, W.J.; Rhee, E.-J.; Oh, K.W.; Lee, W.-Y.; Park, S.E.; Park, S.W.; Park, C.-Y. Restoration of adiponectin expression via the ERK pathway in TNF $\alpha$-treated 3T3-L1 adipocytes. Mol. Med. Rep. 2014, 10, 905-910. [CrossRef] [PubMed]

174. Prins, J.B.; Niesler, C.U.; Winterford, C.M.; Bright, N.A.; Siddle, K.; O’Rahilly, S.; Walker, N.I.; Cameron, D.P. Tumor necrosis factor-alpha induces apoptosis of human adipose cells. Diabetes 1997, 46, 1939-1944. [CrossRef] [PubMed]

175. Nisoli, E.; Briscini, L.; Giordano, A.; Tonello, C.; Wiesbrock, S.M.; Uysal, K.T.; Cinti, S.; Carruba, M.O.; Hotamisligil, G.S. Tumor necrosis factor alpha mediates apoptosis of brown adipocytes and defective brown adipocyte function in obesity. Proc. Natl. Acad. Sci. USA 2000, 97, 8033-8038. [CrossRef]

176. Hotamisligil, G.S.; Peraldi, P.; Budavari, A.; Ellis, R.; White, M.F.; Spiegelman, B.M. IRS-1-Mediated Inhibition of Insulin Receptor Tyrosine Kinase Activity in TNF-alpha- and Obesity-Induced Insulin Resistance. Science 1996, 271, 665-670. [CrossRef] [PubMed]

177. Alzamil, H. Elevated Serum TNF- $\alpha$ Is Related to Obesity in Type 2 Diabetes Mellitus and Is Associated with Glycemic Control and Insulin Resistance. J. Obes. 2020, 2020, 5076858. [CrossRef]

178. Guillemette, L.; Lacroix, M.; Battista, M.-C.; Doyon, M.; Moreau, J.; Ménard, J.; Ardilouze, J.-L.; Perron, P.; Hivert, M.-F. TNF $\alpha$ Dynamics During the Oral Glucose Tolerance Test Vary According to the Level of Insulin Resistance in Pregnant Women. J. Clin. Endocrinol. Metab. 2014, 99, 1862-1869. [CrossRef] [PubMed]

179. Kirwan, J.P.; Mouzon, S.H.-D.; Lepercq, J.; Challier, J.-C.; Huston-Presley, L.; Friedman, J.E.; Kalhan, S.C.; Catalano, P.M. TNF- $\alpha$ Is a Predictor of Insulin Resistance in Human Pregnancy. Diabetes 2002, 51, 2207-2213. [CrossRef]

180. Mushtaq, R.; Akram, A.; Mushtaq, R.; Khwaja, S.; Ahmed, S. The role of inflammatory markers following Ramadan Fasting. Pak. J. Med. Sci. 2018, 35, 77-81. [CrossRef] [PubMed]

181. Shojaie, M.; Ghanbari, F.; Shojaie, N. Intermittent fasting could ameliorate cognitive function against distress by regulation of inflammatory response pathway. J. Adv. Res. 2017, 8, 697-701. [CrossRef] [PubMed]

182. Chandrashekara, S.; Jayashree, K.; Veeranna, H.; Vadiraj, H.; Ramesh, M.; Shobha, A.; Sarvanan, Y.; Vikram, Y.K. Effects of anxiety on TNF- $\alpha$ levels during psychological stress. J. Psychosom. Res. 2007, 63, 65-69. [CrossRef]

183. Stewart, L.K.; Flynn, M.G.; Campbell, W.W.; Craig, B.A.; Robinson, J.P.; Timmerman, K.L.; Mcfarlin, B.K.; Coen, P.M.; Talbert, E. The Influence of Exercise Training on Inflammatory Cytokines and C-Reactive Protein. Med. Sci. Sports Exerc. 2007, 39, 1714-1719. [CrossRef] [PubMed]

184. Paolucci, E.M.; Loukov, D.; Bowdish, D.M.; Heisz, J.J. Exercise reduces depression and inflammation but intensity matters. Biol. Psychol. 2018, 133, 79-84. [CrossRef]

185. Jerković, L.; Voegele, A.F.; Chwatal, S.; Kronenberg, F.; Radcliffe, C.M.; Wormald, M.R.; Lobentanz, E.M.; Ezeh, B.; Eller, P.; Dejori, N.; et al. Afamin Is a Novel Human Vitamin E-Binding Glycoprotein Characterization and In Vitro Expression. J. Proteome Res. 2005, 4, 889-899. [CrossRef]

186. Dieplinger, B.; Egger, M.; Gabriel, C.; Poelz, W.; Morandell, E.; Seeber, B.; Kronenberg, F.; Haltmayer, M.; Mueller, T.; Dieplinger, H. Analytical characterization and clinical evaluation of an enzyme-linked immunosorbent assay for measurement of afamin in human plasma. Clin. Chim. Acta 2013, 425, 236-241. [CrossRef] [PubMed] 
187. Voegele, A.F.; Jerković, L.; Wellenzohn, B.; Eller, P.; Kronenberg, F.; Liedl, K.R.; Dieplinger, H. Characterization of the vitamin E-binding properties of human plasma afamin. Biochemistry 2002, 41, 14532-14538. [CrossRef] [PubMed]

188. Köninger, A.; Edimiris, P.; Koch, L.; Enekwe, A.; Lamina, C.; Kasimir-Bauer, S.; Kimmig, R.; Dieplinger, H. Serum concentrations of afamin are elevated in patients with polycystic ovary syndrome. Endocr. Connect. 2014, 3, 120-126. [CrossRef]

189. Seeber, B.; Morandell, E.; Lunger, F.; Wildt, L.; Dieplinger, H. Afamin serum concentrations are associated with insulin resistance and metabolic syndrome in polycystic ovary syndrome. Reprod. Biol. Endocrinol. 2014, 12, 1-7. [CrossRef]

190. Kollerits, B.; Lamina, C.; Huth, C.; Marques-Vidal, P.; Kiechl, S.; Seppälä, I.; Cooper, J.; Hunt, S.C.; Meisinger, C.; Herder, C.; et al. Plasma Concentrations of Afamin Are Associated With Prevalent and Incident Type 2 Diabetes: A Pooled Analysis in More Than 20,000 Individuals. Diabetes Care 2017, 40, 1386-1393. [CrossRef] [PubMed]

191. Hubalek, M.; Buchner, H.; Mörtl, M.G.; Schlembach, D.; Huppertz, B.; Firulovic, B.; Köhler, W.; Hafner, E.; Dieplinger, B.; Wildt, L.; et al. The vitamin E-binding protein afamin increases in maternal serum during pregnancy. Clin. Chim. Acta 2014, 434, 41-47. [CrossRef] [PubMed]

192. Tramontana, A.; Dieplinger, B.; Stangl, G.; Hafner, E.; Dieplinger, H. First trimester serum afamin concentrations are associated with the development of pre-eclampsia and gestational diabetes mellitus in pregnant women. Clin. Chim. Acta 2018, 476, 160-166. [CrossRef] [PubMed]

193. Jensen, D.M.; Mølsted-Pedersen, L.; Beck-Nielsen, H.; Westergaard, J.G.; Ovesen, P.; Damm, P. Screening for gestational diabetes mellitus by a model based on risk indicators: A prospective study. Am. J. Obstet. Gynecol. 2003, 189, 1383-1388. [CrossRef]

194. Köninger, A.; Mathan, A.; Mach, P.; Frank, M.; Schmidt, B.; Schleussner, E.; Kimmig, R.; Gellhaus, A.; Dieplinger, H. Is Afamin a novel biomarker for gestational diabetes mellitus? A pilot study. Reprod. Biol. Endocrinol. 2018, 16, 1-11. [CrossRef] [PubMed]

195. Kleinwechter, H.; Schäfer-Graf, U.; Bührer, C.; Hoesli, I.; Kainer, F.; Kautzky-Willer, A.; Pawlowski, B.; Schunck, K.; Somville, T.; Sorger, M. Gestational diabetes mellitus (GDM) diagnosis, therapy and follow-up care: Practice Guideline of the German Diabetes Association(DDG) and the German Association for Gynaecologyand Obstetrics (DGGG). Exp. Clin. Endocrinol. Diabetes 2014, 122, 395-405. [PubMed]

196. Dieplinger, H.; Dieplinger, B. Afamin-A pleiotropic glycoprotein involved in various disease states. Clin. Chim. Acta 2015, 446, 105-110. [CrossRef]

197. Morgan, B.P. Complement regulatory molecules: Application to therapy and transplantation. Immunol. Today 1995, 16, 257-259. [CrossRef]

198. Maio, M.; Brasoveanu, L.I.; Coral, S.; Sigalotti, L.; Lamaj, E.; Gasparollo, A.; Visintin, A.; Altomonte, M.; Fonsatti, E. Structure, distribution, and functional role of protectin (CD59) in complement-susceptibility and in immunotherapy of human malignancies (Review). Int. J. Oncol. 1998, 13, 305-323. [CrossRef]

199. Vakeva, A.; Lehto, T.; Takala, A.; Meri, S. Detection of a Soluble Form of the Complement Membrane Attack Complex Inhibitor CD59 in Plasma after Acute Myocardial Infarction. Scand. J. Immunol. 2000, 52, 411-414. [CrossRef]

200. Lehto, T.; Honkanen, E.; Teppo, A.-M.; Meri, S. Urinary excretion of protectin (CD59), complement SC5b-9 and cytokines in membranous glomerulonephritis. Kidney Int. 1995, 47, 1403-1411. [CrossRef]

201. Meri, S.; Lehto, T.; Sutton, C.W.; Tyynelä, J.; Baumann, M. Structural composition and functional characterization of soluble CD59: Heterogeneity of the oligosaccharide and glycophosphoinositol (GPI) anchor revealed by laser-desorption mass spectrometric analysis. Biochem. J. 1996, 316, 923-935. [CrossRef]

202. Gehrs, K.M.; Jackson, J.R.; Brown, E.N.; Allikmets, R.; Hageman, G.S. Complement, age-related macular degeneration and a vision of the future. Arch. Ophthalmol. 2010, 128, 349-358. [CrossRef] [PubMed]

203. Gerl, V.B.; Bohl, J.; Pitz, S.; Stoffelns, B.; Pfeiffer, N.; Bhakdi, S. Extensive deposits of complement C3d and C5b-9 in the choriocapillaris of eyes of patients with diabetic retinopathy. Investig. Ophthalmol. Vis. Sci. 2002, 43, 1104-1108.

204. Nevo, Y.; Ben-Zeev, B.; Tabib, A.; Straussberg, R.; Anikster, Y.; Shorer, Z.; Fattal-Valevski, A.; Ta-Shma, A.; Aharoni, S.; Rabie, M.; et al. CD59 deficiency is associated with chronic hemolysis and childhood relapsing immune-mediated polyneuropathy. Blood 2013, 121, 129-135. [CrossRef] [PubMed]

205. Rosoklija, G.B.; Dwork, A.J.; Younger, D.S.; Karlikaya, G.; Latov, N.; Hays, A.P. Local activation of the complement system in endoneurial microvessels of diabetic neuropathy. Acta Neuropathol. 2000, 99, 55-62. [CrossRef] [PubMed]

206. Falk, R.J.; Scheinman, J.I.; Mauer, S.M.; Michael, A.F. Polyantigenic Expansion of Basement Membrane Constituents in Diabetic Nephropathy. Diabetes 1983, 32, 34-39. [CrossRef] [PubMed]

207. Qin, X.; Goldfine, A.; Krumrei, N.; Grubissich, L.; Acosta, J.; Chorev, M.; Hays, A.P.; Halperin, J.A. Glycation Inactivation of the Complement Regulatory Protein CD59: A Possible Role in the Pathogenesis of the Vascular Complications of Human Diabetes. Diabetes 2004, 53, 2653-2661. [CrossRef]

208. Acosta, J.; Hettinga, J.; Flückiger, R.; Krumrei, N.; Goldfine, A.; Angarita, L.; Halperin, J. Molecular basis for a link between complement and the vascular complications of diabetes. Proc. Natl. Acad. Sci. USA 2000, 97, 5450-5455. [CrossRef]

209. Ghosh, P.; Sahoo, R.; Vaidya, A.; Cantel, S.; Kavishwar, A.; Goldfine, A.; Herring, N.; Bry, L.; Chorev, M.; Halperin, J.A. A specific and sensitive assay for blood levels of glycated CD59: A novel biomarker for diabetes. Am. J. Hematol. 2013, 88, 670-676. [CrossRef]

210. Ghosh, P.; Vaidya, A.; Sahoo, R.; Goldfine, A.; Herring, N.; Bry, L.; Chorev, M.; Halperin, J.A. Glycation of the Complement Regulatory Protein CD59 Is a Novel Biomarker for Glucose Handling in Humans. J. Clin. Endocrinol. Metab. 2014, 99, E999-E1006. [CrossRef] 
211. Bogdanet, D.; O'Shea, P.; Halperin, J.; Dunne, F. Plasma glycated CD59 (gCD59), a novel biomarker for the diagnosis, management and follow up of women with Gestational Diabetes (GDM) - protocol for prospective cohort study. BMC Pregnancy Childbirth 2020, 20, 1-6. [CrossRef]

212. Licht, P.; Lösch, A.; Dittrich, R.; Neuwinger, J.; Siebzehnrübl, E.; Wildt, L. Novel insights into human endometrial paracrinology and embryo-maternal communication by intrauterine microdialysis. Hum. Reprod. Updat. 1998, 4, 532-538. [CrossRef] [PubMed]

213. Ma, Q.; Fan, J.; Wang, J.; Yang, S.; Cong, Q.; Wang, R.; Lv, Q.; Liu, R.; Ning, G. High levels of chorionic gonadotrophin attenuate insulin sensitivity and promote inflammation in adipocytes. J. Mol. Endocrinol. 2015, 54, 161-170. [CrossRef] [PubMed]

214. Sirikunalai, P.; Wanapirak, C.; Sirichotiyakul, S.; Tongprasert, F.; Srisupundit, K.; Luewan, S.; Traisrisilp, K.; Tongsong, T. Associations between maternal serum free beta human chorionic gonadotropin ( $\beta$-hCG) levels and adverse pregnancy outcomes. J. Obstet. Gynaecol. 2016, 36, 178-182. [CrossRef]

215. Ong, C.Y.T.; Liao, A.W.; Spencer, K.; Munim, S.; Nicolaides, K.H. First trimester maternal serum free $\beta$ human chorionic gonadotrophin and pregnancy associated plasma protein A as predictors of pregnancy complications. BJOG 2000, 107, 1265-1270. [CrossRef] [PubMed]

216. WHO Expert Committee on Diabetes Mellitus: Second Report. World Health Organ Tech Rep Ser. 1980, 646, 1-80.

217. Xiong, F.; Li, G.; Sun, Q.; Chen, P.; Wang, Z.; Wan, C.; Yao, Z.; Zhong, H.; Zeng, Y. Obstetric and perinatal outcomes of pregnancies according to initial maternal serum HCG concentrations after vitrified-warmed single blastocyst transfer. Reprod. Biomed. Online 2019, 38, 455-464. [CrossRef] [PubMed]

218. Yue, C.-Y.; Zhang, C.-Y.; Ying, C.-M. Serum markers in quadruple screening associated with adverse pregnancy outcomes: A case-control study in China. Clin. Chim. Acta 2020, 511, 278-281. [CrossRef]

219. Tul, N.; Pusenjak, S.; Osredkar, J.; Spencer, K.; Novak-Antolic, Z. Predicting complications of pregnancy with first-trimester maternal serum free-betahCG, PAPP-A and inhibin-A. Prenat. Diagn. 2003, 23, 990-996. [CrossRef]

220. Savvidou, M.D.; Syngelaki, A.; Muhaisen, M.; Emelyanenko, E.; Nicolaides, K.H. First trimester maternal serum free $\beta$-human chorionic gonadotropin and pregnancy-associated plasma protein A in pregnancies complicated by diabetes mellitus. BJOG: Int. J. Obstet. Gynaecol. 2012, 119, 410-416. [CrossRef]

221. Beneventi, F.; Simonetta, M.; Lovati, E.; Albonico, G.; Tinelli, C.; Locatelli, E.; Spinillo, A. First trimester pregnancy-associated plasma protein-A in pregnancies complicated by subsequent gestational diabetes. Prenat. Diagn. 2011, 31, 523-528. [CrossRef] [PubMed]

222. Sweeting, A.N.; Wong, J.; Appelblom, H.; Ross, G.P.; Kouru, H.; Williams, P.F.; Sairanen, M.; Hyett, J.A. A first trimester prediction model for gestational diabetes utilizing aneuploidy and pre-eclampsia screening markers. J. Matern. Neonatal Med. 2017, 31, 2122-2130. [CrossRef] [PubMed]

223. Hammond, G.L.; Bocchinfuso, W.P. Sex Hormone-Binding Globulin: Gene Organization and Structure/Function Analyses. Horm. Res. 1996, 45, 197-201. [CrossRef]

224. Hammond, G.L. Diverse Roles for Sex Hormone-Binding Globulin in Reproduction. Biol. Reprod. 2011, 85, 431-441. [CrossRef] [PubMed]

225. Glass, A.R.; Swerdloff, R.S.; Bray, G.A.; Dahms, W.T.; Atkinson, R.L. Low Serum Testosterone and Sex-Hormone-Binding-Globulin in Massively Obese Men. J. Clin. Endocrinol. Metab. 1977, 45, 1211-1219. [CrossRef]

226. Guzick, D.S.; Wing, R.; Smith, D.; Berga, S.L.; Winters, S.J. Endocrine consequences of weight loss in obese, hyperandrogenic, anovulatory women. Fertil. Steril. 1994, 61, 598-604. [CrossRef]

227. Hammoud, A.; Gibson, M.; Hunt, S.C.; Adams, T.D.; Carrell, D.T.; Kolotkin, R.L.; Meikle, A.W. Effect of Roux-en-Y Gastric Bypass Surgery on the Sex Steroids and Quality of Life in Obese Men. J. Clin. Endocrinol. Metab. 2009, 94, 1329-1332. [CrossRef]

228. Pitteloud, N.; Mootha, V.K.; Dwyer, A.A.; Hardin, M.; Lee, H.; Eriksson, K.-F.; Tripathy, D.; Yialamas, M.; Groop, L.; Elahi, D.; et al. Relationship between testosterone levels, insulin sensitivity, and mitochondrial function in men. Diabetes Care 2005, 28, 1636-1642. [CrossRef]

229. Kajaia, N.; Binder, H.; Dittrich, R.; Oppelt, P.G.; Flor, B.; Cupisti, S.; Beckmann, M.W.; Mueller, A. Low sex hormone-binding globulin as a predictive marker for insulin resistance in women with hyperandrogenic syndrome. Eur. J. Endocrinol. 2007, 157, 499-507. [CrossRef]

230. Laaksonen, D.E.; Niskanen, L.; Punnonen, K.; Nyyssönen, K.; Tuomainen, T.-P.; Salonen, R.; Rauramaa, R.; Salonen, J.T. Sex hormones, inflammation and the metabolic syndrome: A population-based study. Eur. J. Endocrinol. 2003, 149, 601-608. [CrossRef]

231. Brand, J.S.; Van Der Tweel, I.; Grobbee, D.E.; Emmelot-Vonk, M.H.; Van Der Schouw, Y.T. Testosterone, sex hormone-binding globulin and the metabolic syndrome: A systematic review and meta-analysis of observational studies. Int. J. Epidemiol. 2010, 40, 189-207. [CrossRef] [PubMed]

232. Jaruvongvanich, V.; Sanguankeo, A.; Riangwiwat, T.; Upala, S. Testosterone, Sex Hormone-Binding Globulin and Nonalcoholic Fatty Liver Disease: A Systematic Review and Meta-Analysis. Ann. Hepatol. 2017, 16, 382-394. [CrossRef] [PubMed]

233. Ding, E.L.; Song, Y.; Malik, V.S.; Liu, S. Sex differences of endogenous sex hormones and risk of type 2 diabetes: A systematic review and meta-analysis. JAMA 2006, 295, 1288-1299. [CrossRef] [PubMed]

234. Hu, J.; Zhang, A.; Yang, S.; Wang, Y.; Goswami, R.; Zhou, H.; Zhang, Y.; Wang, Z.; Li, R.; Cheng, Q.; et al. Combined effects of sex hormone-binding globulin and sex hormones on risk of incident type 2 diabetes. J. Diabetes 2015, 8, 508-515. [CrossRef] 
235. Muka, T.; Nano, J.; Jaspers, L.; Meun, C.; Bramer, W.M.; Hofman, A.; Dehghan, A.; Kavousi, M.; Laven, J.S.; Franco, O.H. Associations of Steroid Sex Hormones and Sex Hormone-Binding Globulin With the Risk of Type 2 Diabetes in Women: A Population-Based Cohort Study and Meta-analysis. Diabetes 2016, 66, 577-586. [CrossRef]

236. Pugeat, M.; Crave, J.C.; Elmidani, M.; Nicolas, M.H.; Garoscio-Cholet, M.; Lejeune, H.; Déchaud, H.; Tourniaire, J. Pathophysiology of sex hormone binding globulin (SHBG): Relation to insulin. J. Steroid Biochem. Mol. Biol. 1991, 40, 841-849. [CrossRef]

237. Plymate, S.R.; Matej, L.A.; Jones, R.E.; Friedl, K.E. Inhibition of sex hormone-binding globulin production in the human hepatoma (Hep G2) cell line by insulin and prolactin. J. Clin. Endocrinol. Metab. 1988, 67, 460-464. [CrossRef]

238. Winters, S.J.; Gogineni, J.; Karegar, M.; Scoggins, C.; Wunderlich, C.A.; Baumgartner, R.; Ghooray, D.T. Sex Hormone-Binding Globulin Gene Expression and Insulin Resistance. J. Clin. Endocrinol. Metab. 2014, 99, E2780-E2788. [CrossRef] [PubMed]

239. Shin, J.Y.; Kim, S.-K.; Lee, M.Y.; Kim, H.S.; Ye, B.I.; Shin, Y.G.; Baik, S.K.; Chung, C.H. Serum sex hormone-binding globulin levels are independently associated with nonalcoholic fatty liver disease in people with type 2 diabetes. Diabetes Res. Clin. Pr. 2011, 94, 156-162. [CrossRef]

240. Flechtner-Mors, M.; Schick, A.; Oeztuerk, S.; Haenle, M.M.; Wilhelm, M.; Koenig, W.; Imhof, A.; Boehm, B.O.; Graeter, T.; Mason, R.A.; et al. Associations of Fatty Liver Disease and Other Factors Affecting Serum SHBG Concentrations: A Population Based Study on 1657 Subjects. Horm. Metab. Res. 2013, 46, 287-293. [CrossRef]

241. Hedderson, M.M.; Xu, F.; Darbinian, J.A.; Quesenberry, C.P.; Sridhar, S.; Kim, C.; Gunderson, E.P.; Ferrara, A. Prepregnancy SHBG Concentrations and Risk for Subsequently Developing Gestational Diabetes Mellitus. Diabetes Care 2014, 37, 1296-1303. [CrossRef] [PubMed]

242. Li, M.-Y.; Rawal, S.; Hinkle, S.N.; Zhu, Y.-Y.; Tekola-Ayele, F.; Tsai, M.Y.; Liu, S.-M.; Zhang, C.-L. Sex Hormone-binding Globulin, Cardiometabolic Biomarkers, and Gestational Diabetes: A Longitudinal Study and Meta-analysis. Matern. Med. 2020, 2, 2-9. [CrossRef]

243. Smirnakis, K.V.; Plati, A.; Wolf, M.; Thadhani, R.; Ecker, J.L. Predicting gestational diabetes: Choosing the optimal early serum marker. Am. J. Obstet. Gynecol. 2007, 196, 410.e1-410.e7. [CrossRef] [PubMed]

244. Bulletins-Obstetrics ACoOaGCoP. ACOG Practice Bulletin. Clinical management guidelines for obstetrician-gynecologists. Number 30, September 2001 (replaces Technical Bulletin Number 200, December 1994). Gestational diabetes. Obstet. Gynecol. 2001, 98, 525-538.

245. Siddiqui, K.; George, T.P.; Joy, S.S.; Nawaz, S.S. Association of sex hormone binding globulin with gestational age and parity in gestational diabetes mellitus. J. Matern. Neonatal Med. 2020, 2020, 1-6. [CrossRef]

246. Ajjan, R.; Carter, A.M.; Somani, R.; Kain, K.; Grant, P.J. Ethnic differences in cardiovascular risk factors in healthy Caucasian and South Asian individuals with the metabolic syndrome. J. Thromb. Haemost. 2007, 5, 754-760. [CrossRef]

247. McElduff, A.; Hitchman, R.; McElduff, P. Is sex hormone-binding globulin associated with glucose tolerance? Diabet. Med. 2006, 23, 306-312. [CrossRef]

248. Key, T.J.; Pike, M.C.; Moore, J.W.; Wang, D.Y.; Morgan, B. The relationship of free fatty acids with the binding of oestradiol to SHBG and to albumin in women. J. Steroid Biochem. 1990, 35, 35-38. [CrossRef]

249. Hamllton-Falrley, D.; White, D.; Griffiths, M.; Anyaoku, V.; Kolstlnen, R.; Seppälä, M.; Franks, S. Diurnal variation of sex hormone binding globulin and insulin-like growth factor binding protein-1 in women with polycystic ovary syndrome. Clin. Endocrinol. 1995, 43, 159-165. [CrossRef] [PubMed]

250. Catalano, P.M. Carbohydrate Metabolism and Gestational Diabetes. Clin. Obstet. Gynecol. 1994, 37, 25-38. [CrossRef]

251. Stefan, N.; Kantartzis, K.; Häring, H.-U. Causes and Metabolic Consequences of Fatty Liver. Endocr. Rev. 2008, 29, 939-960. [CrossRef]

252. Venugopal, S.K.; Devaraj, S.; Jialal, I. Macrophage conditioned medium induces the expression of C-reactive protein in human aortic endothelial cells: Potential for paracrine/autocrine effects. Am. J. Pathol. 2005, 166, 1265-1271. [CrossRef]

253. Ganter, U.; Arcone, R.; Toniatti, C.; Morrone, G.; Ciliberto, G. Dual control of C-reactive protein gene expression by interleukin-1 and interleukin-6. EMBO J. 1989, 8, 3773-3779. [CrossRef] [PubMed]

254. Sproston, N.R.; Ashworth, J.J. Role of C-Reactive Protein at Sites of Inflammation and Infection. Front. Immunol. 2018, 9 , 754. [CrossRef] [PubMed]

255. Retnakaran, R.; Hanley, A.J.G.; Raif, N.; Connelly, P.W.; Sermer, M.; Zinman, B. C-Reactive Protein and Gestational Diabetes: The Central Role of Maternal Obesity. J. Clin. Endocrinol. Metab. 2003, 88, 3507-3512. [CrossRef]

256. Jabs, W.J.; Lögering, B.A.; Gerke, P.; Kreft, B.; Wolber, E.-M.; Klinger, M.H.F.; Fricke, L.; Steinhoff, J. The kidney as a second site of human C-reactive protein formation in vivo. Eur. J. Immunol. 2003, 33, 152-161. [CrossRef]

257. Kim, S.H.; Reaven, G.; Lindley, S. Relationship between insulin resistance and C-reactive protein in a patient population treated with second generation antipsychotic medications. Int. Clin. Psychopharmacol. 2011, 26, 43-47. [CrossRef]

258. Moran, A.; Steffen, L.M.; Jacobs, J.D.R.; Steinberger, J.; Pankow, J.S.; Hong, C.-P.; Tracy, R.P.; Sinaiko, A.R. Relation of C-Reactive Protein to Insulin Resistance and Cardiovascular Risk Factors in Youth. Diabetes Care 2005, 28, 1763-1768. [CrossRef]

259. Yan, Y.; Li, S.; Liu, Y.; Bazzano, L.; He, J.; Mi, J.; Chen, W. Temporal relationship between inflammation and insulin resistance and their joint effect on hyperglycemia: The Bogalusa Heart Study. Cardiovasc. Diabetol. 2019, 18, 1-10. [CrossRef] [PubMed]

260. Ridker, P.; Buring, J.; Cook, N.; Rifai, N. C-reactive protein, the metabolic syndrome, and risk of incident cardiovascular events. An 8-year follow-up of 14,719 initially healthy American women. ACC Curr. J. Rev. 2003, 12, 33-34. [CrossRef] 
261. Aronson, D.; Bartha, P.; Zinder, O.; Kerner, A.; Markiewicz, W.; Avizohar, O.; Brook, G.J.; Levy, Y. Obesity is the major determinant of elevated C-reactive protein in subjects with the metabolic syndrome. Int. J. Obes. 2004, 28, 674-679. [CrossRef]

262. Visser, M.; Bouter, L.M.; McQuillan, G.M.; Wener, M.H.; Harris, T.B. Elevated C-Reactive Protein Levels in Overweight and Obese Adults. JAMA 1999, 282, 2131-2135. [CrossRef] [PubMed]

263. Kahn, S.E.; Zinman, B.; Haffner, S.M.; O’Neill, M.C.; Kravitz, B.G.; Yu, D.; Freed, M.I.; Herman, W.H.; Holman, R.R.; Jones, N.P.; et al. Obesity Is a Major Determinant of the Association of C-Reactive Protein Levels and the Metabolic Syndrome in Type 2 Diabetes. Diabetes 2006, 55, 2357-2364. [CrossRef] [PubMed]

264. Alamolhoda, S.H.; Yazdkhasti, M.; Namdari, M.; Zakariayi, S.J.; Mirabi, P. Association between C-reactive protein and gestational diabetes: A prospective study. J. Obstet. Gynaecol. 2019, 40, 349-353. [CrossRef]

265. Savvidou, M.; Nelson, S.M.; Makgoba, M.; Messow, C.-M.; Sattar, N.; Nicolaides, K. First-Trimester Prediction of Gestational Diabetes Mellitus: Examining the Potential of Combining Maternal Characteristics and Laboratory Measures. Diabetes 2010, 59, 3017-3022. [CrossRef] [PubMed]

266. Wolf, M.; Sandler, L.; Hsu, K.; Vossen-Smirnakis, K.; Ecker, J.L.; Thadhani, R. First-Trimester C-Reactive Protein and Subsequent Gestational Diabetes. Diabetes Care 2003, 26, 819-824. [CrossRef]

267. Alyas, S.; Roohi, N.; Ashraf, S.; Ilyas, S.; Ilyas, A. Early pregnancy biochemical markers of placentation for screening of gestational diabetes mellitus (GDM). Diabetes Metab. Syndr. Clin. Res. Rev. 2019, 13, 2353-2356. [CrossRef]

268. Korkmazer, E.; Solak, N. Correlation between inflammatory markers and insulin resistance in pregnancy. J. Obstet. Gynaecol. 2014, 35, 142-145. [CrossRef]

269. Corcoran, S.M.; Achamallah, N.; Loughlin, J.O.; Stafford, P.; Dicker, P.; Malone, F.D.; Breathnach, F. First trimester serum biomarkers to predict gestational diabetes in a high-risk cohort: Striving for clinically useful thresholds. Eur. J. Obstet. Gynecol. Reprod. Biol. 2018, 222, 7-12. [CrossRef]

270. Adam, S.; Pheiffer, C.; Dias, S.; Rheeder, P. Association between gestational diabetes and biomarkers: A role in diagnosis. Biomarkers 2018, 23, 386-391. [CrossRef]

271. Classification and diagnosis of diabetes mellitus and other categories of glucose intolerance. National Diabetes Data Group. Diabetes 1979, 28, 1039-1057. [CrossRef] [PubMed]

272. Amirian, A.; Rahnemaei, F.A.; Abdi, F. Role of C-reactive Protein(CRP) or high-sensitivity CRP in predicting gestational diabetes Mellitus:Systematic review. Diabetes Metab. Syndr. Clin. Res. Rev. 2020, 14, 229-236. [CrossRef]

273. Oh-I, S.; Shimizu, H.; Satoh, T.; Okada, S.; Adachi, S.; Inoue, K.; Eguchi, H.; Yamamoto, M.; Imaki, T.; Hashimoto, K.; et al. Identification of nesfatin-1 as a satiety molecule in the hypothalamus. Nature 2006, 443, 709-712. [CrossRef] [PubMed]

274. Su, Y.; Zhang, J.; Tang, Y.; Bi, F.; Liu, J.-N. The novel function of nesfatin-1: Anti-hyperglycemia. Biochem. Biophys. Res. Commun. 2010, 391, 1039-1042. [CrossRef]

275. Dong, J.; Xu, H.; Wang, P.-F.; Cai, G.-J.; Song, H.-F.; Wang, C.-C.; Dong, Z.-T.; Ju, Y.-J.; Jiang, Z.-Y. Nesfatin-1 Stimulates Fatty-Acid Oxidation by Activating AMP-Activated Protein Kinase in STZ-Induced Type 2 Diabetic Mice. PLoS ONE 2013, 8, e83397. [CrossRef] [PubMed]

276. Li, Q.-C.; Wang, H.-Y.; Chen, X.; Guan, H.-Z.; Jiang, Z.-Y. Fasting plasma levels of nesfatin-1 in patients with type 1 and type 2 diabetes mellitus and the nutrient-related fluctuation of nesfatin-1 level in normal humans. Regul. Pept. 2010, $159,72-77$. [CrossRef]

277. Zhai, T.; Li, S.-Z.; Fan, X.-T.; Tian, Z.; Lu, X.-Q.; Dong, J. Circulating Nesfatin-1 Levels and Type 2 Diabetes: A Systematic Review and Meta-Analysis. J. Diabetes Res. 2017, 2017, 1-8. [CrossRef]

278. Kucukler, F.K.; Gorkem, U.; Simsek, Y.; Kocabas, R.; Gulen, S.; Guler, S. Low level of Nesfatin-1 is associated with gestational diabetes mellitus. Gynecol. Endocrinol. 2016, 32, 759-761. [CrossRef]

279. Ademoglu, E.N.; Gorar, S.; Keskin, M.; Carlioglu, A.; Ucler, R.; Erdamar, H.; Culha, C.; Aral, Y. Serum nesfatin-1 levels are decreased in pregnant women newly diagnosed with gestational diabetes. Arch. Endocrinol. Metab. 2017, 61, 455-459. [CrossRef] [PubMed]

280. Mierzyński, R.; Poniedziałek-Czajkowska, E.; Dłuski, D.; Patro-Małysza, J.; Kimber-Trojnar, Ż.; Majsterek, M.; LeszczyńskaGorzelak, B. Nesfatin-1 and Vaspin as Potential Novel Biomarkers for the Prediction and Early Diagnosis of Gestational Diabetes Mellitus. Int. J. Mol. Sci. 2019, 20, 159. [CrossRef]

281. Fialova, L.; Malbohan, I.M. Pregnancy-associated plasma protein A (PAPP-A): Theoretical and clinical aspects. Bratisl Lek List. 2002, 103, 194-205.

282. Dugoff, L.; Hobbins, J.C.; Malone, F.D.; Porter, T.F.; Luthy, D.; Comstock, C.H.; Hankins, G.; Berkowitz, R.L.; Merkatz, I.; Craigo, S.D.; et al. First-trimester maternal serum PAPP-A and free-beta subunit human chorionic gonadotropin concentrations and nuchal translucency are associated with obstetric complications: A population-based screening study (The FASTER Trial). Am. J. Obstet. Gynecol. 2004, 191, 1446-1451. [CrossRef] [PubMed]

283. Leguy, M.C.; Brun, S.; Pidoux, G.; Salhi, H.; Choiset, A.; Menet, M.C.; Gil, S.; Tsatsaris, V.; Guibourdenche, J. Pattern of secretion of pregnancy-associated plasma protein-A (PAPP-A) during pregnancies complicated by fetal aneuploidy, in vivo and in vitro. Reprod. Biol. Endocrinol. 2014, 12, 129. [CrossRef] [PubMed]

284. Pellitero, S.; Reverter, J.L.; Pizarro, E.; Pastor, M.C.; Granada, M.L.; Tàssies, D.; Reverter, J.-C.; Salinas, I.; Sanmartí, A. Pregnancyassociated plasma protein-a levels are related to glycemic control but not to lipid profile or hemostatic parameters in type 2 diabetes. Diabetes Care 2007, 30, 3083-3085. [CrossRef] 
285. Resch, Z.T.; Chen, B.-K.; Bale, L.K.; Oxvig, C.; Overgaard, M.T.; Conover, C.A. Pregnancy-Associated Plasma Protein A Gene Expression as a Target of Inflammatory Cytokines. Endocrinology 2004, 145, 1124-1129. [CrossRef]

286. Donovan, B.M.; Nidey, N.L.; Jasper, E.A.; Robinson, J.G.; Bao, W.; Saftlas, A.F.; Ryckman, K.K. First trimester prenatal screening biomarkers and gestational diabetes mellitus: A systematic review and meta-analysis. PLoS ONE 2018, 13, e0201319. [CrossRef]

287. Wells, G.; Bleicher, K.; Han, X.; McShane, M.; Chan, Y.F.; Bartlett, A.; White, C.; Lau, S.M. Maternal Diabetes, Large for Gestational Age Births and First Trimester Pregnancy Associated Plasma Protein-A. J. Clin. Endocrinol. Metab. 2015, 100, 2372-2379. [CrossRef]

288. Jayabalan, N.; Lai, A.; Nair, S.; Guanzon, D.; Scholz-Romero, K.; Palma, C.; McIntyre, H.D.; Lappas, M.; Salomon, C. Quantitative Proteomics by SWATH-MS Suggest an Association Between Circulating Exosomes and Maternal Metabolic Changes in Gestational Diabetes Mellitus. Proteomics 2018, 19, e1800164. [CrossRef]

289. Alapatt, P.; Guo, F.; Komanetsky, S.M.; Wang, S.; Cai, J.; Sargsyan, A.; Díaz, E.R.; Bacon, B.T.; Aryal, P.; Graham, T.E. Liver Retinol Transporter and Receptor for Serum Retinol-binding Protein (RBP4). J. Biol. Chem. 2013, 288, 1250-1265. [CrossRef] [PubMed]

290. Majerczyk, M.; Olszanecka-Glinianowicz, M.; Puzianowska-Kuźnicka, M.; Chudek, J. Retinol-binding protein 4 (RBP4) as the causative factor and marker of vascular injury related to insulin resistance. Postepy Hig. Med. Dosw. 2016, 70, 1267-1275.

291. Yang, Q.; Graham, T.E.; Mody, N.; Preitner, F.; Peroni, O.D.; Zabolotny, J.M.; Kotani, K.; Quadro, L.; Kahn, B.B. Serum retinol binding protein 4 contributes to insulin resistance in obesity and type 2 diabetes. Nature 2005, 436, 356-362. [CrossRef]

292. Jin, C.; Lin, L.; Han, N.; Zhao, Z.; Liu, Z.; Luo, S.; Xu, X.; Liu, J.; Wang, H. Plasma retinol-binding protein 4 in the first and second trimester and risk of gestational diabetes mellitus in Chinese women: A nested case-control study. Nutr. Metab. 2020, 17, 1-7. [CrossRef]

293. Khovidhunkit, W.; Pruksakorn, P.; Plengpanich, W.; Tharavanij, T. Retinol-binding protein 4 is not associated with insulin resistance in pregnancy. Metabolism 2012, 61, 65-69. [CrossRef]

294. Huang, Q.-T.; Huang, Q.; Luo, W.; Li, F.; Hang, L.-L.; Yu, Y.-H.; Zhong, M. Circulating retinol-binding protein 4 levels in gestational diabetes mellitus: A meta-analysis of observational studies. Gynecol. Endocrinol. 2015, 31, 337-344. [CrossRef] [PubMed]

295. Hu, S.; Liu, Q.; Huang, X.; Tan, H. Serum level and polymorphisms of retinol-binding protein-4 and risk for gestational diabetes mellitus: A meta-analysis. BMC Pregnancy Childbirth 2016, 16, 52. [CrossRef] [PubMed]

296. Jia, J.; Bai, J.; Liu, Y.; Yin, J.; Yang, P.; Yu, S.; Ye, J.; Wang, N.; Yuan, G. Association between retinol-binding protein 4 and polycystic ovary syndrome: A meta-analysis. Endocr. J. 2014, 61, 995-1002. [CrossRef] [PubMed]

297. Kim, S.-H.; Im, J.-A.; Choi, H.-J. Retinol-binding protein 4 responses during an oral glucose tolerance testing in women with gestational diabetes mellitus. Clin. Chim. Acta 2008, 391, 123-125. [CrossRef]

298. Chan, T.-F.; Chen, H.-S.; Chen, Y.-C.; Lee, C.-H.; Chou, F.-H.; Chen, I.-J.; Chen, S.-Y.; Jong, S.-B.; Tsai, E.-M. Increased Serum Retinol-Binding Protein 4 Concentrations in Women With Gestational Diabetes Mellitus. Reprod. Sci. 2007, 14, 169-174. [CrossRef] [PubMed]

299. Zhaoxia, L.; Mengkai, D.; Qin, F.; Danqing, C. Significance of RBP4 in patients with gestational diabetes mellitus: A case-control study of Han Chinese women. Gynecol. Endocrinol. 2013, 30, 161-164. [CrossRef] [PubMed]

300. Su, Y.-X.; Hong, J.; Yan, Q.; Xu, C.; Gu, W.-Q.; Zhang, Y.-F.; Shen, C.-F.; Chi, Z.-N.; Dai, M.; Xu, M.; et al. Increased serum retinol-binding protein-4 levels in pregnant women with and without gestational diabetes mellitus. Diabetes Metab. 2010, 36, 470-475. [CrossRef]

301. Tepper, B.J.; Kim, Y.-K.; Shete, V.; Shabrova, E.; Quadro, L. Serum Retinol-Binding Protein 4 (RBP4) and retinol in a cohort of borderline obese women with and without gestational diabetes. Clin. Biochem. 2010, 43, 320-323. [CrossRef] [PubMed]

302. Krzyzanowska, K.; Zemany, L.; Krugluger, W.; Schernthaner, G.H.; Mittermayer, F.; Schnack, C.; Rahman, R.; Brix, J.; Kahn, B.B. Serum concentrations of retinol-binding protein 4 in women with and without gestational diabetes. Diabetologia 2008, 51, 1115-1122. [CrossRef]

303. Lewandowski, K.C.; Stojanovic, N.; Bienkiewicz, M.; Tan, B.K.; Prelevic, G.M.; Press, M.; Tuck, S.; O’Hare, P.J.; Randeva, H.S. Elevated concentrations of retinol-binding protein-4 (RBP-4) in gestational diabetes mellitus: Negative correlation with soluble vascular cell adhesion molecule-1 (sVCAM-1). Gynecol. Endocrinol. 2008, 24, 300-305. [CrossRef] [PubMed]

304. Abetew, D.F.; Qiu, C.; Fida, N.G.; Dishi, M.; Hevner, K.; Williams, M.A.; Enquobahrie, D.A. Association of retinol binding protein 4 with risk of gestational diabetes. Diabetes Res. Clin. Pr. 2013, 99, 48-53. [CrossRef]

305. Liu, M.; Chen, Y.; Chen, D. Association between transthyretin concentrations and gestational diabetes mellitus in Chinese women. Arch. Gynecol. Obstet. 2020, 302, 329-335. [CrossRef] [PubMed]

306. Graham, T.E.; Wason, C.J.; Blüher, M.; Kahn, B.B. Shortcomings in methodology complicate measurements of serum retinol binding protein (RBP4) in insulin-resistant human subjects. Diabetologia 2007, 50, 814-823. [CrossRef]

307. Idris, N.; Hatikah, C.C.; Murizah, M.; Rushdan, M. Universal Versus Selective Screening for Detection of Gestational Diabetes Mellitus in a Malaysian Population. Malays Fam Physician 2009, 4, 83-87. [PubMed]

308. Avalos, G.E.; Owens, L.A.; Dunne, F.; Collaborators, F.T.A.D. Applying Current Screening Tools for Gestational Diabetes Mellitus to a European Population: Is It Time for Change? Diabetes Care 2013, 36, 3040-3044. [CrossRef]

309. Alberico, S.; Strazzanti, C.; De Santo, D.; De Seta, F.; Lenardon, P.; Bernardon, M.; Zicari, S.; Guaschino, S. Gestational diabetes: Universal or selective screening? J. Matern. Fetal. Neonatal. Med. 2004, 16, 331-337. [CrossRef]

310. Kuo, C.-H.; Li, H.-Y. Diagnostic Strategies for Gestational Diabetes Mellitus: Review of Current Evidence. Curr. Diabetes Rep. 2019, 19, 155. [CrossRef] 
311. Mo, X.; Tobe, R.G.; Takahashi, Y.; Arata, N.; Liabsuetrakul, T.; Nakayama, T.; Mori, R. Economic Evaluations of Gestational Diabetes Mellitus Screening: A Systematic Review. J. Epidemiol. 2021, 31, 220-230. [CrossRef]

312. Danyliv, A.; Gillespie, P.; O'Neill, C.; Tierney, M.; O'Dea, A.; McGuire, B.E.; Glynn, L.G.; Dunne, F.P. The cost-effectiveness of screening for gestational diabetes mellitus in primary and secondary care in the Republic of Ireland. Diabetologia 2015, 59, 436-444. [CrossRef] [PubMed]

313. Di Cianni, G.; Volpe, L.; Casadidio, I.; Bottone, P.; Marselli, L.; Lencioni, C.; Boldrini, A.; Teti, G.; Del Prato, S.; Benzi, L. Universal screening and intensive metabolic management of gestational diabetes: Cost-effectiveness in Italy. Acta Diabetol. 2002, 39, 69-73. [CrossRef]

314. Miailhe, G.; Kayem, G.; Girard, G.; Legardeur, H.; Mandelbrot, L. Selective rather than universal screening for gestational diabetes mellitus? Eur. J. Obstet. Gynecol. Reprod. Biol. 2015, 191, 95-100. [CrossRef]

315. Cosson, E.; Benbara, A.; Pharisien, I.; Nguyen, M.T.; Revaux, A.; Lormeau, B.; Sandre-Banon, D.; Assad, N.; Pillegand, C.; Valensi, P.; et al. Diagnostic and Prognostic Performances Over 9 Years of a Selective Screening Strategy for Gestational Diabetes Mellitus in a Cohort of 18,775 Subjects. Diabetes Care 2012, 36, 598-603. [CrossRef] [PubMed]

316. Wen, S.W.; Liu, S.; Kramer, M.S.; Joseph, K.S.; Levitt, C.; Marcoux, S.; Liston, R.M. Impact of Prenatal Glucose Screening on the Diagnosis of Gestational Diabetes and on Pregnancy Outcomes. Am. J. Epidemiol. 2000, 152, 1009-1014. [CrossRef] [PubMed]

317. Cosson, E.; Benchimol, M.; Carbillon, L.; Pharisien, I.; Pariès, J.; Valensi, P.; Lormeau, B.; Bolie, S.; Uzan, M.; Attali, J.R. Universal rather than selective screening for gestational diabetes mellitus may improve fetal outcomes. Diabetes Metab. 2006, 32, 140-146. [CrossRef]

318. Farrar, D.; Fairley, L.; Wright, J.; Tuffnell, D.; Whitelaw, D.; Lawlor, D.A. Evaluation of the impact of universal testing for gestational diabetes mellitus on maternal and neonatal health outcomes: A retrospective analysis. BMC Pregnancy Childbirth 2014, 14, 317. [CrossRef]

319. Griffin, M.E.; Coffey, M.; Johnson, H.; Scanlon, P.; Foley, M.; Stronge, J.; O’Meara, N.M.; Firth, R.G. Universal vs. risk factor-based screening for gestational diabetes mellitus: Detection rates, gestation at diagnosis and outcome. Diabet. Med. 2000, 17, 26-32. [CrossRef]

320. Sweeting, A.N.; Ross, G.P.; Hyett, J.; Molyneaux, L.; Constantino, M.; Harding, A.J.; Wong, J. Gestational Diabetes Mellitus in Early Pregnancy: Evidence for Poor Pregnancy Outcomes Despite Treatment. Diabetes Care 2015, 39, 75-81. [CrossRef] [PubMed]

321. Most, O.L.; Kim, J.H.; Arslan, A.A.; Klauser, C. Maternal and neonatal outcomes in early glucose tolerance testing in an obstetric population in New York city. J. Périnat. Med. 2009, 37, 114-117. [CrossRef] [PubMed]

322. Simmons, D.; Nema, J.; Parton, C.; Vizza, L.; Robertson, A.; Rajagopal, R.; Ussher, J.; Perz, J. The treatment of booking gestational diabetes mellitus (TOBOGM) pilot randomised controlled trial. BMC Pregnancy Childbirth 2018, 18, 1-8. [CrossRef] [PubMed]

323. Zhu, Z.; Cao, F.; Li, X. Epigenetic Programming and Fetal Metabolic Programming. Front. Endocrinol. 2019, 10, 764. [CrossRef]

324. Mayeux, R. Biomarkers: Potential uses and limitations. NeuroRx 2004, 1, 182-188. [CrossRef]

325. Mahdi, T.; Hänzelmann, S.; Salehi, A.; Muhammed, S.J.; Reinbothe, T.M.; Tang, Y.; Axelsson, A.S.; Zhou, Y.; Jing, X.; Almgren, P.; et al. Secreted Frizzled-Related Protein 4 Reduces Insulin Secretion and Is Overexpressed in Type 2 Diabetes. Cell Metab. 2012, 16, 625-633. [CrossRef]

326. Schuitemaker, J.H.N.; Beernink, R.H.J.; Franx, A.; Cremers, T.I.F.H.; Koster, M.P.H. First trimester secreted Frizzled-Related Protein 4 and other adipokine serum concentrations in women developing gestational diabetes mellitus. PLoS ONE 2020, 15, e0242423. [CrossRef] [PubMed]

327. Ipekci, S.; Baldane, S.; Kebapcilar, A.G.; Abuşoğlu, S.; Beyhekim, H.; Ilhan, T.T.; Unlu, A.; Kebapçılar, L. Prorenin and secreted frizzled-related protein-4 levels in women with gestational diabetes mellitus. Endocr. Abstr. 2018, 119, 450-453. [CrossRef]

328. Yuan, X.-S.; Zhang, M.; Wang, H.-Y.; Jiang, J.; Yu, B. Increased secreted frizzled-related protein 4 and ficolin-3 levels in gestational diabetes mellitus women. Endocr. J. 2018, 65, 499-508. [CrossRef] [PubMed]

329. Amini, M.; Kazemnejad, A.; Zayeri, F.; Montazeri, A.; Rasekhi, A.; Amirian, A.; Kariman, N. Diagnostic accuracy of maternal serum multiple marker screening for early detection of gestational diabetes mellitus in the absence of a gold standard test. BMC Pregnancy Childbirth 2020, 20, 1-9. [CrossRef]

330. Liu, L.; Hu, J.; Yang, L.; Wang, N.; Liu, Y.; Wei, X.; Gao, M.; Wang, Y.; Ma, Y.; Wen, D. Association of WISP1/CCN4 with Risk of Overweight and Gestational Diabetes Mellitus in Chinese Pregnant Women. Dis. Markers 2020, 2020, 1-10. [CrossRef]

331. Sahin Ersoy, G.; Altun Ensari, T.; Subas, S.; Giray, B.; Simsek, E.E.; Cevik, O. WISP1 is a novel adipokine linked to metabolic parameters in gestational diabetes mellitus. J. Matern. Fetal. Neonatal. Med. 2017, 30, 942-946. [CrossRef] [PubMed]

332. Al-Ghazali, M.J.; Ali, H.A.; Al-Rufaie, M.M. Serum irisin levels as a potential marker for diagnosis of gestational diabetes mellitus. Acta Biomed. 2020, 91, 56-63.

333. Onat, T.; Inandiklioglu, N. Circulating Myonectin and Irisin Levels in Gestational Diabetes Mellitus-A Case-control Study. Z. Geburtshilfe Neonatol. 2021. [CrossRef]

334. Gutaj, P.; Sibiak, R.; Jankowski, M.; Awdi, K.; Bryl, R.; Mozdziak, P.; Kempisty, B.; Wender-Ozegowska, E. The Role of the Adipokines in the Most Common Gestational Complications. Int. J. Mol. Sci. 2020, 21, 9408. [CrossRef] [PubMed]

335. Zhong, L.; Long, Y.; Wang, S.; Lian, R.; Deng, L.; Ye, Z.; Wang, Z.; Liu, B. Continuous elevation of plasma asprosin in pregnant women complicated with gestational diabetes mellitus: A nested case-control study. Placenta 2020, 93, 17-22. [CrossRef] 
336. Yavuzkir, S.; Ugur, K.; Deniz, R.; Ustebay, D.U.; Mirzaoglu, M.; Yardim, M.; Sahin, I.; Baykus, Y.; Karagoz, Z.K.; Aydin, S. Maternal and umbilical cord blood subfatin and spexin levels in patients with gestational diabetes mellitus. Peptides 2020, $126,170277$. [CrossRef]

337. Kang, L.; Li, H.-Y.; Ou, H.-Y.; Wu, P.; Wang, S.-H.; Chang, C.-J.; Lin, S.-Y.; Wu, C.-L.; Wu, H.-T. Role of placental fibrinogen-like protein 1 in gestational diabetes. Transl. Res. 2020, 218, 73-80. [CrossRef]

338. Liu, L.; Hu, J.; Wang, N.; Liu, Y.; Wei, X.; Gao, M.; Ma, Y.; Wen, D. A novel association of CCDC80 with gestational diabetes mellitus in pregnant women: A propensity score analysis from a case-control study. BMC Pregnancy Childbirth 2020, 20, 1-9. [CrossRef]

339. Deischinger, C.; Leitner, K.; Baumgartner-Parzer, S.; Bancher-Todesca, D.; Kautzky-Willer, A.; Harreiter, J. CTRP-1 levels are related to insulin resistance in pregnancy and gestational diabetes mellitus. Sci. Rep. 2020, 10, 1-9. [CrossRef]

340. The Top 10 Research Priorities for Diabetes in Pregnancy. Available online: https://www.jla.nihr.ac.uk/news/the-top-10 -research-priorities-for-diabetes-in-pregnancy / 26184 (accessed on 7 January 2021). 